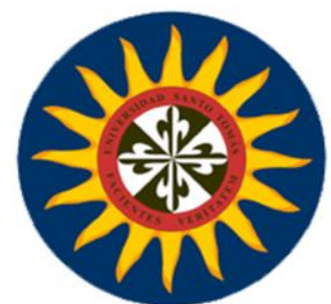

DESARROLLO Y DESERCIÓN ESCOLAR DE ADULTOS.

ESTUDIO DE CASO: LA EDUCACIÓN DE ADULTOS DEL COLEGIO

INTEGRADO DE FONTIBÓN IBEP (I.E.D) DE BOGOTÁ

JULIA PALACIOS CORTÉS

UNIVERSIDAD SANTO TOMÁS

FACULTAD DE SOCIOLOGIA

MAESTRÍA EN PLANEACIÓN PARA EL DESARROLLO

BOGOTÁ D.C.

2016 


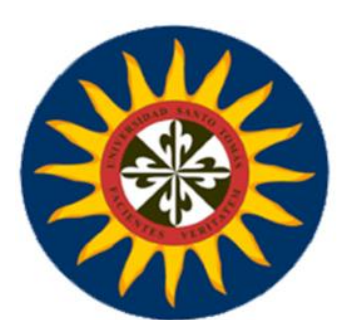

DESARROLLO Y DESERCIÓN ESCOLAR DE ADULTOS.

ESTUDIO DE CASO: LA EDUCACIÓN DE ADULTOS DEL COLEGIO INTEGRADO DE FONTIBÓN IBEP (I.E.D) DE BOGOTÁ

\section{JULIA PALACIOS CORTÉS}

Trabajo de grado para optar al título de Magister en Planeación para el Desarrollo

Ph.D. FABIO LOZANO VELÁSQUEZ

Tutor

\section{UNIVERSIDAD SANTO TOMÁS}

FACULTAD DE SOCIOLOGIA

MAESTRÍA EN PLANEACIÓN PARA EL DESARROLLO

BOGOTÁ D.C.

2016 
Nota de aceptación

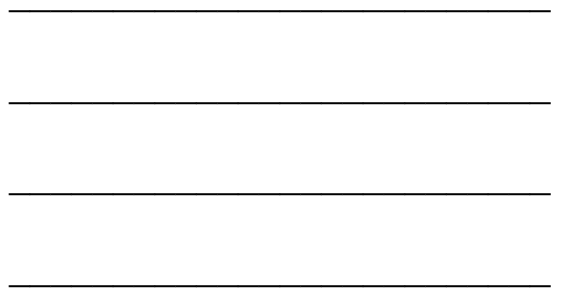

Firma del jurado

Firma del jurado

Bogotá, D.C. julio de 2016 


\section{DEDICATORIA}

"A mi Karenn Daniela, para que el desarrollo de sus capacidades y bienestar la colmen de felicidad, porque su formación, da muestra de que es posible tener jóvenes actuando conforme a otro tipo de desarrollo para el país, que busque el bienestar de las personas"

A todos los estudiantes que me han aportado experiencia y que me han hecho reflexionar sobre otro tipo de educación que tenga en cuenta su bienestar como desarrollo"

Gulia Palacias Cartés 


\section{AGRADECIMIENTOS}

A todos los docentes de la Maestría en Planeación para el Desarrollo de la Universidad Santo Tomás, por sus aportes teóricos, conceptuales y metodológicos, por su colaboración y apoyo durante el desarrollo del programa, por su profesionalismo y dedicación en la formación de futuros Maestrantes emprendedores que aporten a la construcción de una Colombia mejor, especialmente a: Fabio Lozano, tutor de la tesis, Álvaro Beltrán Palacio, docente de

filosofía y letras y a Doris Herrera, directora de la Maestría, quienes con sus aportes, reflexiones, diálogos y dedicación, me hicieron encausar el rumbo de la investigación para la consecución de esta propuesta. 
TABLA DE CONTENIDO

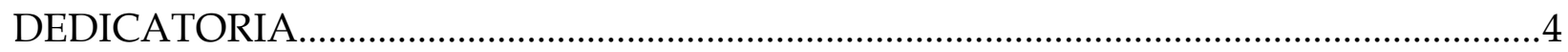

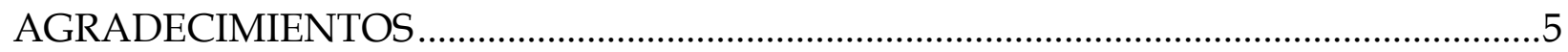

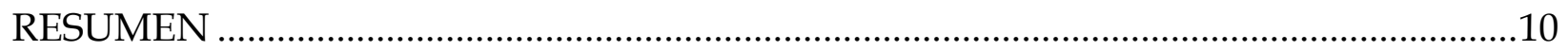

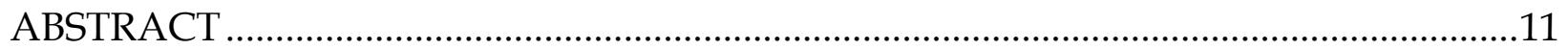

CAPÍTULO I: INTRODUCCIÓN ……………........................................................................12

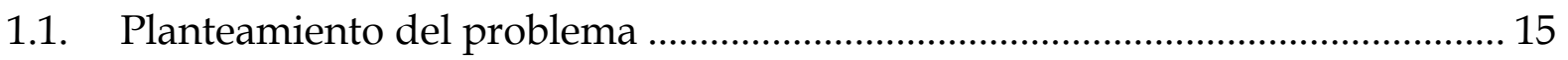

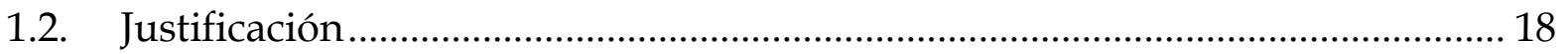

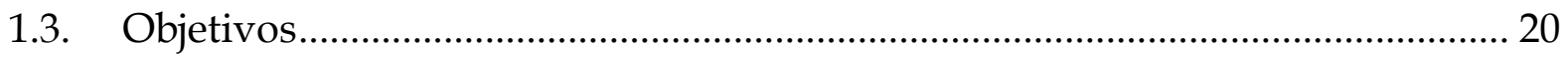

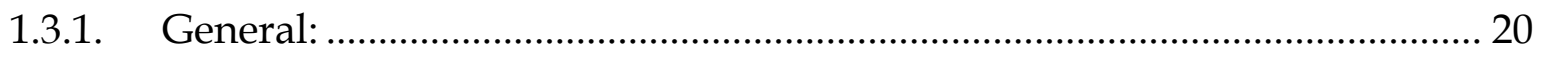

1.3.2. Específicos:_....................................................................................... 20

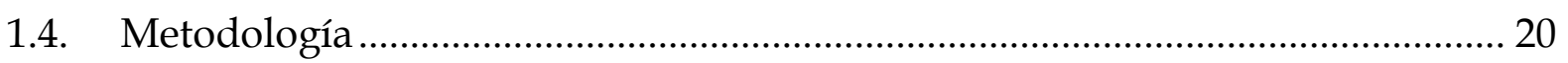

CAPÍTULO II: HORIZONTE TEÓRICO Y CONCEPTUAL …..............................................24

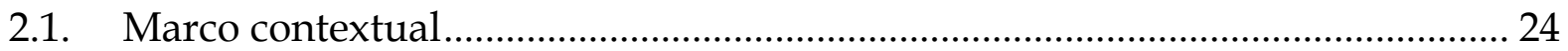

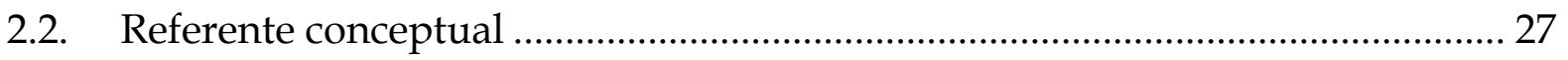

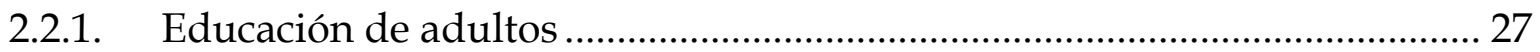

2.2.2. Evolución histórica de la educación formal de adultos en Colombia........ 32

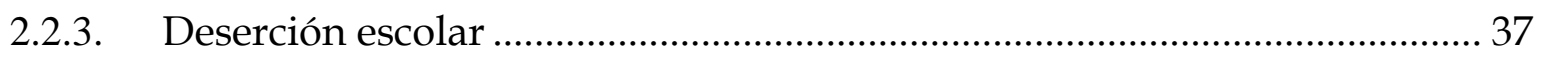

2.2.4. La educación componente esencial del desarrollo humano.......................... 38

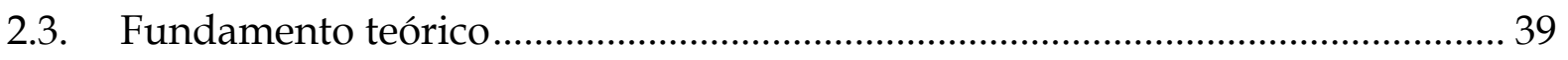

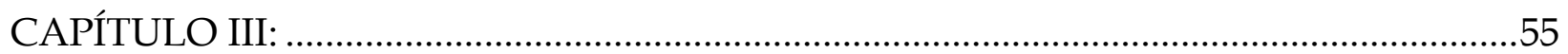




\section{CARACTERIZACIÓN DE LA DESERCIÓN ESCOLAR EN LA JORNADA}

NOCTURNA DEL COLEGIO INTEGRADO DE FONTIBÓN-IBEP ..................................55

3.1. Dimensiones de la deserción escolar en el Colegio Integrado de Fontibón ..... 55

3.2. Motivos del ingreso a la jornada nocturna y de la deserción ................................. 61

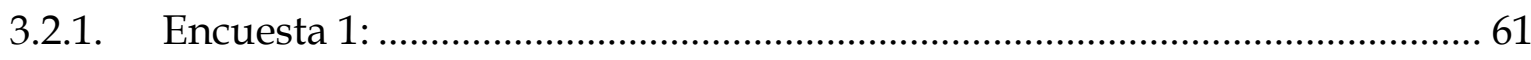

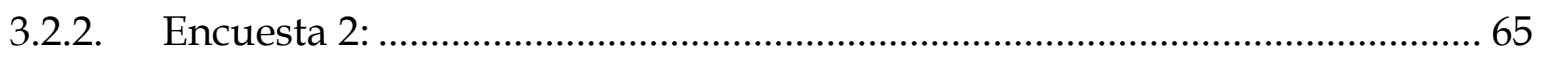

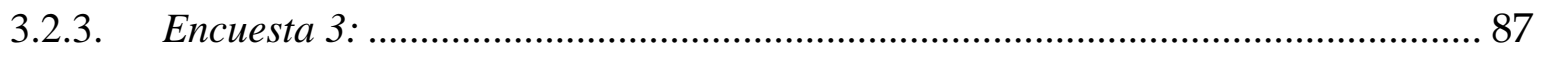

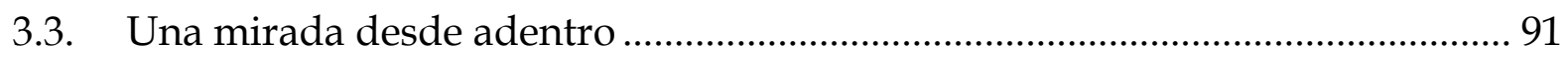

3.4. Voces de los protagonistas desde sus relatos de vida ........................................ 99

3.4.1. Relatos de estudiantes: factores que inciden para desertar en el estudio 100

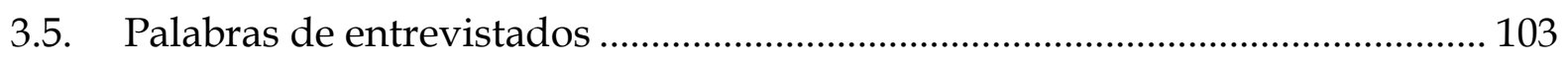

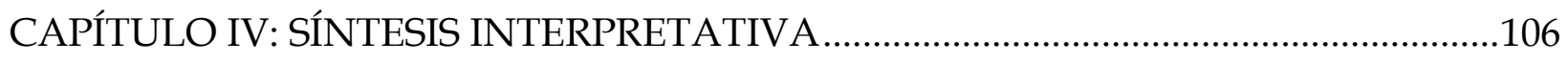

3.5.1. Contexto familiar: (Necesidades de subsistencia, protección y afecto) ... 107

3.5.2. Contexto escolar: (Necesidades de entendimiento, ocio y creación) ....... 109

3.5.3. Contexto social y personal: (Necesidades de identidad, libertad y participación)

3.5.4. Contexto institucional - políticas públicas ................................................... 112

5. CONCLUSIONES Y RECOMENDACIONES ………………..................................116

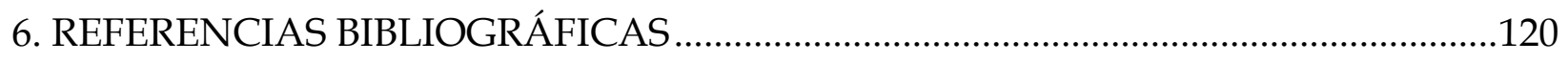

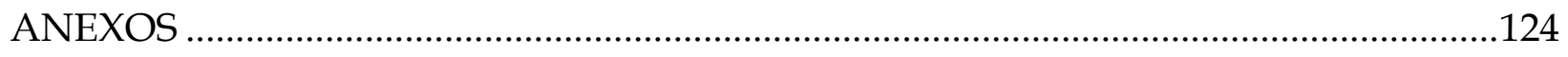

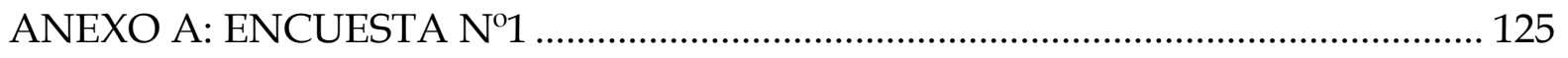

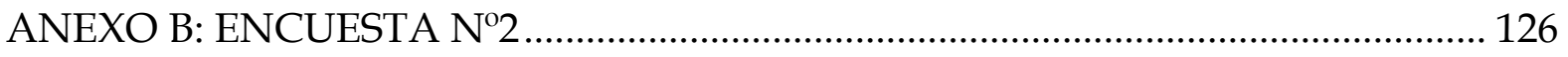

ANEXO C: ENCUESTA No3 A DOCENTES Y DIRECTIVOS....................................... 136 


\section{ÍNDICE DE GRÁFICAS}

Gráfica 1. Comportamiento de estudiantes matriculados y que terminaron según periodo escolar en el año 2014.

Grafica 2. Matriculados Vs retirados por ciclo escolar año 2014.

Gráfica 3. Estudiantes matriculados Vs alumnos retirados en el año 2015

Gráfica 4. Datos por género. Razones para elegir la jornada nocturna

Grafica 5. Datos por género. Razones para el abandono de estudio en la jornada nocturna.

Grafica 6. Datos que muestran con quien vive el estudiante.

Grafica 7. Datos sobre problemas que ha presentado el alumno en los últimos dos años.

Gráfica 8. Pérdida de cursos $\quad 58$

Gráfica 9. Cursos perdidos. $\quad 58$

Gráfica 10. Razones de pérdida de cursos 58

Gráfica 11. Veces que se ha retirado

Gráfica 12. Tiempo que tarda para retomar estudios 60

Gráfica 13. Razones relacionadas con el colegio para retirarse 62

Gráfica 14. Razones relacionadas con la familia para retirarse $\quad 64$

Gráfica 15. Razones personales para retirarse $\quad 66$

Gráfica 16. Razones para volver a estudiar $\quad 68$

$\begin{array}{ll}\text { Gráfica 17. Apoyo a nivel institucional } & 70\end{array}$

Gráfica 18. Participación en actividades culturales y deportivas $\quad 72$

Gráfico 19. Participación en la toma de decisiones $\quad 72$

Gráfico 20. Porcentaje de satisfacción de los estudiantes con el colegio $\quad 75$

$\begin{array}{ll}\text { Gráfica 21. Apoyo familiar } & 76\end{array}$ 
Gráfica 22. Datos. Personas con las que comparte el tiempo extraescolar. Casa 77

Gráfica 23. Razones para retirarse nuevamente $\quad 79$

Gráfica 24. Razones para trabajar $\quad 80$

Gráfica 25. Afectación del trabajo en el estudio $\quad 81$

Gráfica 26. Razones de tipo familiar que causan el retiro de estudiantes. 83

Gráfica 27. Razones de tipo personal que causan el retiro de estudiantes. 84

Gráfica 28. Razones de tipo institucional que causan el retiro de estudiantes 85

Gráfica 29. Trabajos que los estudiantes desempeñan 89

Gráfica 30. Datos de estudiantes con seguridad social 90

\section{ÍNDICE DE TABLAS}

Tabla 1. Herramientas metodológicas aplicadas en la investigación

Tabla 2. Matriculas educación de adultos 2012-2013. Localidad Fontibón

Tabla 3. Población escolar vulnerable localidad de Fontibón 2012-2013 


\section{RESUMEN}

El siguiente trabajo: “Desarrollo y deserción escolar. Estudio de caso: La educación de adultos del colegio Integrado de Fontibón IBEP (I.E.D) de Bogotá", busca interpretar, desde una perspectiva de desarrollo alternativo, las vivencias de estudiantes y docentes sobre la significación de la deserción escolar en la educación de adultos.

Para ello se planteó un horizonte de comprensión desde fundamentos contextuales, teóricos y conceptuales en el marco de las actuales discusiones sobre desarrollo y se identificó la visión de los estudiantes y los profesores sobre factores familiares, económicos y sociales de los estudiantes jóvenes y adultos que abandonaron temporalmente el colegio Integrado de Fontibón IBEP.

En desarrollo de la presente investigación fue preciso caracterizar cuantitativa y cualitativamente la deserción escolar que se presenta en la jornada nocturna del colegio Integrado de Fontibón IBEP (I.E.D) de Bogotá. La significación de la deserción escolar de la voz de los sujetos de estudio, permite encausar la problemática hacia reales soluciones y plantear lo que debe brindar la educación de adultos a sus estudiantes.

La metodología utilizada es de tipo mixta: cualitativa y cuantitativa. La estructura que articula las ideas orientadoras de este proyecto, se origina y desprenden de reflexiones sobre los actos educativos, observados en el colegio en la jornada nocturna.

Palabras claves: Deserción escolar, educación de adultos, desarrollo humano, desarrollo alternativo. 


\begin{abstract}
The following work: "Development and School Dropouts. Case study: the Adult Education at Colegio Integrado de Fontibón IBEP (I.E.D.) in Bogotá", seeks to interpret, from a perspective of alternative development, the experiences of students and teachers about the school dropouts significance in adult education.
\end{abstract}

So that a horizon of understanding is raised from contextual, theoretical and conceptual foundations within the framework of current discussions on development and the vision of students and teachers was identified related to family, social and economic factors of young and adults students who temporarily abandoned their studies at Colegio Integrado de Fontibón IBEP.

During the present investigation development, it was necessary to characterize quantitatively and qualitatively the dropout that occurs in the night day at Colegio Integrado de Fontibón IBEP (I.E.D.) in Bogotá. The significance of the desertion School by the voice of those study subjects, allows us to prosecute the problematic towards real solutions and to approach what adults education must provide to its students.

The methodology used is of mixed type: qualitative and quantitative one. The structure that articulates the ideas guiding this project, is originated and emerged from reflections on the educational acts, observed at the mentioned school in the night day.

Key words: scholar dropping out, adult education, human development, alternative development. 


\section{CAPÍTULO I: INTRODUCCIÓN}

En la práctica diaria de la profesión de docente muchas veces se hace un alto para preguntarse: ¿qué está pasando con los estudiantes?, ¿por qué los estudiantes ya no responden a incentivos o motivaciones propios de su labor académica?, ¿cómo es que se van por quince días, un mes o hasta dos meses y vuelven con deseos de seguir estudiando y con promesas de cumplir con sus obligaciones académicas que pronto rompen? Ante respuestas desoladoras viene luego un natural desaliento en el docente, un dejar pasar, dejar hacer y la decisión fácil de: "Yo me quedo con los que respondan a mis metas propuestas".

Solo cuando se logra conocer historias de vida, donde se encuentra que la mayoría de estudiantes tienen proyectos truncados, familias descompuestas, que no tienen identidad, con escasez de afecto, de amistades, de entendimiento, se discierne que las necesidades humanas de esta población, son múltiples e interdependientes y que, las políticas de educación para esta población están lejos de brindarles satisfacción sinérgica integral a estas "necesidades humanas fundamentales que son finitas, pocas y clasificables"(Max-Neef, 1998, p. 42); necesidades que en esta investigación indagaremos si son las causantes del retiro temporal de sus estudios.

En el contexto real y a raíz de los comentarios espontáneos de los estudiantes de sujetos de estudio, sobre la decisión de retirarse del Colegio, se veía la necesidad de conocer el trasfondo del problema en la vida cotidiana de la jornada nocturna. La investigadora había tenido conversaciones con los estudiantes de dicha jornada, de manera informal, sobre la intención de algunos de ellos de retirarse. Se comenzaron a intuir algunas pistas explicativas de su ingreso 
tardío al estudio, de sus retiros, de sus motivos para regresar y de su situación socio-económica.

En estos comentarios se percibió que la deserción temporal podía ser un problema de intencionalidad y de actitud, generalizable. A diario el docente suele preguntar por alguien que no ha vuelto y el comentario normal es "parece" que se va retirar. Este "parece" informa una intencionalidad y crea un ambiente de inestabilidad, que oculta el problema de la deserción temporal: ni el mismo estudiante logra en verdad explicar la confusión de sus propósitos. Fue en este contexto de interacción con los estudiantes donde se vio la necesidad de registrar la información, para descifrar en el trasfondo de sus narraciones y de sus comentarios, las posibles causas del problema del abandono de sus estudios y la consecuente inestabilidad que se genera en el colegio al ver disminuidos los grupos de estudiantes en cada ciclo escolar, avizorando un posible cierre de la jornada y por ende la posibilidad de que esta población se quede sin recibir la educación que desde circunstancias anteriores les ha sido negada.

En el presente trabajo se concibe la educación como uno de los medios para satisfacer las necesidades humanas fundamentales, que atienda al objetivo de mejorar la calidad de vida de los estudiantes y por tanto su desarrollo humano, contemplado como la expansión de las capacidades de que disfrutan los individuos, para llevar una vida que merezca la pena. (Sen, 2010). Para lograrlo se considera que se debe pensar en una educación de adultos que propenda por un desarrollo que pueda conciliar el crecimiento económico, la solidaridad social y el crecimiento de las personas y de toda la persona, donde "la realización de las necesidades no sean la meta sino el motor de desarrollo, capaz de estimular 
permanentemente la generación de satisfactores sinérgicos ${ }^{1}$ dentro de su contexto cultural local". (Max-Neef, 1998, p. 42).

Significa, entonces, que en este trabajo vincularemos la educación de adultos con el desarrollo, pero desde una visión dirigida a retener y no a excluir, a garantizar el goce de derechos y la realización plena de las personas. En esto se difiere del Ministerio de Educación Nacional, cuando afirma que "la educación es considerada como factor de competitividad en el desarrollo económico. Hay que complementar y actualizar el recurso humano, con el fin de contribuir al mejoramiento del nivel de cualificación del talento humano del país", (MEN, 2015). Al parecer de la autora allí se mira a las personas como objetos al servicio del desarrollo económico, en lugar de ver el desarrollo al servicio de las personas.

Se pretende, por consiguiente, generar la inquietud de plantear una propuesta educativa desde el desarrollo alternativo, que dé lineamientos para una política pública en educación formal para adultos, en la que se garantice que la educación no puede estar al servicio de una concepción capitalista del desarrollo, como productividad y crecimiento económico, con indicadores como el del producto interno bruto (PIB), sino con la concepción alternativa del desarrollo como crecimiento cualitativo de las personas. (Max-Neef, 1998) y como proceso de concientización y liberación (Freire, 1997). Es decir que no solo se acumulen conocimientos, sino que los estudiantes permanentemente sean críticos del mismo conocimiento y planteen su propia emancipación en busca de su bienestar.

Desde estas inquietudes se planteó entonces esta investigación, con las características que se señalan a continuación:

\footnotetext{
1 Satisfactores sinérgicos: aquellos que satisfacen varias necesidades a la vez
} 


\subsection{Planteamiento del problema}

Muchas ciudades en el mundo, tanto las naciones llamadas en vías de desarrollo como las que se consideran "desarrolladas" se enfrentan hoy a la situación de miles o millones de personas que debido a circunstancias personales o sociales no han logrado terminar sus estudios básicos y tienen que enfrentar sus posibilidades de progreso y, en concreto, su acceso al mundo laboral, desde el bloqueo que les genera su condición de no graduados en el nivel de educación media. El problema no es obviamente solo de inserción en el ámbito de la producción y el consumo, sino de posibilidades para el desarrollo de las potencialidades de cada persona y de la construcción de una sociedad equitativa que brinden a sus miembros oportunidades de plenitud de vida y atención de sus propias necesidades. Y en las condiciones actuales la no posesión del "título de bachiller" se convierte a la vez en reflejo y en factor de exclusión y marginación social.

Múltiples factores de carácter histórico y estructural acompañan esta situación que en el caso colombiano se incrementa debido a la masiva expulsión de personas de sus lugares de habitación y trabajo que ha llevado a que desde 1985 se haya generado el desplazamiento de aproximadamente 7 millones 300 mil personas. (CODHES, 2014). Esta expulsión ha generado la ruptura de procesos educativos en millones de niños y la pérdida de conocimientos de vida que tenían los adultos. En efecto por una parte los niños y jóvenes han debido dejar sus escuelas y colegios y los adultos, quienes generalmente vienen de ambientes campesinos, deben ahora enfrentarse a ciudades en las que sus patrimonios de saber no parecen servir para vivir. 
En general las migraciones forzadas o forzosas conforman a nivel mundial una situación de marginación y empobrecimiento social que se convierte en un reto específico para la educación de personas que por sus edades o por la fuerza de estas mismas circunstancias se ven obligadas a hacerse adultos asumiendo la responsabilidad directa de sobrevivencia de sí mismos y de sus allegados.

Si bien estas migraciones se convierten en uno de los factores predominantes de generación de nuevos retos para la educación como ingrediente esencial del desarrollo de poblaciones adultas, no es el único factor. Otros hechos asociados, por ejemplo, a los ajustes estructurales en la economía debido a las políticas neoliberales, han llevado a la desaparición de empresas y al incremento de desempleo y aumento de las dependencias.

El problema es reconocido a nivel mundial y ha llevado a múltiples acciones entre las que se destacan las seis conferencias internacionales de Educación de adultos que desde 1949 ha organizado la UNESCO; de las cuales las dos últimas se realizaron en Alemania en Julio de 1997 y en Brasil en 2009. Ellas condujeron a la adopción de asentados documentos: La "Declaración de Hamburgo sobre la Educación de Adultos"; la "Agenda para el Futuro", (UNESCO, 1997), "Informe Mundial sobre el Aprendizaje y la Educación de Adultos". (UNESCO, 2010). En ellos se reconoce que el aprendizaje y la educación de adultos son claves en el abordaje de los retos sociales y del desarrollo a nivel mundial y se plantean avances, especialmente en el ámbito de alfabetización y los retos de desarrollo de capacidades, enriquecimiento de conocimientos frente a la atención de sus propias necesidades y las de la sociedad. 
En medio de todas estas circunstancias, se han generado instituciones que pretenden ofrecer una alternativa a los adultos para su educación. Sin embargo, se registra igualmente niveles importantes de deserción que llevan incluso a que técnicos y decisores de política recomienden o procedan a la supresión de estos espacios sin que la visión, los sentimientos, los análisis y las implicaciones, para estudiantes, docentes $y$ otros involucrados, sean suficientemente reconocidas y escuchadas.

La deserción escolar constituye un motivo de crisis educativa, porque lo que pretendía ser una respuesta a una carencia y parecía estar funcionando bien, está presentando dificultades. Irse de la institución educativa tiene incidencia, no sólo para la parte administrativa y para los usuarios del servicio, sino también para los docentes. Estos últimos también viven con la incertidumbre de qué pasará con sus estudiantes y con ellos mismos, pues pueden, por ejemplo, ser trasladados o perder sus trabajos, si la decisión de los diseñadores y ejecutores de políticas públicas es cerrar estos espacios.

En síntesis, el problema se enuncia en la siguiente pregunta: ¿Qué significación tienen, en una perspectiva de desarrollo alternativo, las vivencias con respecto a la deserción escolar de estudiantes de la jornada nocturna del Colegio Integrado de Fontibón IBEP, entre los años 2014 y 2015?

Se aborda en este estudio a partir de un caso específico: la educación de adultos en la jornada nocturna del Colegio Integrado de Fontibón IBEP, entre los años 2014 y 2015. Se ha elegido este caso para poder darle una delimitación al tema haciendo viable esta investigación en las circunstancias precisas de la autora y de la maestría: ya que en la labor del ejercicio de la docencia en educación de adultos, es sorprendente ver como a los 8 días de iniciado el año escolar los 
alumnos dejan de asistir al colegio y a lo largo del semestre escolar, la situación continua como algo normal, volviéndose trascendente cuando se anuncian cierres de cursos y se buscan responsables que casi siempre recae en los docentes. Es así como los docentes manifiestan los inconvenientes que tienen con chicos con discapacidad cognitiva, con problemas de convivencia, con problemas de consumo de sustancias psicoactivas, y al unísono todos solicitan que se deberían considerar estas situaciones para que se mantengan menos estudiantes por curso que los exigidos por alguna resolución distrital o nacional, es allí donde surgen las soluciones y acuerdos coyunturales que lo que hacen es desmejorar cada vez más la calidad de educación que se les ofrece a estos estudiantes, sin que se revise a profundidad las verdaderas causas del problema.

\subsection{Justificación}

El abandono del propósito de estudiar, motivado, al parecer por la satisfacción de sus necesidades básicas y por otras expectativas de vida, se convierte en un problema de investigación, precisamente, porque termina siendo un efecto contrario al natural anhelo de esta población de continuar estudiando. Los alumnos van y vuelven, prolongando sus estudios y por ende estarán en desventaja de tener acceso a mejores oportunidades para un mejor nivel de vida, se exponen a remuneraciones bajas en el mercado laboral, a tener servicios de salud y seguridad de mala calidad o simplemente a no tenerlos.

Este hecho constituye una negación de posibilidades ya que, al no tener el título de bachiller, se les cierran oportunidades de empleo o mejora en sus salarios y por ende de movilidad social. La continua deserción escolar de esta población, no sólo justifica, sino que obliga a cuestionar tal situación, con el fin de dar aportes para su transformación. 
La educación como un derecho fundamental, implica que todas las personas tengan acceso a ella, sin embargo, a la población de jóvenes y adultos del Colegio Integrado de Fontibón sujeto de este estudio de caso no se les concedió el derecho a una mínima escolaridad en su edad, y ahora en extra edad reinician el proceso intentando recuperar "el tiempo perdido", sin embargo al poco tiempo de iniciar sus estudios muchos de ellos desertan, por esto se hace necesario hacer un ejercicio de comprensión del fenómeno que ayuda evidenciar las miradas de estos estudiantes y de sus profesores sobre los factores relacionados con el abandono de sus estudios.

La Declaración de Hamburgo sobre la Educación de Adultos y la Agenda para el Futuro, reconocieron que el aprendizaje y la educación de adultos constituyen instrumentos clave para abordar los actuales retos sociales y del desarrollo a nivel mundial. (UNESCO, 1997), pues solo así se podrá tener ciudadanos participes de su devenir social y económico y por tanto de su bienestar, de ahí la necesidad de revisar las connotaciones que tiene la deserción como un impedimento para lograr un desarrollo humano, donde el sujeto sea la población de estudio.

En el contexto de la Maestría en planeación para el desarrollo, se justifica realizar esta investigación, pues al conocer las vivencias de los estudiantes que abandonan los estudio se puede tener una visión de los problemas del desarrollo de la economía clásica inmersos en la educación de adultos, haciendo de esta formación un instrumento que prepara individuos calificados que les sirven a las empresas y al potencial capitalista, cuestionándola desde el desarrollo alternativo si se piensa como una educación que brinde satisfacción de las necesidades humanas fundamentales y que se enfoque en el desarrollo humano 
integral como alternativa de desarrollo que transforme a la población de educandos adultos en sujetos de su propio desarrollo desde lo local.

\subsection{Objetivos}

\subsubsection{General:}

Interpretar, desde una perspectiva de desarrollo alternativo, las vivencias de estudiantes y docentes sobre la significación de la deserción escolar en la educación de adultos a partir del estudio de caso de la jornada nocturna del Colegio Integrado de Fontibón IBEP.

\subsubsection{Específicos:}

a) Plantear un horizonte de comprensión desde fundamentos contextuales, teóricos y conceptuales, que resulten pertinentes para esta investigación en el marco de las actuales discusiones sobre desarrollo.

b) Caracterizar cuantitativa y cualitativamente la deserción escolar que se presenta en el colegio Integrado de Fontibón IBEP.

c) Identificar la visión de los estudiantes y los profesores sobre factores familiares, económicos y sociales de los estudiantes jóvenes y adultos que abandonaron temporalmente el colegio Integrado de Fontibón IBEP.

\subsection{Metodología}

Este trabajo utiliza una metodología de tipo mixta: cuantitativa y cualitativa y, por consiguiente, usa categorías en vez de variables. Desde el enfoque cualitativo: "Estudia la realidad en su contexto natural, tal y como sucede, 
intentando sacar sentido de, o interpreta los fenómenos de acuerdo con los significados que tienen para las personas implicadas" (Rodríguez, Gil, \& García, 1996, p.62).

En la metodología de tipo cualitativo se aplicaron varias herramientas a saber: observación participante, análisis e interpretación de encuestas, entrevistas y relatos de vida. En las encuestas, entrevistas, relatos de su cotidianidad y experiencia personal se describen las situaciones problemáticas y los significados en la vida de los estudiantes (en especial aquellos estudiantes que han abandonado el estudio y han regresado a la jornada nocturna) y los docentes, de la deserción escolar desde un enfoque de desarrollo alternativo.

La estructura inductivo-deductiva, que articula las ideas orientadoras de este proyecto, se origina y desprenden de reflexiones sobre los actos educativos, observados en el colegio nocturno y, en las reflexiones sobre desarrollo económico desde lo clásico hasta las propuestas de desarrollo alternativo, que están comentados en el marco conceptual y contextual del presente trabajo.

La investigación se realizó con estudiantes de las 4 cohortes comprendidas entre los años 2014 a 2015, en la jornada nocturna del colegio Integrado de Fontibón IBEP (I.E.D) de Bogotá, correspondiente a cuatro semestres académicos. En estos periodos se presento el cierre de cursos y mayor deserción temporal.

Posteriormente, se analizaron y se interpretaron los datos y la información obtenida de las vivencias de los estudiantes y de la investigadora, con el fin de organizarlas en categorías, estableciendo relaciones entre las categorías y la clasificación de necesidades fundamentales propuestas por Max-Neef (1998). Lo 
anterior para relacionar el desarrollo visto desde los satisfactores de las necesidades humana fundamentales con la significación de la deserción escolar.

Las encuestas, entrevistas y los relatos de vida se realizaron a estudiantes de todos los ciclos; puesto que en todos hay estudiantes que han abandonado sus estudios y han regresado. La muestra de estudiantes (71) corresponde a un total de 342 estudiantes de Secundaria Básica y Media, de la jornada nocturna del colegio Integrado de Fontibón IBEP. La primera encuesta se aplicó a 71 estudiantes de los ciclos 3 y 4, específicamente a los cursos 302, 303, 402 y 404, para determinar por qué los estudiantes se encuentran en esta jornada y, muy posiblemente, si estos estudiantes son producto de una primera deserción, o bien si son de dos o de varias deserciones escolares. Esta encuesta se aplicó a 16 estudiantes del ciclo 302 con edades entre 14 y 45 años; a 13 estudiantes del ciclo 303 con edades entre 15 a 50 años; a 20 estudiantes del ciclo 402 con edades entre 14 a 55 años; a 22 estudiantes del ciclo 404 con edades entre 15 a 49 años. De esta población el $20 \%$ eran de género femenino y el $80 \%$ eran de género masculino. Es importante aclarar que esta muestra correspondió a 342 alumnos que terminaron el año escolar, de 454 que se matricularon al inicio del año 2014.

En el primer semestre del año 2015, a 60 estudiantes de ciclo 4, se les invito a elaborar sus relatos de vida, de las cuales se escogieron 10 relatos, que expresaron como una circunstancia de su vida el abandono escolar. Luego se aplicó una segunda encuesta a 33 estudiantes del ciclo 6, que abandonaron sus estudios y regresaron, para determinar los factores de su deserción temporal. Posteriormente, se realizaron 3 entrevistas semiestructuradas a una estudiante del ciclo 6 y a dos estudiantes del ciclo 3. Estas entrevistas, permitieron determinar situaciones más complejas y personales al interior de sus vidas. 
Finalmente, se hizo una observación participante de la interacción social con los estudiantes, de 22 años como docente de la educación con adultos en la jornada nocturna, para complementar la información del fenómeno de la deserción temporal de los estudiantes. En la tabla 1 se puede observar la distribución de las herramientas metodológicas aplicadas:

Tabla 1. Herramientas metodológicas aplicadas en la investigación

\begin{tabular}{|c|c|c|c|c|}
\hline $\begin{array}{l}\text { Herramienta } \\
\text { Metodológica }\end{array}$ & Muestra & $\begin{array}{c}\text { Total de } \\
\text { estudiantes }\end{array}$ & $\begin{array}{c}\mathrm{N}^{\circ} \\
\text { estudiantes }\end{array}$ & $\begin{array}{c}\text { ¿A qué Ciclos o } \\
\text { comunidad } \\
\text { educativa se } \\
\text { aplicó? }\end{array}$ \\
\hline \multirow{4}{*}{ Encuesta 1} & \multirow{4}{*}{71} & 22 & 16 & 302 \\
\hline & & 28 & 13 & 303 \\
\hline & & 30 & 20 & 402 \\
\hline & & 30 & 22 & 404 \\
\hline \multirow{3}{*}{ Relatos de vida } & \multirow{3}{*}{60} & 36 & 20 & 401 \\
\hline & & 39 & 20 & 402 \\
\hline & & 36 & 20 & 403 \\
\hline Encuesta 2 & 33 & 39 & 33 & 601 \\
\hline \multirow{2}{*}{$\begin{array}{c}\text { Entrevista } \\
\text { semiestructurada }\end{array}$} & \multirow[t]{2}{*}{3} & 21 & 1 & 601 \\
\hline & & 42 & 2 & $302-303$ \\
\hline \multirow[t]{2}{*}{ Encuesta 3} & \multirow[t]{2}{*}{9} & 2 & 1 & $\begin{array}{l}\text { Directivo } \\
\text { Docente }\end{array}$ \\
\hline & & 12 & 8 & Docente \\
\hline $\begin{array}{l}\text { Observación } \\
\text { Participante }\end{array}$ & 1 & 1 & 1 & Investigadora \\
\hline
\end{tabular}

Fuente propia: Investigación: Desarrollo y deserción escolar de la educación de adultos.... 


\section{CAPÍTULO II: HORIZONTE TEÓRICO Y CONCEPTUAL}

En este capítulo se encontrará una breve descripción de la situación de la jornada nocturna del Colegio Integrado de Fontibón-IBEP, la cual es el objeto del estudio de caso, y una síntesis de los diferentes planteamientos de los teóricos sobre: la educación de adultos, su evolución histórica, la deserción escolar temporal y las alternativas de desarrollo comparadas con las del desarrollo clásico del S. XVIII, que en el presente S. XXI, están en práctica y que son el eje del funcionamiento de un anacrónico sistema educativo colombiano.

\subsection{Marco contextual}

El colegio Integrado de Fontibón IBEP, es una institución de carácter oficial, que ofrece todos los ciclos escolares en su jornada diurna (desde preescolar hasta educación media) y en su jornada nocturna (desde básica primaria hasta educación media). Cuenta con 3 sedes ubicadas en la Localidad de Fontibón (localidad 9) en Bogotá. Las 3 sedes se ubican en el sector occidental de la localidad.

En la sede A del colegio, se ofrece la jornada nocturna por ciclos en educación básica secundaria y media, de acuerdo al decreto 3011 de 1997, así: ciclo 1 comprende los grados $1^{\circ}$ y $2^{\circ}$ de básica primaria; el ciclo 2 comprende los grados $3^{\circ}, 4^{\circ}$ y $5^{\circ}$ de básica primaria; el ciclo 3 comprende los grados $6^{\circ}$ y $7^{\circ}$ de básica secundaria; el ciclo 4 comprende los grados $8^{\circ}$ y $9^{\circ}$ de básica secundaria; el ciclo 5 comprende el grado 10 de educación media y el ciclo 6 comprende el grado 11 de educación media. Los estudiantes se gradúan con el título de Bachiller Académico. (Decreto No. 3011,1997 ) 
Se denomina ciclo (educación para adultos): a los procesos y acciones curriculares organizadas de modo tal que integren áreas de conocimiento y proyectos pedagógicos, de duración menor a la dispuesta para los ciclos regulares del servicio público educativo, que permite alcanzar los fines y objetivos de la educación básica y media de acuerdo con las particulares condiciones de población adulta. (Dirección de Evaluación - Secretaría de Educación del Distrito - SED -, 2012)

La población escolar de la jornada nocturna oscila entre las edades de 15 hasta 70 años, predominando las edades entre los 18 y 35 años. En la jornada nocturna del colegio Integrado de Fontibón IBEP, se inicia el año escolar con una población entre 30 y 40 estudiantes por curso y en el transcurso del año desertan entre $30 \%$ y $40 \%$ de cada curso, excepto en los ciclos 5 y 6 donde el porcentaje es del 5\% ó 10\%. Lo anterior según estadistas de matriculados vs. Retirados, tomados de los archivos del colegio y de la autora de este trabajo los cuales se encuentran en graficas en el capítulo 3 de este trabajo.

Tabla 2. Matriculas en educación de adultos 2012-2013. Localidad Fontibón

\begin{tabular}{|c|c|c|c|r|}
\hline \multirow{2}{*}{ Año } & \multicolumn{2}{|c|}{ Matriculas } & \multicolumn{2}{c|}{ Rangos de Edad } \\
\cline { 2 - 5 } & Localidad & $\begin{array}{c}\text { Colegio Integrado de } \\
\text { Fontibón IBEP }\end{array}$ & $18-24$ años & $>25$ años \\
\hline 2012 & 1.059 & 560 & 472 & 362 \\
\hline 2013 & 824 & 490 & 664 & 265 \\
\hline 2014 & 847 & 454 & Sin Información & 238 \\
\hline
\end{tabular}

Fuente: Tablas 50 y 52 año 2012, tablas 45 y 47 año 2013, tablas 45 y 47 año 2014. Boletín Estadístico SED

Elaboración: Oficina asesora de Planeación-SED- Grupo de Análisis Sectorial

En la localidad de Fontibón se presentó una matrícula en la jornada nocturna para el año 2012 de 1.059 estudiantes, para el año 2013 de 824 estudiantes 
y para el año 2014 de 847 estudiantes, distribuidos en los dos colegios que ofrecen educación de nocturna para jóvenes y adultos. En la tabla 2 se observa la variabilidad de matrícula que se presentó entre los años 2012, 2013 y 2014, siempre de forma descendente.

En la tabla se corrobora la información, de que cada vez, población más joven se vincula a la educación de adultos que se ofrece en la jornada nocturna y como se evidencia en las encuestas aplicadas en esta investigación esta situación, se da por el deseo de terminar pronto el bachillerato, con el deseo como ya se dijo "de recuperar el tiempo perdido" y poder ingresar a la vida laboral, así mismo por las responsabilidades de adulto que adquieren los jóvenes entre esas sus hijos o trabajar para contribuir económicamente al hogar o vivir independientemente por conflictos familiares. Para los mismos años 2012, 2013 y 2014, en todas las jornadas de la localidad de Fontibón, se encontraron los siguientes datos de población escolar vulnerable:

Tabla 3. Población escolar vulnerable localidad de Fontibón 2012-2013

\begin{tabular}{|c|c|c|c|}
\hline Año/ Población vulnerable Localidad 9 & $\mathbf{2 0 1 2}$ & $\mathbf{2 0 1 3}$ & $\mathbf{2 0 1 4}$ \\
\hline Victimas de conflicto & 566 & 350 & 322 \\
\hline En situación de desplazamiento & 553 & 339 & 311 \\
\hline Desvinculados de grupos armados & 10 & 8 & 8 \\
\hline Hijos de adultos desmovilizados & 3 & 3 & 3 \\
\hline Con discapacidad & 275 & 269 & 295 \\
\hline
\end{tabular}

Fuente: Tablas 55 y 53 año 2012, tablas 50 y 48 año 2013, tablas 48 y 50 año 2014. Boletín Estadístico SED.

Elaboración: Oficina asesor de Planeación-SED- Grupo de Análisis Sectorial 
De esta población vulnerable, se atiende una gran parte en la jornada nocturna, lamentablemente no hay datos estadísticos de estas cifras, pues esta información se guardaba cuidadosamente por las directivas para evitar conflictos, discriminación por parte del resto de la población y salvaguardar la seguridad de estas personas.

En general se atiende en la jornada nocturna además de la población vulnerable, estudiantes con dificultades de aprendizaje o convivencia, que abandonaron la educación en su edad escolar o simplemente no tuvieron la oportunidad de educarse por dificultades socio económicas. Datos tomados de la tabla 50, 52, 53 y 55 del año 2013 y de las tablas 45, 47, 50 y 48 del año 2013. (Dirección de Evaluación - Secretaría de Educación del Distrito -SED-, 2012 -2013). Por eso se insiste en que esta jornada es quizás la única oportunidad de educación que tiene esta población en busca de un mejor bienestar.

\subsection{Referente conceptual}

\subsubsection{Educación de adultos}

En general, la educación de jóvenes adultos ha tomado diferentes denominaciones: educación popular, educación comunitaria, alfabetización, educación permanente y educación formal. Lamentablemente, la Constitución Política de Colombia, en su artículo 67, al darle obligatoriedad a la educación solo entre los 5 y 15 años de edad, no incentiva la existencia de los colegios nocturnos y, por ende, tampoco la existencia de una política de retención en educación de adultos, que garantice que todas las personas, sin que interese su edad, recibirán educación. Ni siquiera una reparación o compensación para las personas, a quienes 
no se les concedió el derecho a una mínima escolaridad en su edad, que se garantizaría con una educación permanente. (Bustamante, 2006).

El estado solo reconoce en sus estadísticas la deserción de la población en edad escolar (PEE): mediante el artículo 67 de la Constitución Política que la educación será obligatoria entre los 5 y los 15 años de edad y comprenderá como mínimo, un año de preescolar y nueve de educación básica, en conexidad, si se completara el ciclo de bachillerato, se sumarian 2 años más para cursar la media. Es por eso que la Población en Edad Escolar está comprendida desde 5 años hasta los 17 años de edad, por ello la población adulta se reconocería a partir de los 18 años de edad, sin embargo, en esta jornada se encuentra población entre 14 y 17 años de edad, que deben abandonar sus estudios para trabajar y encuentran la jornada nocturna la opción para culminar su bachillerato.

Para el MEN la educación formal de adultos comprende la alfabetización y la educación básica para jóvenes y adultos que por cualquier circunstancia no ingresaron al servicio educativo o desertaron prematuramente del mismo. Pretende brindar la formación en competencias básicas de lenguaje y comunicación, matemáticas, ciencias sociales, ciencias naturales y competencias ciudadanas, empleando programas curriculares y metodologías ajustados a las características psicológicas de su desarrollo personal y a las condiciones socioculturales del medio, con horarios flexibles y generalmente de carácter semipresencial, apoyada con materiales educativos de autoaprendizaje". (www.mineducacion.gov.co/1621/article-82806.html)

"La educación para adultos tiene por objetivo primordial mejorar las condiciones de vida de las personas que, por algún motivo no han tenido acceso al 
sistema educativo. Se busca su inclusión en la vida económica, política y social, y el fortalecimiento de su desarrollo personal y comunitario. (...). La educación de adultos debe estar contextualizada, debe proyectar el estudiante a su comunidad, debe estar en conexión con procesos de formación para el trabajo, la producción y la participación, debe ser un puente a la vida y un motor de cambio social". (Colombia Aprende, s.f.)

Para la UNESCO la educación de adultos designa "la totalidad de los procesos organizados de educación, sea cual sea el contenido, el nivel o el método, sean formales o no formales, ya sea que prolonguen o reemplacen la educación inicial..." (Citado por Martínez, 2006, p.2). Así pues, el concepto de adulto se transforma en alguien que desarrolla sus aptitudes y evoluciona en sus actitudes a medida que enriquece sus conocimientos y participa en el desarrollo socio-cultural de su contexto (con fines no sólo laborales sino de todas las áreas de la vida), lo cual sería concordante con unas políticas en educación de adultos pensadas en el desarrollo humano.

Educación de adultos: "[...] designa la totalidad de los procesos organizados de educación, sea cual sea el contenido, el nivel o el método, sean formales o no formales, ya sea que prolonguen o reemplacen la educación inicial dispensada en las escuelas y universidades, y en forma de aprendizaje profesional, gracias a las cuales las personas consideradas como adultos por la sociedad a la que pertenecen, desarrollan sus aptitudes, enriquecen sus conocimientos, mejoran sus competencias técnicas o profesionales o les dan una nueva orientación, y hacen evolucionar sus actitudes o su comportamiento en la doble perspectiva de un enriquecimiento integral del hombre y una participación en un desarrollo socioeconómico y cultural equilibrado e independiente". Sin embargo, "la 
educación de adultos no puede ser considerada intrínsecamente: sino como un subconjunto integrado en un proyecto global de educación permanente". (Recomendación relativa al desarrollo de la educación de adultos, Nairobi: 1976, para. I, 1).

Educación permanente y aprendizaje: “[...] designa un proyecto global encaminado tanto a reestructurar el sistema educativo existente, como a desarrollar todas las posibilidades de formación fuera del sistema educativo, - en ese proyecto, el hombre es el agente de su propia educación, por medio de la interacción permanente de sus acciones y su reflexión, - la educación permanente lejos de limitarse al periodo de escolaridad, debe abarcar todas las dimensiones de la vida, todas las ramas del saber y todos los conocimientos prácticos que puedan adquirirse por todos los medios y contribuir a todas las formas de desarrollo de la personalidad, - los procesos educativos, que siguen a lo largo de la vida los niños, los jóvenes y los adultos, cualquiera que sea su forma, deben considerarse como un todo". (Recomendación relativa al desarrollo de la educación de adultos, Nairobi: 1976, para. I, 2).

Aprendizaje de adultos: “[...] comprende la educación formal y la permanente, la educación no formal y toda la gama de oportunidades de educación informal y ocasional existentes en una sociedad educativa multicultural, en la que se reconocen los enfoques teóricos y los basados en la práctica". (Declaración de Hamburgo sobre la educación de adultos, UIE, 1997, para. 3). Educación no formal: “[...] a pesar de las impresiones en sentido contrario, no constituye un sistema educativo distinto y separado, paralelo al sistema de educación formal. Es cualquier actividad educativa organizada y sistemática, realizada fuera del marco del sistema formal, para ofrecer tipos seleccionados de aprendizaje a subgrupos específicos de la población, tanto adultos como niños. Así 
definida, la educación no formal incluye, por ejemplo, programas de extensión agrícola y de formación de agricultores, programas de alfabetización de adultos, formación para la adquisición de competencias ocupacionales ofrecida fuera del sistema formal, clubes juveniles con sólidos propósitos educativos y diversos programas comunitarios de instrucción en salud, nutrición, planificación familiar, cooperativas, etc.".

En la Ley General de Educación (Ley 115), en el título III, cap. II, art. 50-51, se define la educación para adultos como: "aquella que se ofrece a las personas en edad relativamente mayor a la aceptada regularmente en la educación por niveles y grados del servicio público educativo, que desean suplir y completar su formación, o validar sus estudios (...) con el fin de actualizar sus conocimientos y desarrollar sus capacidades de participación en la vida económica, política, social, cultural y comunitaria". (MEN, 1994). Este planteamiento de la Ley General de Educación de Colombia es lo que debe ofrecer la educación de adultos del colegio Integrado de Fontibón IBEP, si se propone como meta educativa el desarrollo humano, entendido como "la libertad de opciones para vivir dignamente según sus deseos de bienestar". (Sen, 2010 p. 82) y para ello debe pensarse en una educación que plantee el aprendizaje de conocimientos desde la trasdisciplinaridad y no fragmentados siguiendo un currículo como se hace en la actualidad.

Dada que las características (biológicas, psicológicas, sociales) de los adultos, su aprendizaje no puede limitarse a un ejercicio intelectual: desarrollo de asignaturas, debe ser significativo, en el sentido que pueda transformarse en experiencia vital o en praxis, que sea funcional para su vida. 
Luego la educación de adultos debe mejorar la pertinencia e integralidad, se tiene que pensar diferente a la educación de jóvenes, una educación integral que dé prioridad a las competencias comunicativas, enseñar a pensar y a convivir. Es importante volver a motivar al estudiante con el estudio, enseñándolo a innovar, a liderar, a ser ciudadano, a manejar la economía de su hogar, a que sea capaz de determinar los satisfactores de sus necesidades básicas humanas por medio de la auto organización y auto gestión que le den mejor calidad de vida.

Actualmente se concibe la educación de adultos como un ideal que se debe llevar a cabo a lo largo de toda la vida y sin fronteras (sin límites de espacio, edad y tiempo). En el mismo sentido se entiende la alfabetización, ya que se alfabetiza a lo largo de toda la vida y se debe ir más allá de aprender a leer y a escribir: hay que leer, escribir y adaptarse a los cambios y transformaciones toda la vida (aprender a aprender permanentemente y estar al tanto de las transformaciones tecnológicas), es lo que la UNESCO considera como alfabetización funcional y apta para la adaptación social, ya que es la mano de obra potencial de un país y su deficiencia impide el desarrollo económico. Desde este punto de vista la educación de adultos estaría al servicio del desarrollo económico, en lugar del desarrollo económico estar al servicio de las personas. (Max Neef, 1998, pág. 47). Es decir, se piensa en seres productivos para un sistema de desarrollo económico, pero no en el desarrollo de sus capacidades que le den bienestar y calidad de vida.

\subsubsection{Evolución histórica de la educación formal de adultos en Colombia}

En Colombia la educación formal de adultos se inició en 1903, con la creación de centros nocturnos, a través de la ley 39, artículo 38, la cual establecía 
que debía ser gratuita, pero no obligatoria. (Diario oficial Número 11.931, 1903). Solo hasta 1947 el Ministerio de Educación Nacional crea un pensum y reglamenta los exámenes comprobatorios.

La educación de adultos surgió de las recomendaciones de la UNESCO en los años 1948 y 1949, al querer darle un enfoque pedagógico a la formación de las personas mayores de 14 años que fueran iletrados, recomendando métodos para su desarrollo, inicialmente, para erradicar el analfabetismo. Dio sus primeros resultados en el año de 1961, en los países de Uruguay y Cuba. En este último se alfabetizaron 707.212 adultos, utilizando el enfoque de educación funcional ${ }^{2}$.

Entre 1948 y 1949 se le asigna a la empresa privada el pago de los maestros y los costos de funcionamiento de la alfabetización y los maestros en su mayoría, eran voluntarios. En 1952, con el decreto 2320 del 24 de septiembre, se establecen las normas de la enseñanza secundaria en los establecimientos nocturnos, los cuales debían estar destinados a personas mayores de 16 años que se encontraran trabajando.

El Decreto 2320 dicta normas sobre establecimientos nocturnos de enseñanza secundaria: "Por el cual se concede licencia de funcionamiento a establecimientos nocturnos de enseñanza secundaria". La norma indicaba que para matricularse en un colegio nocturno se requiere no tener menos de 16 años y presentar una certificación laboral, donde el patrono informará que el estudiante tiene libres de trabajo obligatorio las horas en que deberá concurrir al establecimiento educativo y que posee buena conducta moral y social (Diario

\footnotetext{
2 Educación Funcional: cuando lo que se aprende puede utilizarlo en una situación concreta para resolver un problema determinado.
} 
Oficial Número 28038, 1952). Además, en su artículo undécimo autoriza al Ministerio de Educación para que favorezca la fundación de secciones nocturnas de enseñanza

secundaria en los colegios nacionales, ya sean costeadas dichas secciones nocturnas por el Gobierno Nacional o por los alumnos. Es decir, esta educación se deja a cargo de los privados incluso los mismos alumnos deben asumir los gastos.

Al exigir que para matricularse es necesario que el patrón certifique al aspirante, indica que el decreto se establece es para responder a necesidades de las empresas, con el fin obtener mano de obra calificada en los procesos de producción, que se presentan por esta época, (en ocasión de los avances del desarrollo de la industria en Colombia), ya que "los grupos en el poder dirigen la educación para el pueblo según sus fines" (Bustamante, 2006, p. 25).

En consecuencia, se infiere que el ofrecimiento de la educación nocturna para adultos ha sido destinado a satisfacer necesidades de la industria en pro del desarrollo económico y, por tanto, "segrega y es para segregados sociales". (Velásquez, 1990) citado por (Bustamante, 2006, pág. 27).

Desde 1958 se inician campañas de alfabetización, generando rubros específicos para dicha actividad. En 1966, con el decreto 1830, se define la educación de adultos como "un proceso integral y permanente destinado a elevar el nivel cultural, profesional y social de quienes no recibieron los ciclos educativos en la edad correspondiente, o de quienes después de haber realizado estudios primarios, medios o superiores, necesitan ampliar su información para adaptarse a los cambios del desarrollo científico y tecnológico de la época". (Diario Oficial 33995, 1966). 
En 1972, se nombran docentes alfabetizadores, lo cual permite normalizar la educación de adultos y se declara el año de la alfabetización en Colombia; se incluye aquí la enseñanza por radio y televisión.

Las experiencias con organismos diferentes al Ministerio de Educación Nacional se inician prácticamente en 1976 donde se crea un comité para el diseño curricular para la educación de adultos en el cual participan el MEN, el Fondo de Capacitación Popular, La Universidad Pedagógica y la Secretaría de Educación del Distrito (de Santafé de Bogotá D.C.). Posteriormente, mediante un convenio suscrito con la Santa Sede se inicia la educación Contratada con las Prefecturas y Vicariatos Apostólicos. Finalmente se crea la Educación cooperativa mediante contratación del MEN con las Juntas de acción Comunal, facultándolas para organizar colegios bajo la forma de "Cooperativas Educacionales". (OEI Sistemas Educativos Nacionales - Colombia, 1994)

La educación básica y media para adultos está regulada por la Ley General de Educación. En el capítulo II, art. 50 y 51, de la Ley General, se definen e indican los objetivos específicos de la educación para adultos; los cuales son:

a) Adquirir y actualizar su formación básica y facilitar el acceso a los distintos niveles educativos;

b) Erradicar el analfabetismo;

c) Actualizar los conocimientos, según el nivel de educación, y

d) Desarrollar la capacidad de participación en la vida económica, política, social, cultural y comunitaria.

El decreto 3011 de diciembre 19 de 1997, en sus artículos 16, 18, 19 y 24, regula la educación básica y media para adultos y explica que podrá ser de manera presencial, semi-presencial o abierta, a distancia y en jornada diurna, 
nocturna, sabatina o dominical. “Cuando se adopte la modalidad semi-presencial se debe garantizar una presencialidad no inferior al cincuenta por ciento $(50 \%)$ de las horas de trabajo académico y el desarrollo de prácticas, asesorías, tutorías, trabajos grupales y elaboración de módulos y guías". En el decreto 3011 además, se enuncian los principios (art.3), su organización (art.5), sus lineamientos (arts. 16, 18,19 y 24) y su funcionamiento general.

Igual que antes, en la actualidad, se percibe que vuelven las condiciones fabriles, reforzadas por intereses neoliberales de la globalización del mercado, que proclaman la necesidad de una educación conveniente a los requerimientos de las empresas; sin tener en cuenta las necesidades de bienestar de los sujetos, como personas con potencialidades y capacidades. A propósito, Steinberg y Kincheloe (2004), citado por Jennifer Gidley (2006, p. 2), señala que “las empresas son ahora la fuente más prominente de nuestro currículo cultural. Las escuelas, las iglesias y las familias ya no son las instituciones dominantes en la educación de los jóvenes. Son las corporaciones". A pesar de que todas las ciencias han evolucionado, la economía sigue con los principios clásicos del siglo XVIII, pensando en el desarrollo como crecimiento económico y exigiéndole a la educación de adultos que permanezca al servicio de esta visión funcionalista.

Frente a la situación de seguir viendo la educación de adultos al servicio del desarrollo como crecimiento económico, se postulan como alternativas, los enfoques de Amartya Sen, Paulo Freire y de Max Neef, para tratar de devolverle a los seres humanos su lugar protagónico. En consecuencia, frente a una educación para adultos, destinada a preparar trabajadores útiles, al servicio del mejoramiento de la producción y del crecimiento económico, se propone en esta investigación relacionar la deserción escolar con la privación de necesidades humanas básicas que contrasta con un desarrollo de una economía al servicio de 
las personas, que tenga como propósito el goce de los derechos de los individuos y el desarrollo del crecimiento de las potencialidades humanas, que permitan dar el paso de "la eficiencia a la sinergia" (Max Neef, 1998, pág. 81). Una educación concientizadora que le abra camino a la expresión de las insatisfacciones sociales. (Freire, 1976).

\subsubsection{Deserción escolar}

La deserción escolar constituye el eje fundamental del trabajo y se trata de un término transferido del argot militar a la educación, en el sentido de abandono o retirada del deber o compromiso adquirido. En educación significa el abandono del sistema escolar por parte de los estudiantes, provocado por la combinación de factores que se generan, tanto al interior del sistema como en contextos de tipo social, familiar, individual y del entorno. (MEN, 2016). El sentido más común es abandono de los estudios por su propia voluntad o por retiro forzoso, cuando influyen factores externos como la pobreza, el desplazamiento, el conflicto social, el conflicto escolar y otros, que no dependen de su voluntad. En la deserción se cuenta al porcentaje de población estudiantil, que abandona sus estudios en forma temporal o definitiva y al estudiante que, estando matriculado en una institución educativa suspende sus estudios.

El retiro de los estudiantes o deserción escolar temporal se configura como un efecto social, determinado por factores institucionales, pedagógicos y socioeconómicos de los estudiantes (Montero, 2007). La repercusión social de la deserción escolar es múltiple, porque puede llegar a ocurrir varias veces en la vida de los estudiantes, especialmente, cuando estudiantes ya vulnerables por su pobreza, se retiran y a su regreso se suman nuevos problemas, tales como desplazamiento, violencia, deficiente salud, drogadicción y la responsabilidad de 
buscar su propio sustento y el de sus familias, "sin que hayan existido mecanismos de ayuda desde el Estado, desde la Institución y desde los docentes y sin que la voz de los estudiantes haya sido escuchada" (Bustamante, 2006, p. 17), razón por la que en este trabajo se le da significado a la deserción desde las vivencias de los estudiantes.

Por consiguiente, la deserción implica, además, un sentido invisible, que se esconde tras un fracaso escolar, con sentimientos personales de pérdida de autoestima y vivencias de frustración, que provocan autoexclusión sociocultural, tal como se conoció en las informaciones obtenidas de la voz de los sujetos investigados. Esta situación viene empeorando con las exclusiones generadas por las nuevas tecnologías que, para los adultos mayores, significan adaptarse al paradigma de una nueva era del conocimiento.

\subsubsection{La educación componente esencial del desarrollo humano}

El desarrollo como libertad, definido "como un proceso de expansión de las libertades reales y capacidades de que disfrutan los individuos", (Sen, 2010, p. 19) plantea que va más allá de las variables cuantitativas y se extiende al conjunto de oportunidades de los individuos, constituyéndose en una alternativa de la visión desarrollo tradicional. En consecuencia, los problemas económicos de escasez de los estudiantes no son solo un fenómeno meramente material, sino algo más complejo, que además los excluye de las políticas sociales de equidad, y de los derechos económicos, democráticos, sociales y culturales.

En concreto, el desarrollo humano es un paradigma que privilegia el aumento de la riqueza de la vida humana en lugar de la riqueza de la economía, entendiendo que los bienes materiales son sólo una parte de la vida misma. Por lo 
tanto, va más allá del aumento o la disminución de los ingresos de un país, comprende la creación de un entorno en el que las personas puedan desarrollar su máximo potencial y llevar adelante una vida productiva y creativa, de acuerdo con sus necesidades e intereses. Las personas son la verdadera riqueza de las naciones. Por lo tanto, el desarrollo implica ampliar las oportunidades para que cada persona pueda vivir una vida que valore. El desarrollo como crecimiento económico es sólo un medio importante para expandir las libertades y para que cada persona tenga más oportunidades. Las capacidades más esenciales para el desarrollo humano son disfrutar de una vida larga y saludable, haber sido educado, acceder a los recursos necesarios para lograr un nivel de vida digno y poder participar en la vida de la comunidad. "Sin estas capacidades, se limita considerablemente, la variedad de opciones disponibles y muchas oportunidades en la vida, permanecen inaccesibles". (Sen, 2010, p.19,21). Es posible una educación para estos jóvenes y adultos, a partir de sus saberes, que satisfaga sus necesidades, oriente el desarrollo en bien del ser humano y haga posible el mejoramiento de su calidad de vida. Esto es, Aprendizajes pertinentes que ofrezcan oportunidades a favor de su bienestar (Sen, 2010), porque esto les permitiría ser ciudadanos que participan o incluso son artífices de su desarrollo., ser críticos ante la depredación de la naturaleza o ser más conscientes del uso de los satisfactores de sus necesidades.

\subsection{Fundamento teórico}

A nivel local, los problemas generados en la deserción escolar temporal, comprometen al colegio, al sistema educativo y a la sociedad, porque, por una parte, el contexto ha cambiado y la concepción de la educación para adultos, sus prácticas y los programas, continúan apenas con pequeñas variaciones y; por otra, los procesos del desarrollo económico, también se encuentran 
descontextualizados, porque sus políticas públicas y sus concepciones del desarrollo continúan pensando exclusivamente en el bienestar material, medido por los índices del ingreso per cápita, sin tener en cuenta que "el mejor proceso de desarrollo será aquel que permita elevar más la calidad de vida de las personas" y que esta calidad de vida "dependerá de las posibilidades que tengan las personas de satisfacer adecuadamente sus necesidades humanas fundamentales". (Max Neef, 1998, pág. 40).

Cuando se planteó esta investigación, se propuso indagar la deserción escolar desde las necesidades básicas de los estudiantes y cómo estas problemáticas, económicas y de conflicto familiar miradas desde un sistema de desarrollo económico clásico causa el abandono de sus estudios y se vuelve en un círculo vicioso que se prolonga por años abandonando a su suerte a esta población a quienes se les continúa negando el derecho a educarse. El sistema educativo tampoco les ofrece otra expectativa de mejor vida, se pierde el interés por el estudio, por consiguiente, un mejor bienestar y finalmente esta población se convierte en un problema social pues son los potenciales generadores de violencia e inseguridad o simplemente se convierten todos sus problemas en una patología colectiva de frustración, cada vez más difícil de resolver, si continuamos con enfoques ortodoxos y tradicionales (Max Neef, 1998, pág. 44)

Con base en la teoría tradicional de desarrollo Económico y en las políticas neoliberales que ha seguido la educación, Easterly, se opone a que Organismos Internacionales continúen con los planes de ayuda económica a nivel educativo. Su preocupación es cuestionar si los incentivos de los Organismos Internacionales responden al crecimiento económico (medido desde una mirada reduccionista de índices como el PIB) y se pregunta, ¿educar para hacer qué? Agrega que a pesar de los nobles sentimientos que despierta la educación, los 
rendimientos de la educación han sido decepcionantes en las últimas décadas en la búsqueda de crecimiento. Por lo cual recomienda controlar el crecimiento de la población, para economizar en máquinas y en escuelas. (Easterly, 2001)

La concepción de Easterly, por supuesto, obedece al desarrollo desde una visión dominante, tecnócrata, reduccionista. Sin embargo, son este tipo de teóricos de las políticas neoliberales, impulsadores del desarrollo como crecimiento económico, quienes están construyendo los discursos orientadores de los Objetivos de Desarrollo del Milenio y de la planeación de los Objetivos de Desarrollo Sostenible, proclamados en Agenda post 2015.

Según datos obtenidos de los estudiantes, los jóvenes adultos que deciden abandonar sus estudios, inicialmente, lo hicieron porque debían ayudar con los oficios del hogar, con labores de agricultura y con el cuidado de hermanos o de algún familiar enfermo. Posteriormente, cuando ingresan al mundo laboral y desean continuar estudiando, se transforman en hombres y mujeres destinados al "rebusque". Es decir, a múltiples oficios que permanecen "invisibles" a los ojos de la economía y que pueden verse incluidos en este planteamiento de Max-Neef: "Si contáramos esos trabajos invisibles, que son realizados en su mayoría por las mujeres, comprobaríamos que suponen el 20 o el 30 por ciento del PIB y que NO son contabilizados por la economía, pero que son esenciales para la satisfacción de las necesidades básicas" (Max Neef,1998, p.40), pero estos oficios invisibles no les mejoran su calidad de vida, porque son mal remunerados o incluso no se obtiene remuneración.

Este "rebusque" constituye el diario vivir de los estudiantes en mención y se da en el contexto de una concepción del desarrollo que hace caso omiso del bienestar de las personas y de la necesidad de una vida digna. Por 
consiguiente, esta investigación se sitúa en las fronteras de las contradicciones surgidas, entre las concepciones de las escuelas clásicas de economía para el desarrollo y las concepciones alternativas, construidas en las reflexiones hechas sobre la pobreza y la inequidad social.

Con el fin de comprender las situaciones de vida de estos estudiantes y sustentar las reflexiones surgidas, este trabajo rastrea algunas ideas de pensadores que han analizado las contradicciones de las concepciones del desarrollo; pues, se evidencia en la historia de la evolución de la educación de adultos que son las empresas y la economía (crecimiento económico y productivo) las que les determinan a los estudiantes los requisitos de estudio, su currículo y las formas de vida, más adaptadas a los intereses de la producción para su industria, que al desarrollo de sus potencialidades y a la satisfacción de sus necesidades fundamentales.

Los estudiantes que han abandonado sus estudios vuelven por exigencias en el trabajo y por las expectativas que con un título de bachiller podrán conseguir trabajo y mejor remuneración, ante esta presión social y la poca remuneración que reciben en sus trabajos actuales, cuando lo consiguen, vuelven a abandonar sus estudios, pero la desmotivación por el estudio continúa, porque lo que se enseña no tiene sentido para ellos.

En concreto, porque existe un abismo entre el desarrollo como crecimiento y el desarrollo humano, entre lo que los estudiantes necesitan para el trabajo y lo que necesitan para desarrollarse integralmente como seres humanos. Estas reflexiones de la investigación se fundamentan en quienes han sustentado sus discursos a favor de posibilidades alternativas de desarrollo, como Max Neef, Amartya Sen, Paulo Freire y Arturo Escobar Velásquez. 
Frente a esta propuesta del crecimiento económico como fundamento del desarrollo, impuesto por las teorías de la economía clásica, que parecen estar más lejos que cerca de las soluciones esperadas, Manfred Max-Neef, , plantea una concepción alternativa de desarrollo como crecimiento cualitativo de las personas (Max-Neef, 1998, pág. 40) y argumenta que se requiere una nueva manera de contextualizar el desarrollo, teniendo en cuenta, no sólo el Orden Económico Internacional sino, especialmente, el local, lo cual implica tener en cuenta algunos aspectos fundamentales como "modificar sustancialmente las visiones dominantes sobre estrategias de desarrollo"; "reconocer la incomplitud e insuficiencia de las teorías económicas y sociales, que han servido de sustento y orientación a los procesos de desarrollo hasta el presente y un nuevo modo de interpretar la realidad", orientado por "una teoría de las necesidades humanas para el desarrollo", es decir, por un desarrollo a escala humana. (Max Neef, 1998, pág. 37).

Según las indagaciones hechas, la deserción de los estudiantes adultos sujetos de esta investigación, está relacionada con la insatisfacción de la mayoría de sus necesidades humanas fundamentales, bien porque carezcan de satisfactores $^{3} \mathrm{o}$ bien porque los satisfactores que obtienen no sean los adecuados para desarrollar sus potencialidades humanas. Aquí claramente Max Neef nos aporta una clasificación de necesidades y posibles satisfactores entre los que se encuentran y se relacionan con esta investigación están:

MATRIZ DE NECESIDADES Y SATISFACTORES

${ }^{3}$ Satisfactores: aquello que da solución o respuesta a algo 


\begin{tabular}{|c|c|c|c|c|c|c|c|c|}
\hline \multirow{3}{*}{$\begin{array}{c}\text { NECESIDAD } \\
\text { SUBSISTENCIA }\end{array}$} & \multicolumn{8}{|c|}{ SATISFACTORES } \\
\hline & \multicolumn{2}{|l|}{ SER } & \multicolumn{2}{|c|}{ TENER } & \multicolumn{2}{|l|}{ HACER } & \multicolumn{2}{|l|}{ ESTAR } \\
\hline & & & & & & & & \\
\hline & Salud física & $x$ & Alimentación & $x$ & Alimentar & & Entorno vital & $\mathrm{x}$ \\
\hline & Salud mental & & Abrigo & $x$ & Procrear & & Entorno social & $x$ \\
\hline & Equilibrio & & Trabajo & $x$ & Descansar & & & \\
\hline & Solidaridad & & & & Trabajar & $X$ & & \\
\hline & Humor & & & & & & & \\
\hline & Adaptabilidad & $x$ & & & & & & \\
\hline \multicolumn{9}{|l|}{ PROTECCIÓN } \\
\hline & Cuidado & & Sistemas de seguros & $x$ & Cooperar & $x$ & Contorno vital & \\
\hline & Adaptabilidad & $x$ & Ahorro & & Prevenir & & Contorno social & $x$ \\
\hline & Autonomía & $x$ & Seguridad social & $x$ & Planificar & & Morada & \\
\hline & Equilibrio & & Sistemas de salud & $x$ & Cuidar & $x$ & & \\
\hline & Solidaridad & & Legislaciones & & Curar & & & \\
\hline & & & Derechos & $X$ & Defender & & & \\
\hline & & & Familia & $x$ & & & & \\
\hline & & & Trabajo & $x$ & & & & \\
\hline \multicolumn{9}{|l|}{ AFECTO } \\
\hline & Autoestima & $x$ & Amistades & & \begin{tabular}{|l}
$\begin{array}{l}\text { Hacer el } \\
\text { amor }\end{array}$ \\
\end{tabular} & & Privacidad & \\
\hline & Solidaridad & $x$ & Pareja & $x$ & Acariciar & $x$ & Intimidad & \\
\hline & Respeto & $x$ & Familia & $x$ & $\begin{array}{l}\text { Expresar } \\
\text { emociones }\end{array}$ & $x$ & Hogar & $x$ \\
\hline & Tolerancia & $x$ & Animales domésticos & & Compartir & $x$ & $\begin{array}{l}\text { Espacios de } \\
\text { encuentro }\end{array}$ & \\
\hline & Generosidad & $x$ & Plantas & & Cuidar & & & \\
\hline & Receptividad & $\mathrm{X}$ & Jardines & & Cultivar & & & \\
\hline & Pasión & & & & Apreciar & $x$ & & \\
\hline & Voluntad & $x$ & & & & & & \\
\hline & Sensualidad & & & & & & & \\
\hline & Humor & & & & & & & \\
\hline \multicolumn{9}{|l|}{ ENTENDIMIENTO } \\
\hline & Conciencia & & Literatura & $x$ & Investigar & $x$ & $\begin{array}{l}\text { Ámbitos de } \\
\text { interacción } \\
\text { formativa }\end{array}$ & $x$ \\
\hline & Critica & $x$ & Maestros & $x$ & Estudiar & $x$ & Escuelas & \\
\hline
\end{tabular}




\begin{tabular}{|c|c|c|c|c|c|c|c|c|}
\hline & Receptividad & $x$ & Método & & Experimentar & $x$ & Universidades & \\
\hline & Curiosidad & $x$ & \begin{tabular}{|l} 
Políticas \\
educacionales
\end{tabular} & $x$ & Ayudar & & Academias & \\
\hline & Asombro & $x$ & $\begin{array}{l}\text { Políticas } \\
\text { comunicacionales }\end{array}$ & $x$ & Analizar & $x$ & Agrupaciones & $x$ \\
\hline & Disciplina & $x$ & & & Meditar & & Comunidades & $x$ \\
\hline & Intuición & & & & Interpretar & $X$ & Familia & $x$ \\
\hline & Racionalidad & $x$ & & & & & & \\
\hline \multicolumn{9}{|l|}{ PARTICIPACIÓN } \\
\hline & Adaptabilidad & $x$ & Derechos & & Afiliarse & $x$ & $\begin{array}{l}\text { Ámbitos de } \\
\text { interacción } \\
\text { participativa }\end{array}$ & $x$ \\
\hline & Receptividad & & Responsabilidades & $x$ & Cooperar & $x$ & Cooperativas & \\
\hline & Solidaridad & $x$ & Obligaciones & & Proponer & $X$ & Asociaciones & \\
\hline & Disposición & $x$ & Atribuciones & & Compartir & & Iglesias & \\
\hline & Convicción & & Trabajo & $\mathrm{X}$ & Discrepar & & Comunidades & \\
\hline & Entrega & $x$ & & & Acatar & $x$ & Vecindarios & \\
\hline & Respeto & $\mathrm{x}$ & & & Dialogar & & Familia & $x$ \\
\hline & Pasión & & & & Acordar & & & \\
\hline & Humor & & & & Opinar & $x$ & & \\
\hline \multicolumn{9}{|l|}{ OCIO } \\
\hline & Curiosidad & $x$ & Juegos & & Divagar & & Privacidad & \\
\hline & Receptividad & & Espectáculos & & Abstraerse & & Intimidad & \\
\hline & Imaginación & & Fiestas & & Soñar & $x$ & $\begin{array}{l}\text { Espacios de } \\
\text { encuentro }\end{array}$ & \\
\hline & $\begin{array}{l}\text { Despreocupac } \\
\text { ión }\end{array}$ & & Calma & $x$ & Añorar & & Tiempo libre & $x$ \\
\hline & Humor & & & & Fantasear & & Ambientes & \\
\hline & Tranquilidad & & & & Evocar & & Paisajes & \\
\hline & Sensualidad & & & & Relajarse & & & \\
\hline & & & & & Divertirse & & & \\
\hline & & & & & Jugar & & & \\
\hline \multicolumn{9}{|l|}{ CREACIÓN } \\
\hline & Pasión & $x$ & Habilidades & $x$ & Trabajar & & $\begin{array}{l}\text { Ámbitos de } \\
\text { producción y } \\
\text { retroalimentación }\end{array}$ & \\
\hline & Voluntad & $x$ & Destrezas & & Inventar & & Talleres & \\
\hline
\end{tabular}




\begin{tabular}{|c|c|c|c|c|c|c|c|c|}
\hline & Intuición & & Método & & Construir & $\mathrm{x}$ & Ateneos & \\
\hline & Imaginación & $x$ & Trabajo & & Idear & & Agrupaciones & \\
\hline & Audacia & & & & Componer & & Audiencia & \\
\hline & Racionalidad & & & & Diseñar & $x$ & $\begin{array}{l}\text { Espacios de } \\
\text { Expresión }\end{array}$ & $x$ \\
\hline & Autonomía & & & & Interpretar & & Libertad temporal & \\
\hline & Inventiva & $x$ & & & & & & \\
\hline & Curiosidad & & & & & & & \\
\hline IDENTIDAD & & & & & & & & \\
\hline & Pertenencia & $\mathrm{x}$ & Símbolos & & $\begin{array}{l}\text { Compromete } \\
\text { rse }\end{array}$ & $x$ & Socio - ritmos & \\
\hline & Coherencia & $x$ & Lenguaje & & Integrarse & $x$ & $\begin{array}{l}\text { Entornos de la } \\
\text { cotidianidad }\end{array}$ & \\
\hline & Diferencia & & Hábitos & $X$ & Confundirse & & $\begin{array}{l}\text { Ámbitos de } \\
\text { pertenencia }\end{array}$ & $x$ \\
\hline & Autoestima & $x$ & Costumbres & $x$ & Definirse & $x$ & $\begin{array}{l}\text { Etapas } \\
\text { madurativas }\end{array}$ & \\
\hline & Asertividad & $\mathrm{x}$ & Grupos de referencia & & Conocerse & $x$ & & \\
\hline & & & Sexualidad & & Reconocerse & $\mathrm{x}$ & & \\
\hline & & & Valores & $x$ & Actualizarse & & & \\
\hline & & & Normas & & Crecer & & & \\
\hline & & & Roles & $x$ & & & & \\
\hline & & & Memoria Histórica & $x$ & & & & \\
\hline & & & Trabajo & & & & & \\
\hline LIBERTAD & & & & & & & & \\
\hline & Autonomía & $x$ & $\begin{array}{l}\text { Igualdad de } \\
\text { derechos }\end{array}$ & & Discrepar & & Plasticidad & \\
\hline & Autoestima & $x$ & & & Optar & & Espacio - temporal & \\
\hline & Voluntad & $x$ & & & Diferenciarse & $\mathrm{x}$ & & \\
\hline & Pasión & & & & Arriesgar & & & \\
\hline
\end{tabular}




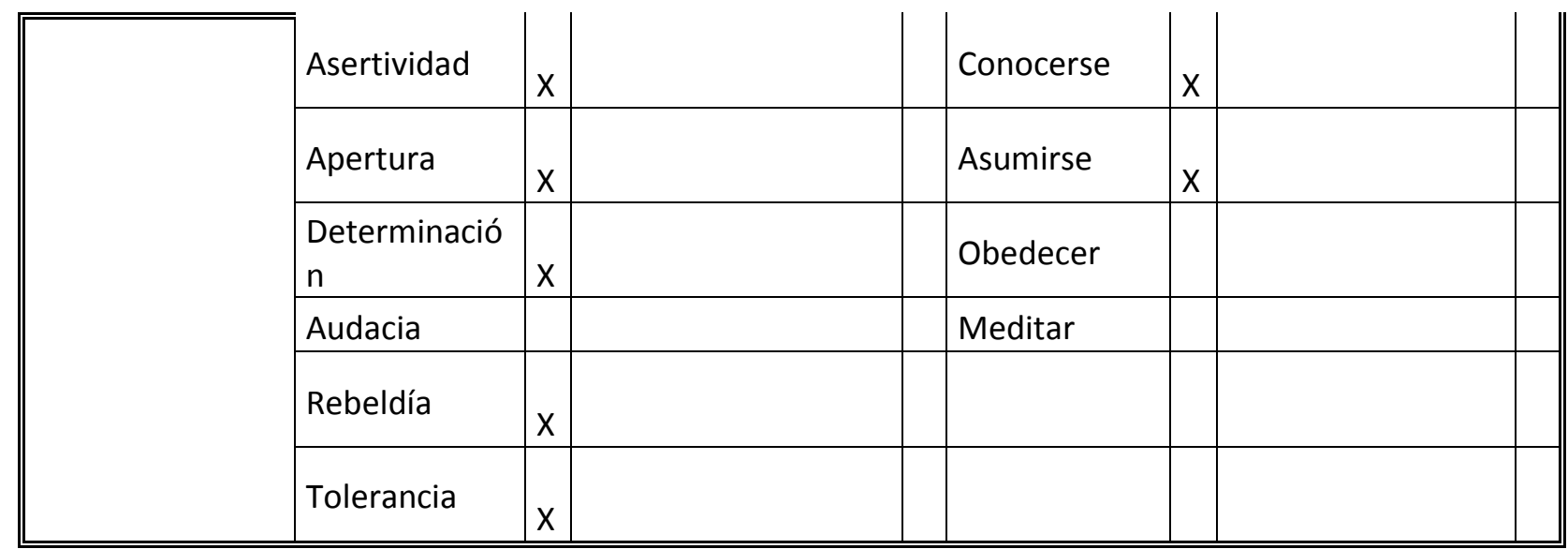

Fuente: Matriz tomada de la pagina 58 y 59. Desarrollo a Escala Humana. Max Neef. Elaboración: propia que se complemento de la Fuente para esta investigación

Los satisfactores relacionados con las necesidades que se encuentran marcados con equis $(\mathrm{X})$, son los que posiblemente están inmersos en la problemática de deserción temporal que ocurre en la educación de adultos de la jornada nocturna del Colegio Integrado de Fontibón IBEP (I.E.D) de Bogotá.

Este contexto desafortunado implica revisión de algunos lineamientos de las políticas educativas para adultos, más centradas en los objetivos temáticos que en las necesidades y potencialidades de las personas. A propósito, Max-Neef, considera que ese deseo de modernización uniformizadora, no ha dejado acabar con la pobreza y con inequidades sociales (situación en que viven muchos estudiantes según lo corroborado en las encuestas) y es preciso pensar en lo valores de uso (los servicios de la naturaleza, los trabajos no asalariados o trabajos invisibles), y en la diversidad, porque son esenciales para la satisfacción de las necesidades fundamentales.

Finalmente, para orientar el desarrollo en una sociedad compleja, como la actual, la visión de los economistas resulta insuficiente y se requiere de la integración de un "enfoque transdisciplinario", que se ubique en una época de 
transiciones que requiere "cambios de paradigma", por tanto, se requiere conocer, no sólo sus necesidades sino también la cobertura y calidad de sus satisfactores y que tenga en cuenta postulados como: "el desarrollo se refiere a las personas y no a los objetos". (Max Neef, 1998, pág. 40).

En esta línea crítica del desarrollo limitado al crecimiento económico, Sen considera: la educación como un problema de interés público, que no se puede dejar al rumbo de los vaivenes del mercado y trae a colación una reflexión de conocimiento común: los discursos sobre derechos humanos y libertad política son muy conocidos y divulgados y "sin embargo, vivimos en un mundo de notables privaciones, miseria y opresión". Este pensador propone y defiende el desarrollo de las capacidades y el aprovechamiento de las oportunidades sociales, porque facilitan la participación económica y contribuyen en la generación de riqueza personal. Por ejemplo, “las oportunidades sociales para recibir educación y asistencia sanitaria, que pueden exigir la intervención del Estado, complementan las oportunidades individuales para participar en la economía y en la política y contribuyen a fomentar nuestras propias iniciativas en la superación de nuestras respectivas privaciones" (Sen, 2010, pág. 16).

Según la teoría del economista Sen, Amartya, la educación para adultos debería apoyarse en procesos de desarrollo, entendidos como formas de expansión de las capacidades humanas, con un enfoque de desarrollo humano que "conduzca directamente al bienestar y a libertad de los individuos y que indirectamente influya en el cambio social y en la producción económica" (Sen, 2010, pág. 354). Es decir, la educación con una política pública, que actúe con el propósito de satisfacer las necesidades humanas, sin la pretensión de privilegiar solo el conocimiento. 
La visión del desarrollo humano, surge como alternativa al desarrollo. Sin desconocer la importancia del crecimiento económico, enfatiza la necesidad de comprenderla como uno de los recursos al servicio del crecimiento cualitativo de las personas, en el sentido que la prioridad debe ser la economía al servicio de los seres humanos (Max-Neef, 1998, pag.46). A propósito, comenta Banerjee \& Dulfo, mientras hace alusión a las capacidades de Sen, “lo más probable es que una niña pobre de África no vaya a la escuela más que unos pocos años, aunque sea brillante, y que no reciba la nutrición necesaria para ser la atleta de la élite que podría haber sido, ni la financiación para emprender un negocio si tiene una gran idea". (Banerjee \& Dulfo, 2013, p. 22) De aquí que desarrollo humano implique el desarrollo de múltiples potencialidades de los estudiantes, que les permitan crecer como personas, para sostenerse dignamente en el colegio y en el contexto social.

En la prolongación de este discurso alternativo, se consultaron planteamientos y estrategias de la educación liberadora, propuestos por Paulo Freire como opción de resistencia de los pueblos catalogados como subdesarrollados, ante los proyectos devastadores de los países dominantes (desarrollados), creadores de dependencia y de enajenación. Paulo Freire, se interesó por la educación de los adultos y percibió que, sobre todo a nivel de primaria y secundaria, la educación se prestaba a la manipulación de los estudiantes y terminaba domesticándolos. Cuando, por el contrario, la educación debería crear conciencia de la situación de dominación y transformarse en liberadora de la opresión creada por la dependencia.

En su libro La educación como práctica de la libertad de 1997, argumenta su concepción de la educación, como una acción creadora de conciencia crítica y como liberadora del "miedo a la libertad", interpretado en el contexto de 
esta investigación como un criterio de potenciación del desarrollo humano, que invita a los dominados a "descolonizarse" y a liberarse de una "élite superpuesta", que a nombre de la liberación, le ha negado al pueblo su integración al contexto como sujeto, a través de "mitos dirigidos por la publicidad organizada". Así lo expresa Freire: "Este es el dilema que se presenta hoy, en forma ineludible, a los países subdesarrollados, o del Tercer Mundo: educación para la domesticación alienada y educación para la libertad. Educación para el hombre-objeto o educación para el hombre-sujeto" (Freire, 1997, p. 26 - 34).

Como defensor de la valoración de hombre como sujeto del desarrollo humano, frente al hombre-objeto del crecimiento económico, expresa que, al concebir al hombre como sujeto-persona, lo normal de su naturaleza no debería ser la dominación sino la liberación. Entonces, el hombre dependiente, domesticado por el discurso dominante y oprimido por su ignorancia, requiere de una educación que le permita disfrutar de la práctica de su libertad, teniendo en cuenta, sin embargo, que "nadie libera a nadie, ni nadie se libera solo. Los hombres se liberan en comunión". (Freire, 1976, p. 37).

Su visión antropológica sitúa el problema de la dependencia en un plano global, desde el cual se percibe que tanto opresores como oprimidos, han perdido su calidad humana. Por tanto, ambos comparten el mismo plano existencial de negación de su humanidad y ambos deben liberarse. La diferencia surge por el generador del problema social de deshumanización, pues, quienes generaron la violencia, la explotación, el desconocimiento de los otros y toda la caracterización negativa denunciada por Freire, fueron los opresores. Ya que, "quien instaura la negación de los hombres no son aquellos que fueron despojados de su humanidad, sino aquellos que se la negaron, negando también la suya" (Freire, 1976, p. 56). 
El problema es la deshumanización, creada por los explotadores y la solución, la liberación de la especie humana del flagelo de la relación opresoroprimido. Pero, mientras que, quienes poseen el poder han tenido la desgracia de "prohibirles ser" a los oprimidos, éstos buscan "su derecho a ser", en una dialéctica existencial que les permita llegar a ser libres, sin que esto signifique llegar a cambiar de "lugar o de polo" (de oprimidos a opresores). Freire concluye: “Es por esto por lo que sólo los oprimidos, liberándose, pueden liberar a los opresores. Éstos, en tanto clase que oprime, no pueden liberar ni liberarse". (Freire, 1997, pág. 57).

También, acompañaron este proceso de reflexión, las críticas de alternativas del postdesarrollo, argumentadas por el intelectual Arturo Escobar, quien confronta el desarrollo preguntándose por el sentido real del concepto de desarrollo, mediante la deconstrucción del discurso desarrollista, propuesto por las potencias de la Economía Mundial y propagado por las Naciones Unidas.

Su enfoque crítico y demoledor del discurso de la ideología desarrollista, se apoya en ideas de Foucault y de Habermas, para develar los prejuicios, fábulas y mitos que, como también lo dice Paulo Freire, constituyen "sombras de élites superpuestas o ideologías", que cuando han tratado de imponerse, como camisa de fuerza, han traído "nefastas consecuencias de su aplicación en el Tercer Mundo". Los pueblos que han aplicado estas imposiciones, no se han desarrollado y en cambio han visto afectado su ambiente y quienes "en verdad se han venido desarrollando, enriqueciendo y acumulando poder, han sido los que en este juego desigual se habían situado desde antes como los más privilegiados en la estructura económica, social y política existente". (Escobar, 2007, pág. 8). 
La alternativa propuesta por Escobar, ante la postura única del capitalismo neoliberal, como patrón de los sistemas económicos y tecnológicos, es la de deconstruir los discursos hegemónicos (creadores de dominio del pensamiento y de la acción), para los cuales se categorizó el lenguaje con premisas como "la creencia en el papel de la modernización, en la industrialización, en la urbanización, en que sólo mediante el desarrollo material podría producirse el progreso social, cultural y político (...) y que la inversión de capital era el elemento más importante del crecimiento económico y el desarrollo" (Escobar, 2007, pág. 78), las cuales justifican las formas dominantes de producción económica y sociocultural, con que han pretendido desarrollar los países declarados subdesarrollados, especialmente, cuando la economía del desarrollo ha declarado como su objetivo la economía subdesarrollada.

En consecuencia, se concluyó lo que aún continúa vigente, esto es, que el desarrollo de los países subdesarrollados depende de "grandes suministro de capital para proporcionar la infraestructura, la industrialización y la modernización global de la sociedad" (Escobar, 2007, pág. 78). Entonces, en la deconstrucción del discurso que sustenta el desarrollo, Escobar identifica no sólo el proceso de formación del capital sino también todos los factores de la red productiva, cultural e institucional, de planificación y de agencias técnicas de la red de relaciones de la organización, que cubría toda la geografía cultural, económica y política del Tercer Mundo, que le permiten concluir: "Para entender el desarrollo como discurso es necesario mirar no a los elementos mismos sino al sistema de sus relaciones recíprocas. Es este sistema de relaciones el que permite la creación sistemática de objetos, conceptos y estrategias; él determina lo que puede pensarse y decirse". (Escobar, 2007, pág. 80) 
Para concluir estas breves ideas críticas que ayudan a comprender problemas sociales como la deserción, hay que entender la concepción neoliberal de los países dependientes y subdesarrollados, en un discurso organizado para crear un sistema de desarrollo, que siempre se ha impuesto con sus planificaciones, un desarrollo que favorece al capitalismo, pero que depreda la naturaleza, empobrece a la población, creándole necesidades que no son las suyas, y enfermedades entre otras, sin tener en cuenta la tradición histórica y cultural de los países del Tercer Mundo.

Los enfoques alternativos, que cuestionan el concepto de desarrollo vigente, examinan el discurso de la economía como construcción cultural, "exploran la literatura reciente de la antropología económica que postula la existencia de modelos marginales en la práctica económica, de los grupos populares del Tercer Mundo actual, discute la necesidad de una política cultural que tome en serio la existencia de diversos modelos locales sustentados implícitamente por grupos del Tercer Mundo" (Escobar, 2007, pág. 107)

Vale la pena concluir con estas significativas palabras de Arturo Escobar, a propósito de la resistencia soberbia de los economistas a ver su ciencia como un discurso cultural: "Esta labor de crítica cultural debe comenzar con el reconocimiento claro de que la teoría económica es un discurso que construye una imagen particular de la economía (...) y cualquier modelo, sea éste local o universal, es una construcción del mundo y no una verdad objetiva e irrebatible sobre él.(...) En la economía existe, por tanto, un etnocentrismo que es preciso develar, es decir, un efecto hegemónico logrado mediante representaciones que rinden culto a una visión de la economía al tiempo que suprimen otras" (Escobar, 2007, pág. 113). 
Finalmente, en Colombia han primado tres puntos de vista sobre la manera de concebir el servicio educativo para las personas adultas: 1) el tradicional, en procura de capacitarlos para el servicio de las empresas, 2) el social como concientización para liberación de la enajenación y 3) el alternativo de desarrollo humano, que le apuesta al desarrollo integral de las potencialidades de los estudiantes. 


\section{CAPÍTULO III:}

\section{CARACTERIZACIÓN DE LA DESERCIÓN ESCOLAR EN LA JORNADA NOCTURNA DEL COLEGIO INTEGRADO DE FONTIBÓN-IBEP}

En este trabajo, nos referimos a caracterización, como la determinación de los atributos que tuvo la deserción escolar en los cuatro (4) periodos académicos de los años 2014 y 2015 en el Colegio Integrado de Fontibón IBEP.

La caracterización se presenta desde diferentes aproximaciones: cuantitativa a partir de registros de matrículas en los cuatro (4) cohortes mencionados y de encuestas aplicadas por la autora en tres (3) periodos diferentes, una aproximación etnográfica desde la experiencia de 22 años de la autora como docente de la educación nocturna y una cualitativa obtenida de algunos relatos de vida y de entrevistas hechas a los estudiantes.

\subsection{Dimensiones de la deserción escolar en el Colegio Integrado de Fontibón}

De las listas de matriculados y retirados de la jornada nocturna del colegio Integrado de Fontibón IBEP, encontradas en los archivos del colegio, correspondientes al primer semestre y segundo semestre del 2014, y al primer semestre y segundo semestre del 2015, se extrajeron los datos para graficarlos, con el fin de analizar la deserción de los estudiantes.

Las cifras sobre deserción utilizadas convencionalmente hacen la comparación del número de estudiantes matriculados al inicio del año frente al número de los que terminan el ciclo escolar. Sin embargo, para nuestro estudio de 
caso, esta forma de seguimiento conduce a conclusiones que no reflejan claramente las dinámicas de ingreso y el abandono de estudios en la jornada nocturna.

Las tres gráficas que se presentan a continuación muestran datos en número y porcentaje frente a estudiantes matriculados y aquellos que terminaron el año escolar, de igual manera los estudiantes matriculados y los retirados en el transcurso de los años 2014 y 2015.

Gráfica \#1. Comportamiento de estudiantes matriculados y que terminaron según periodo escolar en el año 2014.

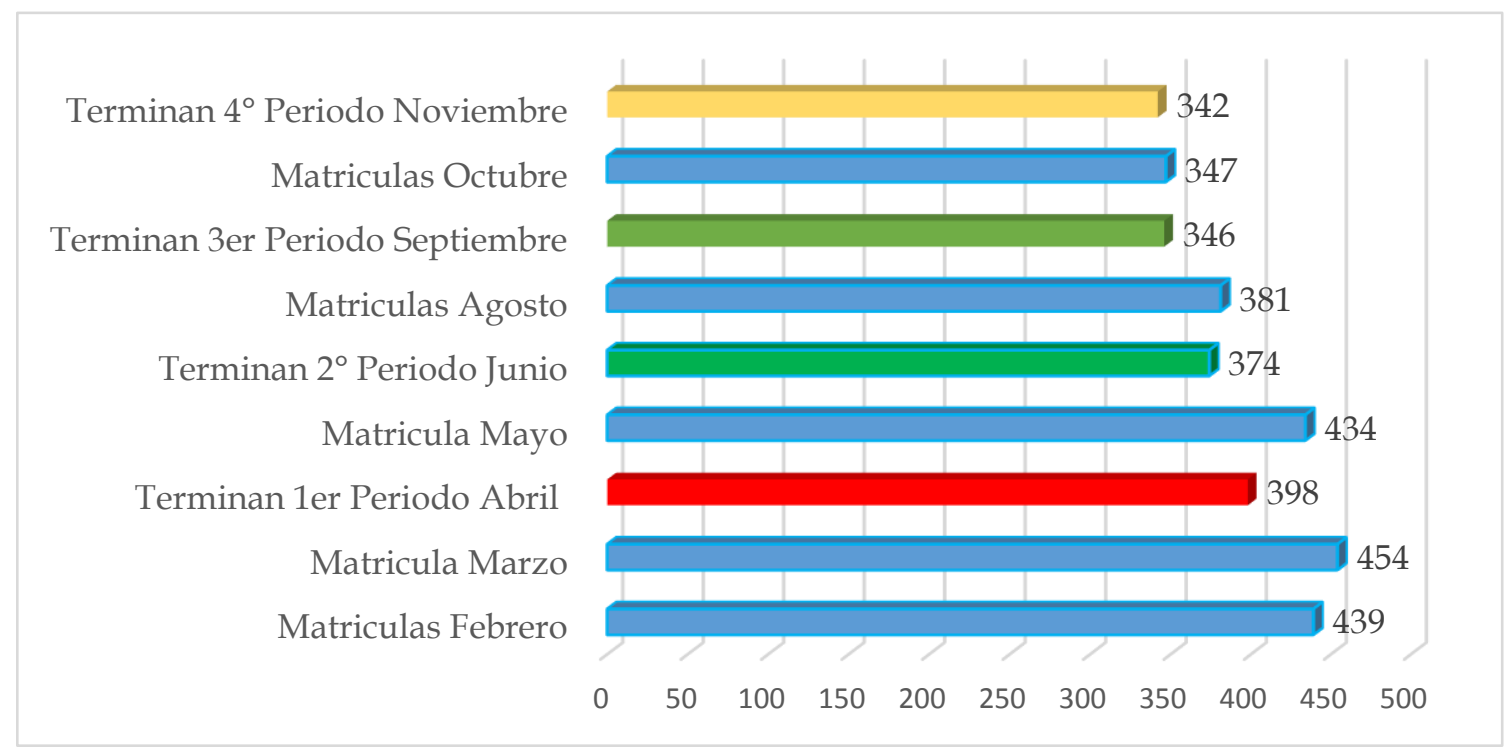

Fuente. Datos tomados del colegio Integrado de Fontibón. Elaboración propia de la autora

La gráfica \#1 arroja una información sobre la deserción de estudiantes, teniendo en cuenta las cifras de ingreso en el mes de febrero y las de finalización para el cuarto periodo en el mes de noviembre.

El ingreso se da con una cifra de cuatrocientos treinta y nueve (439) estudiantes y con una finalización para el cuarto periodo de Trescientos cuarenta y dos (342) estudiantes, lo cual arroja una diferencia de noventa y siete (97) 
estudiantes que presentaron deserción durante los cuatro periodos, siendo este un equivalente en porcentaje del $22.1 \%$; de igual manera se evidencia que en el mes de marzo se registraba un total de cuatrocientos cincuenta y cuatro (454) estudiantes matriculados, de los cuales solamente terminaron el primer periodo trecientos noventa y ocho (398), arrojando una diferencia de cincuenta y seis (56) estudiantes, lo que equivale a un porcentaje de deserción de 12,3\% en menos de un mes; en el mes de mayo nuevamente se cuenta con cuatrocientos treinta y cuatro (434) estudiantes matriculados, de los cuales solo trescientos setenta y cuatro (374) finalizan en el mes de junio, lo que arroja una cifra de deserción de sesenta (60) estudiantes que equivale a un porcentaje de $13.8 \%$ entre matriculados y los que finalizan en este periodo.

Así mismo se puede observar que la cifra de matriculados en el mes de mayo es similar a la cifra de matriculados en el mes de febrero, pero inferior a la que resulta del mes de marzo y superior a la que muestra la terminación del primer periodo, lo cual significa que sobre el total de los que terminaron en abril se tiene un numero de treinta y seis (36) nuevos estudiantes. "Los registros disponibles no permiten saber cuántos de estos estudiantes son nuevos y cuántos son reingresados".

Esta variación se repite cíclicamente, pero se evidencia que, en los periodos finales, las diferencias entre los estudiantes matriculados y los que terminaron es menor, presentándose deserción del $9 \%$, lo que permite identificar qué en estos meses se presenta una mayor estabilidad. 
Gráfica \#2. Matriculados Vs retirados por ciclo escolar año 2014.

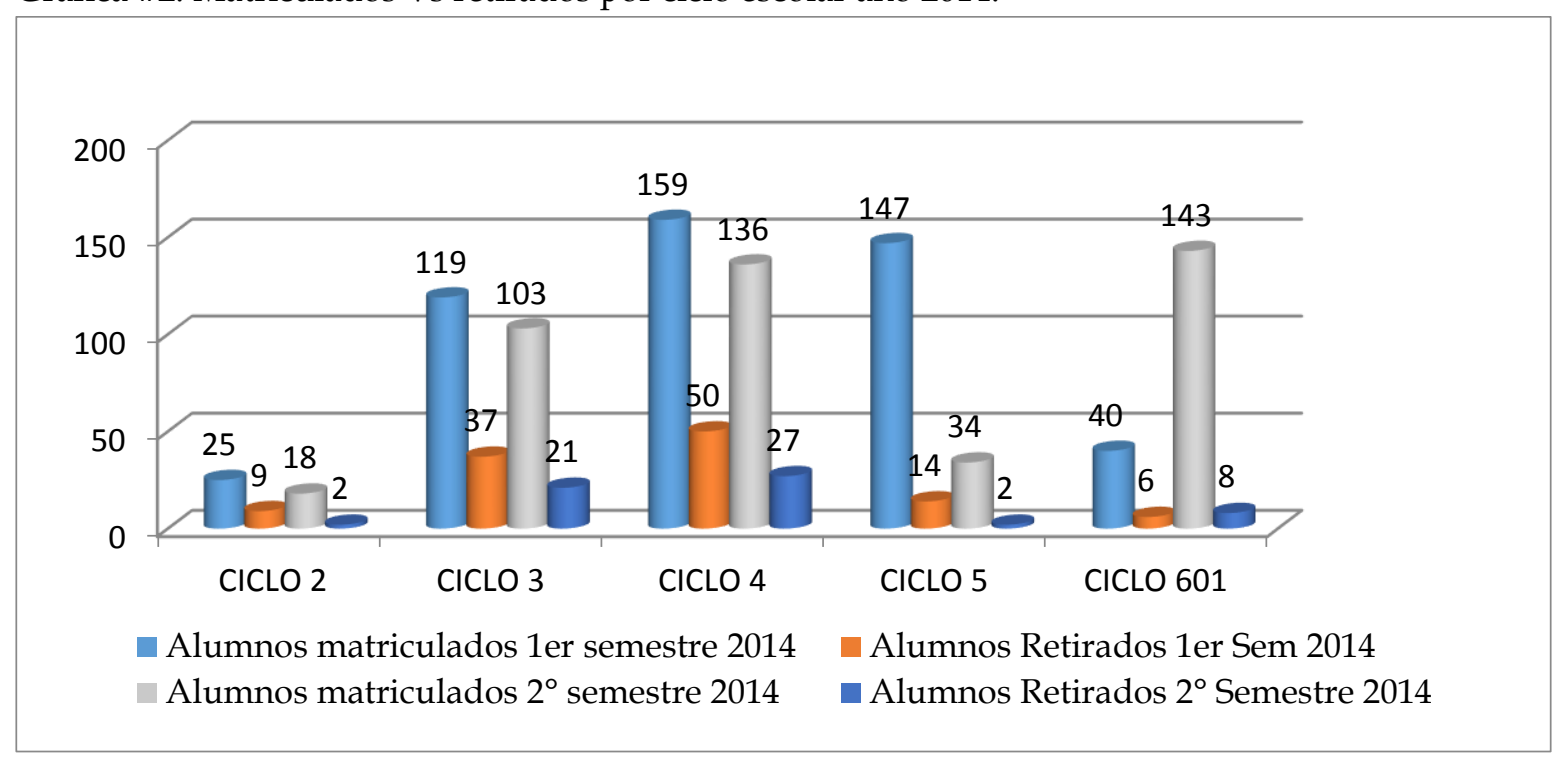

Fuente. Datos tomados del colegio Integrado de Fontibón. Elaboración propia de la autora

La grafica \#2 permite identificar el número de estudiantes matriculados y retirados por ciclo escolar para el año 2014. Teniendo en cuenta que lo que se busca es evidenciar el número de retirados por ciclo, se puede dar cuenta que el porcentaje de estudiantes que no culminaron sus estudios en el primer semestre es el siguiente: en el ciclo dos $36 \%$, en el ciclo tres $31.1 \%$ y en el ciclo cuatro $31.4 \%$, mientras que para el segundo semestre se da de la siguiente manera: en el ciclo dos $11.1 \%$, en el ciclo tres $20.4 \%$ y en el ciclo cuatro $19.9 \%$. Ahora con los ciclos cinco y seis que son semestralizados los porcentajes de retiros se presentan de la siguiente manera: en el primer semestre $9,5 \%$ para el ciclo cinco y $23.1 \%$ para el ciclo seis y para el segundo semestre $19,4 \%$ para el ciclo cinco y $31.9 \%$ para el ciclo seis. En este último caso los retiros en el primer semestre fueron inferiores a los del segundo semestre. 
Gráfica \#3. Estudiantes matriculados Vs alumnos retirados en el año 2015

\section{Matricula Vs. Retiros del año 2015}

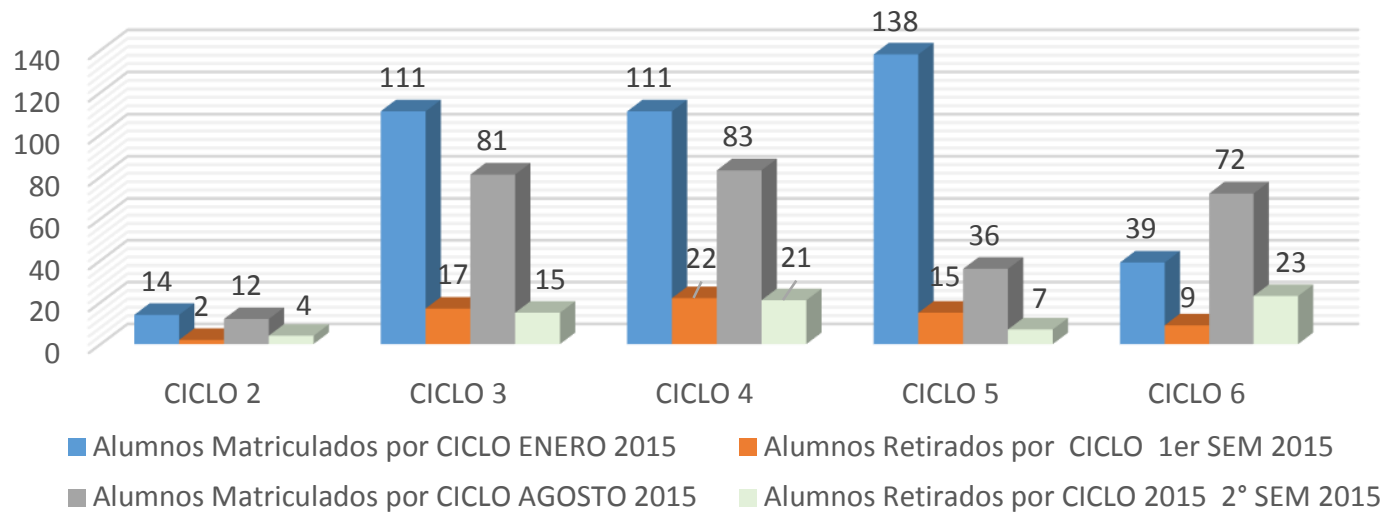

Fuente. Datos tomados del colegio Integrado de Fontibón. Elaboración propia de la autora

La grafica \# 3 permite evidenciar que para el año 2015 el número de matrículas es superior a 30 estudiantes por curso y de igual manera que al finalizar el semestre los retiros que se presentaron por ciclo en forma porcentual fueron los siguientes: en el primer semestre para el ciclo dos 14.3\%, para el ciclo tres $15.3 \%$ y para el ciclo cuatro $19,8 \%$, y en el segundo semestre para el ciclo dos $33,3 \%$, para el ciclo tres $18,5 \%$ y para el ciclo cuatro $25,3 \%$. De igual manera se obtiene la información porcentual para los ciclos cinco y seis, donde en el primer semestre para el ciclo cinco se presenta $10,9 \%$ y para el ciclo seis $23.1 \%$, y en el segundo semestre para el ciclo cinco $19.4 \%$ y el ciclo seis $31.9 \%$.

Haciendo un análisis de los resultados que arrojan las gráficas presentadas, pero también de aspectos internos del colegio es importante mencionar que la situación que se da del retiro de los estudiantes frente al número de matriculados en los años 2014 y 2015 genero inestabilidad en el colegio ya que generalmente se toma la decisión de cerrar cursos, sin importar la movilidad que se presenta durante todo el año, pero de igual manera también cabe anotar que se 
presentan situaciones internas del colegio como carencia de infraestructura física y cambio de personal para el área administrativa que a veces no resulta ser apto para el desempeño de las funciones haciendo que esto influya de alguna manera en los retiros de los estudiantes sin decir que esta sea la mayor causa.

Cabe resaltar que para los años 2014 y 2015 no se produjo cierre de cursos en los ciclos 5 y 6 y se logró mantener el número de estudiantes matriculados de 25 a 30; la explicación para esto es que, aunque se retiraron algunos así mismo se da el ingreso de nuevos estudiantes, ya que a lo largo del año se abren matriculas, aunque es necesario mencionar que para el segundo semestre disminuye el número de matrículas por ciclo.

Con la información presentada, se evidencia que los mayores retiros en los dos años se dan en el segundo semestre, pero que en los últimos ciclos los retiros disminuyen. Cabe aclarar que las cifras no son oficiales es decir no son fuente directa del área administrativa ya que los estudiantes al momento de retirarse no informan su decisión al colegio ni hacen el retiro de sus papeles, por lo cual la información se toma y se tiene en cuenta del resultado de las listas de asistencia de los docentes.

Ahora bien, no se puede desconocer que, para los años presentados, la Secretaría de Educación de Bogotá -S.E.D.-, no hizo solicitud para el cierre de la jornada nocturna teniendo en cuenta que no se cumplió con los estándares de matrículas exigidas (en algunos casos se termina el año con grupos inferiores a 20 estudiantes). Así la institución mostro un gran interés por mantener la jornada de educación nocturna para jóvenes y adultos, de ahí que realizaron una serie de reuniones con rectores y docentes de otros colegios que también cuentan con educación para adultos y jóvenes en jornada nocturna, con el fin de apostarle a 
unos lineamientos pedagógicos y curriculares que permitan la aplicación de nuevas prácticas en la educación para esta población la cual por diferentes razón opta por adelantar sus estudios en la jornada nocturna, estos lineamientos se socializaron en el primer semestre del año 2016.

\subsection{Motivos del ingreso a la jornada nocturna y de la deserción}

Con el fin de caracterizar la deserción escolar en nuestro estudio de caso, nos preguntamos cuáles eran los motivos por los cuales, por una parte, los estudiantes eligen la jornada nocturna para terminar sus estudios de básica secundaria y media y, por otra parte, porque desertan sin culminar su propósito.

Para el efecto, se aplicaron varias encuestas, la primera con el deseo de investigar qué los motiva a estudiar en la jornada nocturna, y cuáles son las razones por las que abandonan sus estudios; una segunda encuesta averigua más a profundidad desde diferentes dimensiones, este segundo aspecto. A continuación, se presentan los datos obtenidos en dichas encuestas:

\subsubsection{Encuesta 1:}

Esta primera encuesta se aplicó con los grados sexto y séptimo para los ciclos tres (3) y con los grados octavo y noveno para los ciclos cuatro (4), el fin de esta encuesta era indagar por las razones que llevaron a los alumnos a elegir matricularse en la jornada nocturna del colegio Integrado de Fontibón IBEP para cursar sus estudios. (Ver Anexo A. Encuesta No1).

Los resultados de esta encuesta se verán reflejados en la gráfica \# 4 que se presenta a continuación. Esta encuesta se aplicó a 70 estudiantes de los 
cuales 36 fueron hombres representando un porcentaje de 51\% y 34 fueron mujeres con un porcentaje de $49 \%$. Lo que permitió analizar esta información en la primera parte de la encuesta, fueron las razones más preponderantes frente a cada género, para que los estudiantes definieran las razones que los llevan a cursar sus estudios en la jornada nocturna; de las 22 razones expuestas, cinco tuvieron mayor relevancia y son las que se presentan a continuación.

Es así que se obtiene lo siguiente, determinando la prioridad de las respuestas dadas por los encuestados: 1. La razón más importante tanto para hombres como para mujeres es, la facilidad que se tiene para terminar los estudios de bachillerato en un tiempo más corto, ya que en esta jornada se termina la educación básica y media en tres (3) años. 2. Con un porcentaje similar se encuentra que la edad con la cual cuentan los estudiantes es un factor de gran influencia, ya que la mayoría de estos jóvenes y adultos se encuentran en edad extraescolar. 3. Presentando un porcentaje mayor en los hombres que en las mujeres se encuentra que otra de las razones es por pereza y desmotivación para el estudio, en este caso cabe hacer la reflexión citando lo expuesto por Francisco Cajiao cuando menciona que "lo que se enseña no es significativo para los estudiantes, es preponderante formar ciudadanos conscientes, capaces y convencidos de que pueden transformar la realidad para hacer un mundo mejor" (Cajiao, 2016, pág. 1). 4. Nuevamente con un porcentaje superior en hombres que en mujeres se encuentra que otra de las razones, tiene que ver con los problemas de comportamiento y de disciplina que presentan los estudiantes en la jornada diurna y 5. Con porcentajes similares se encuentra una respuesta que tiene que ver con la situación económica de la población dando como resultado que su ingreso a la jornada nocturna responde de alguna manera a la necesidad de trabajar en el día, lo cual implico que se retiran de sus estudios en la jornada diurna. 
Grafica \#4. Datos por género. Razones para elegir la jornada nocturna.

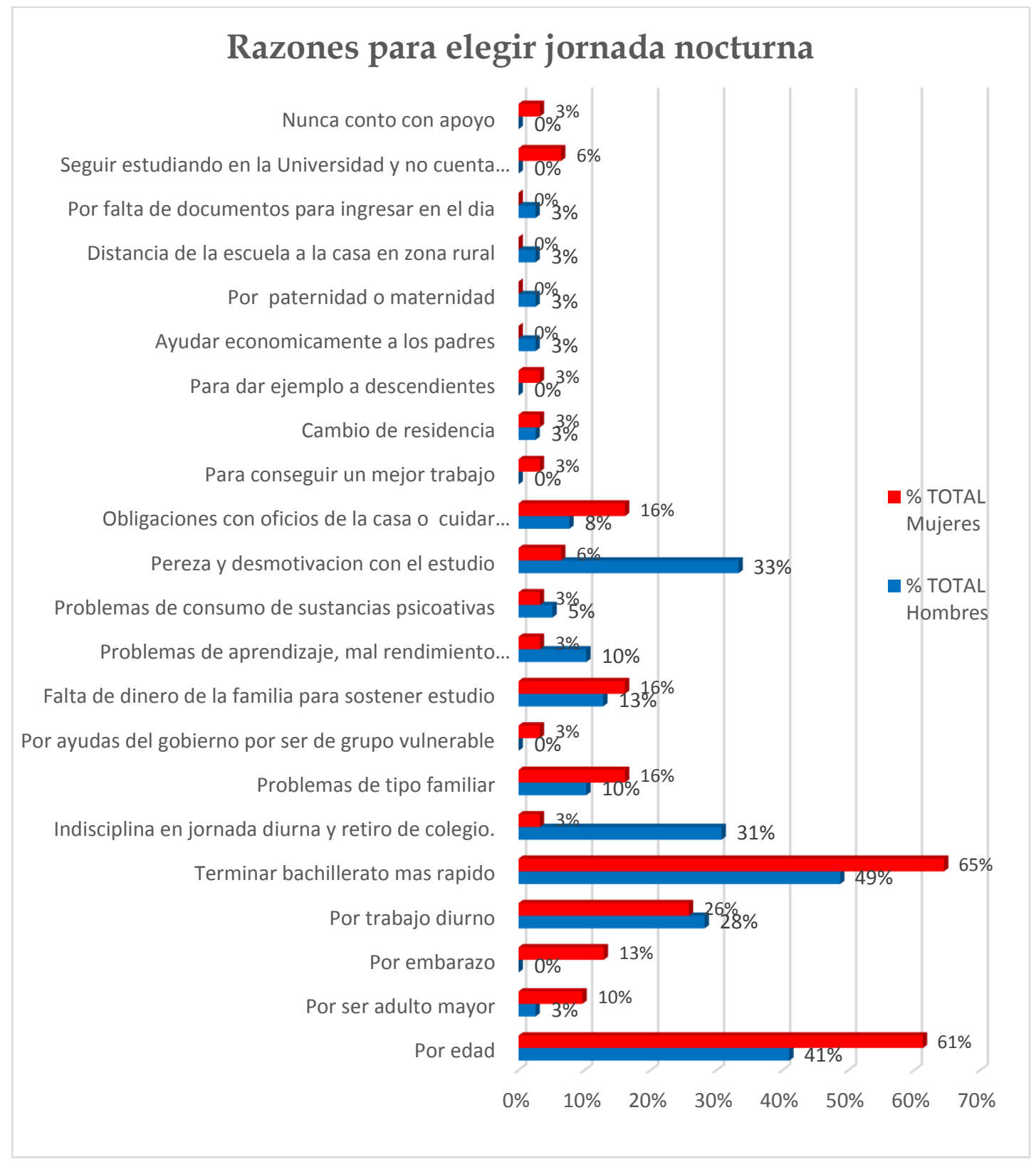

Fuente. Elaboración propia de la autora

Como casos de importante relevancia se debe mencionar que el porcentaje resulta ser el mismo tanto para hombres como para mujeres, en dos de las razones que se presentaron en la encuesta las cuales fueron: 1. Que deben ayudar con los oficios de la casa y 2. Por problemas de adicción al consumo de sustancias psicoactivas. 
Por último cabe resaltar que los factores hasta aquí mencionados y relacionados con la matriz de necesidades humanas fundamentales son: subsistencia, conocimiento y protección.

Grafica \#5. Datos por género. Razones para el abandono de estudio en la jornada nocturna.

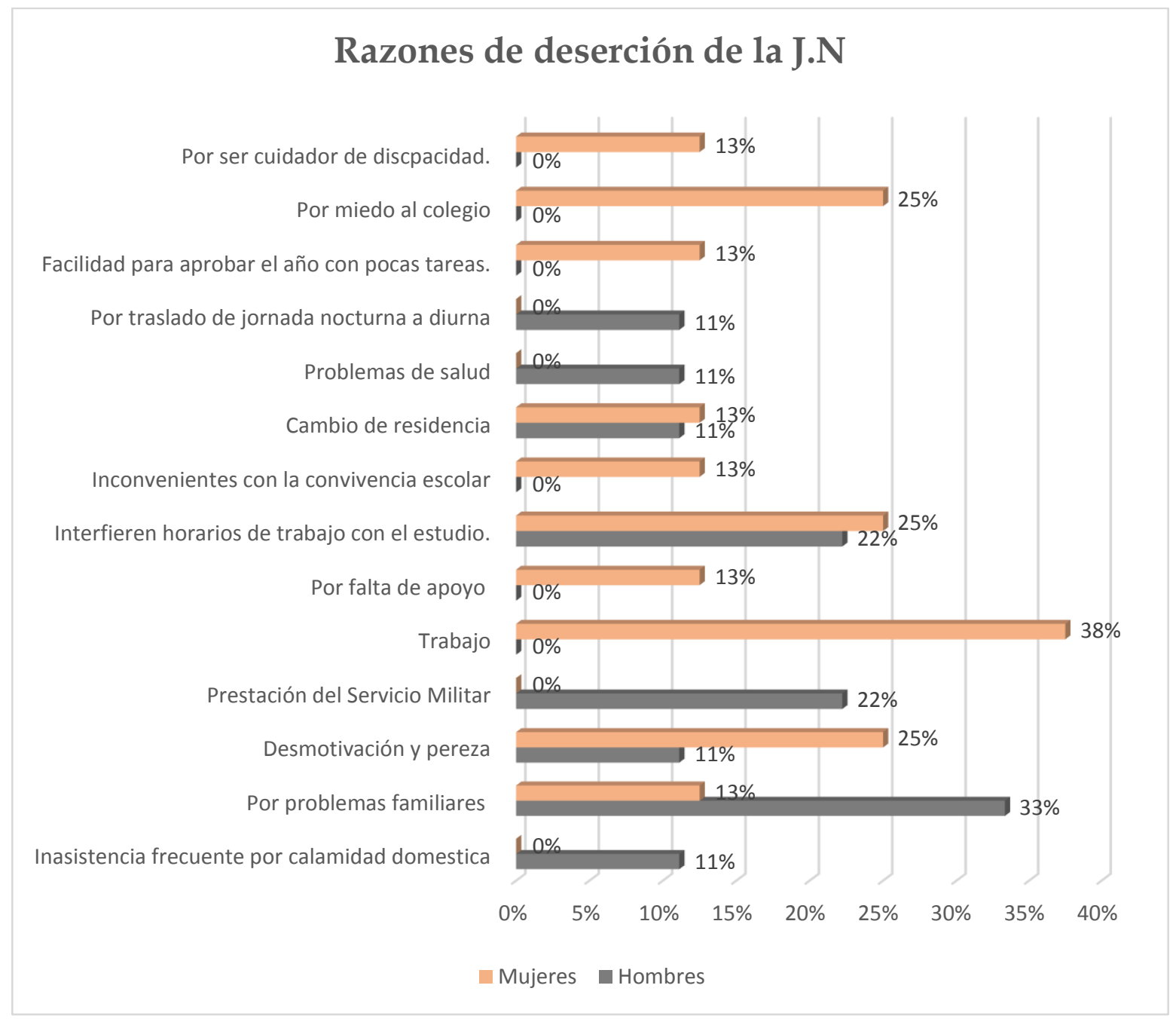

Fuente. Encuestas. Elaboración propia de la autora

El análisis de la segunda parte de la encuesta se da a partir de la indagación que se hace para determinar las razones que llevan a que los estudiantes abandonen sus estudios en la jornada nocturna, permitiendo identificar las más relevantes para obtener como resultado lo siguiente: 1. La razón que presenta mayor porcentaje tanto en hombres como en mujeres, tiene que ver 
con la necesidad de dedicarse al trabajo ya que los horarios laborales interfieren en su jornada escolar, lo que permite extraer que tienen unos horarios laborales que abarcan las horas de la noche, pero aquí también es importante aclarar que este porcentaje de interferencia está relacionado tanto para hombres como para mujeres, pero no se puede confundir con lo que muestra la gráfica frente al retiro por temas de trabajo donde el gran porcentaje es absolutamente marcado para las mujeres. 2. De manera muy marcada y teniendo en cuenta lo que muestra la gráfica se da cuenta que los hombres se deben retirar por la influencia que tiene los problemas familiares. 3. Con un porcentaje alto de las mujeres sobre los hombres se encuentra que el abandono tiene relación o está dado por la desmotivación o falta de interés que siente para culminar los estudios. 4. Tanto hombres y mujeres muestran un porcentaje similar frente al retiro por cambio de residencia, situación que muchas veces está ligada con el tema laboral o inconvenientes económicos. En este análisis también cabe resaltar que influye de manera considerable que los hombres abandonan sus estudios debido a que deben prestar su servicio militar, que es evidente dado por las edades que se presentan en la jornada nocturna, situación que llama a la reflexión sobre la importancia de revisar este tema, para hacer un proceso de concientización en los estudiantes hombres. Por ultimo vale la pena mencionar el comportamiento que se ve en la gráfica frente al porcentaje de mujeres que manifiestan se retiran por el temor o miedo que representa el colegio y que más que el colegio es el enfrentarse con el sistema académico de la jornada

nocturna y todas las complejidades del mismo en cuestiones de seguridad y convivencia.

\subsubsection{Encuesta 2:}

La encuesta \# 2 aplicada a treinta y tres (33) estudiantes de la jornada nocturna del grado once (11) para el ciclo seis (6), busco identificar y extraer los antecedentes familiares, socioeconómicos y motivacionales y al mismo tiempo la 
incidencia que tiene el desempeño escolar, la institución, la familia y la vida personal del estudiante que lo lleva a que abandone o deserte de forma temporal sus estudios.

\subsubsection{Información general:}

La información general permite identificar por medio de las gráficas \#8 y \#9 en su respectivo orden; con que personas vive el estudiante (ya que ellas aportan y hacen parte de sus dinámicas diarias), y cuales han sido los problemas que se le han presentado en los dos últimos años (2014-2015, que corresponden a los años del estudio de caso,) teniendo en cuenta que esto permitirá nutrir la investigación y establecer causas que llevan a los estudiantes a abandonar sus estudios.

Gráfica \# 6. Datos que muestran con quien vive el estudiante.

\section{Con quién vive actualmente el estudiante}

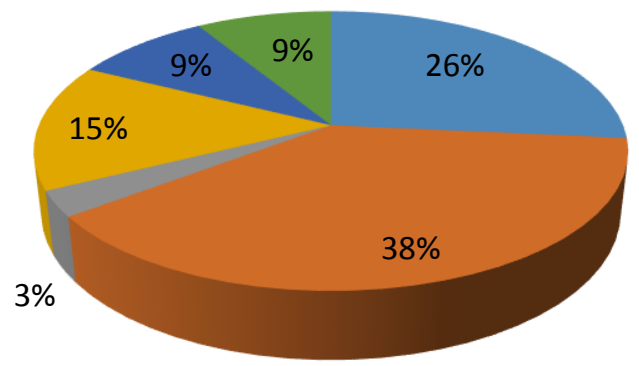

口AMILIA

- CONYUGE E HIJOS

- MADRE Y HERMAN@S

口HIJ@S

- SOLO

- PADRES

Fuente. Encuestas. Elaboración propia de la autora

La grafica \# 6 arroja los resultados de la información recolectada sobre con quien vive él estudiante. De los treinta y tres (33) estudiantes encuestados se encontró: 1. Un 38\% viven con su cónyuge e hijos. 2. El 26\% con su familia; cabe aclarar que este tipo de familia que se presenta en el resultado, no 
hace referencia a la compuesta por papá, mamá y hermanos, sino por otras personas como, padrastro, madrastra y hermanastros, tíos o abuelos. 3 . El 15\% vive únicamente con sus hijos, lo que permite al mismo tiempo identificar que son cabeza de hogar, es importante mencionar que la mayor parte de los encuestados que arrojo este porcentaje corresponde a mujeres. 4 . Con un porcentaje de $9 \%$ se encuentra que los estudiantes viven con sus padres y solos respectivamente. 5. Con un porcentaje del $3 \%$ se encuentra que viven con su madre y hermanos.

Gráfica \# 7. Datos sobre problemas que ha presentado el alumno en los últimos dos años.

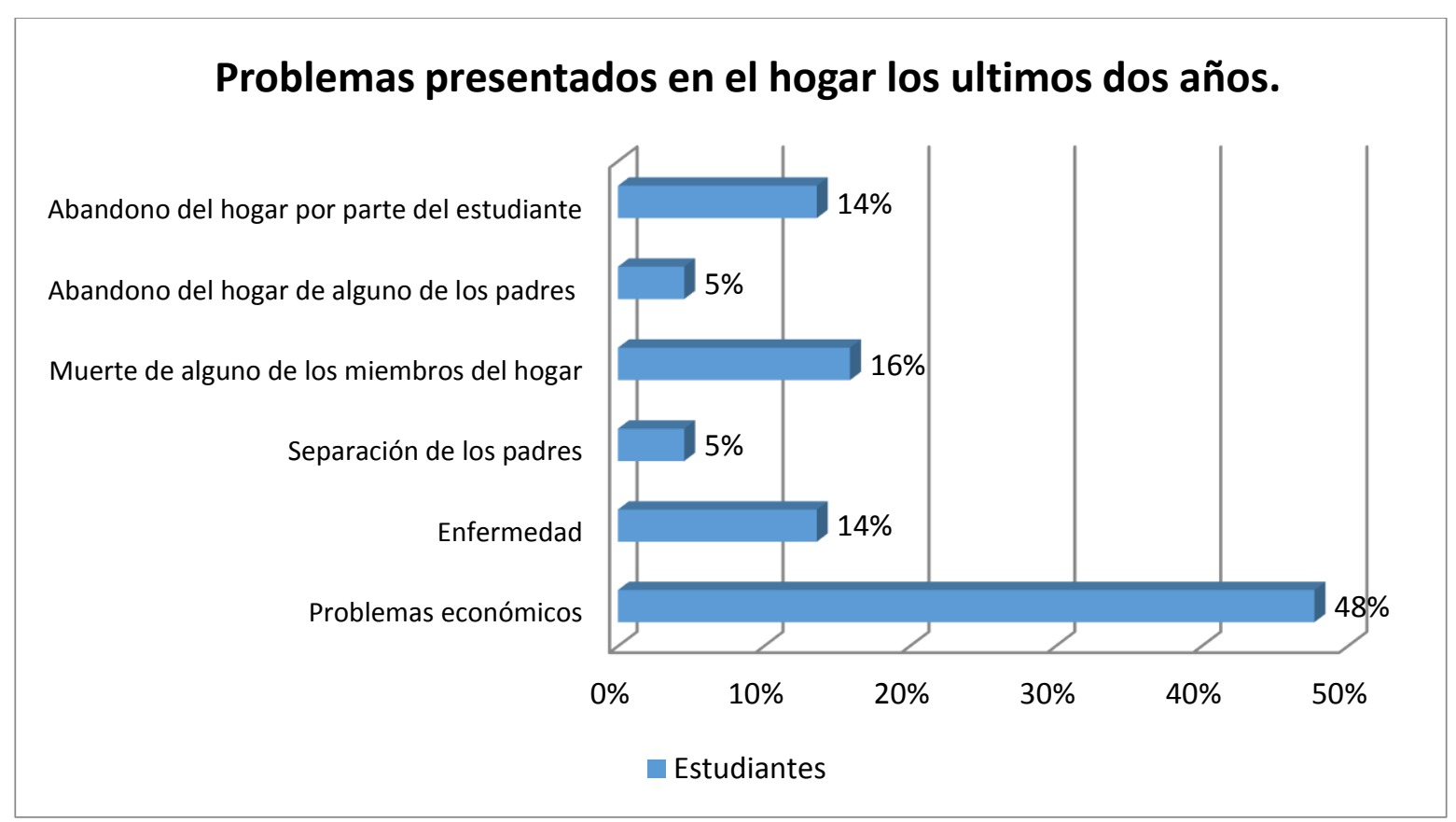

Fuente. Encuestas. Elaboración propia de la autora

La Grafica \#7 evidencia cuales son los problemas que presentó con mayor regularidad el estudiante y que se muestran en el siguiente orden: 1. Con una diferencia considerable a los demás ítem aparece el tema económico como uno de los mayores inconvenientes para los alumnos. 2. Por muerte de alguno de los miembros de la familia. 3. Problemas de salud, es decir enfermedad del alumno. 4. Abandono del hogar por parte del estudiante, en este último problema 
mencionado se puede relacionar con datos que arroja la gráfica \#8 donde se indaga con quien vive el estudiante. 5. Abandono de alguno de los miembros de la familia en este caso conyugue, papá o mamá y 6. Separación de los padres que es diferente al abandono de hogar por parte de alguno de estos.

\subsubsection{Incidencias del desempeño escolar en la deserción temporal.}

A partir de la investigación se da cuenta que el desempeño escolar de los estudiantes influye en gran medida para tomar la decisión de abandonar sus estudios de forma temporal, razón por la cual se hizo necesario indagar sobre la perdida de cursos y la cantidad de veces. La gráfica \# 8 permite identificar de manera porcentual si el estudiante en el transcurso de sus estudios ha perdido un curso, mostrando que de los treinta y tres estudiantes encuestados el $59 \%$ si ha perdido y un $41 \%$ no se ha visto afectado por esto. Ahora, la gráfica \# 9 permite tener la información de cuantos cursos han perdido estos estudiantes que contestaron de forma afirmativa haber perdido un año escolar, evidenciando que las cifras más altas se encuentran entre las pérdidas de uno, dos y tres años, lo cual nos da un porcentaje de $78 \%$ obtenido de la suma de estas pérdidas en su respectivo orden.

Gráfica \# 8. Pérdida de cursos

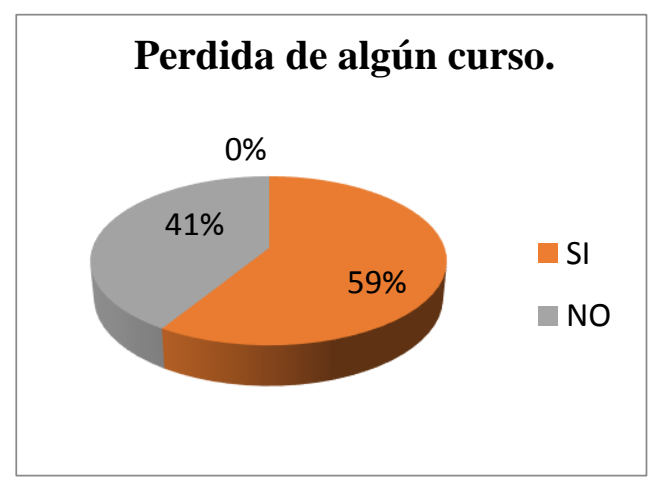

Grafica \# 9. Cursos perdidos

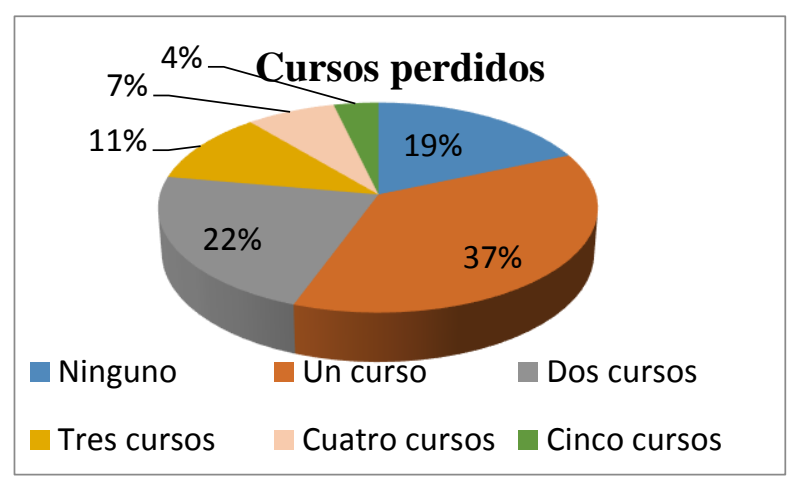

Fuente. Encuestas. Elaboración propia de la autora 
A si mismo las razones que dan los estudiantes frente al último año escolar que se perdió, se refleja en la información que arroja la gráfica \#10 donde las cuatro predominantes, fueron las siguientes: 1. Porque no le gusta el estudio. 2. Por inasistencias repetidas, lo que le implico fallas en el colegio. 3 y 4 con un mismo porcentaje por problemas de dinero en la familia y por falta de tiempo, esto coincide con la primera encuesta, donde los estudiantes señalan su desmotivación y los problemas económicos como una razón de abandono de los estudios.

Gráfica \#10. Razones de pérdida de cursos

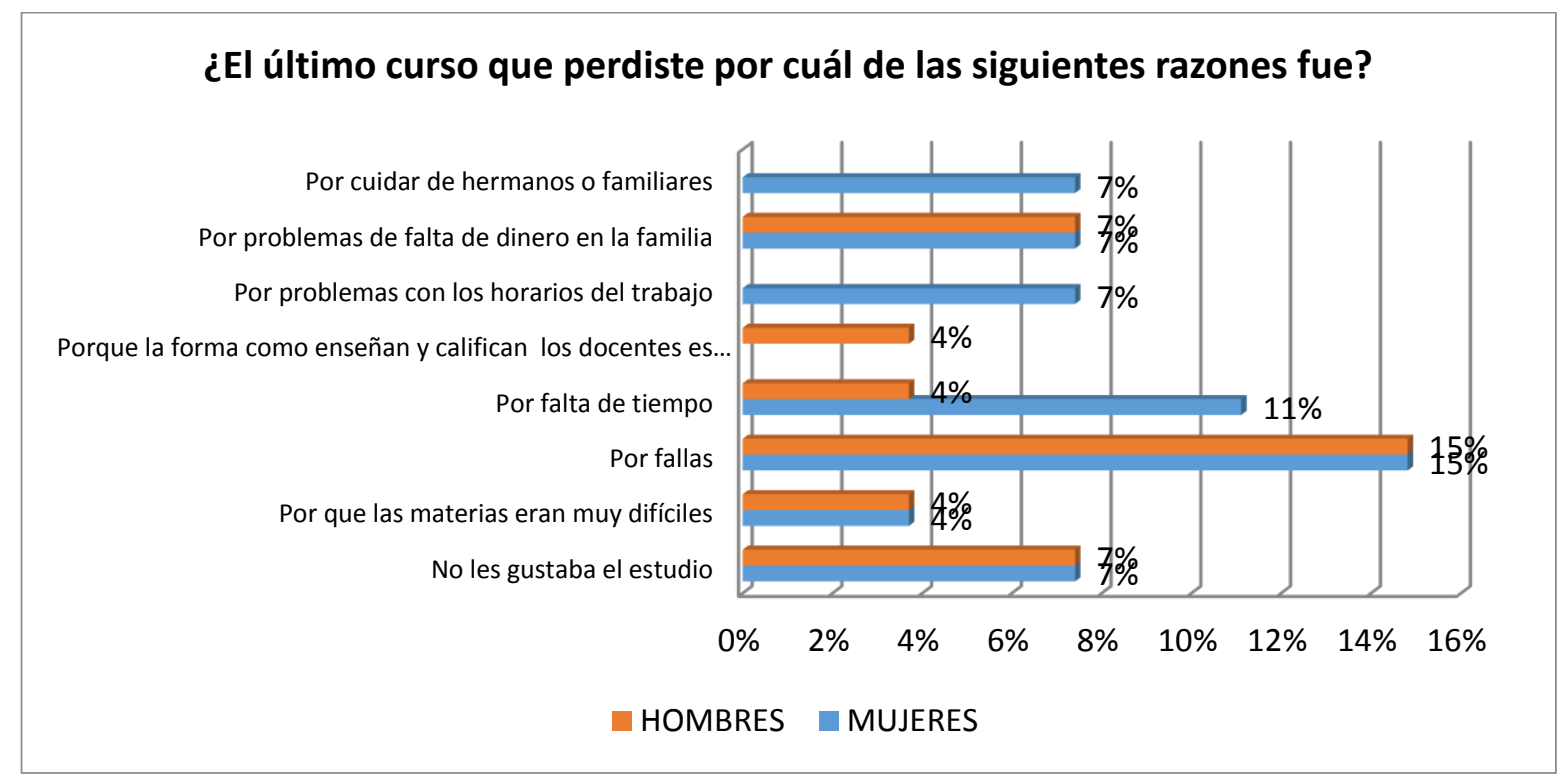

Fuente. Encuestas. Elaboración propia de la autora

Con estudiantes que se retiraron (entre los años 2014 y 2015, los cuales corresponden a la investigación), se indago sobre cuantas veces prolongaron la terminación de sus estudios, solicitándoles que su respuesta fuera concreta. La información obtenida de esta pregunta se relaciona en la gráfica \# 11 de la siguiente manera: $62 \%$ corresponde al retiro por una sola vez, $24 \%$ al retiro por dos veces, $6 \%$ al retiro por tres veces, otro $6 \%$ al retiro por 4 y 5 veces es decir un $3 \%$ cada uno y un $2 \%$ corresponde a más de 5 veces. 
Gráfica \#11. Veces que se ha retirado.

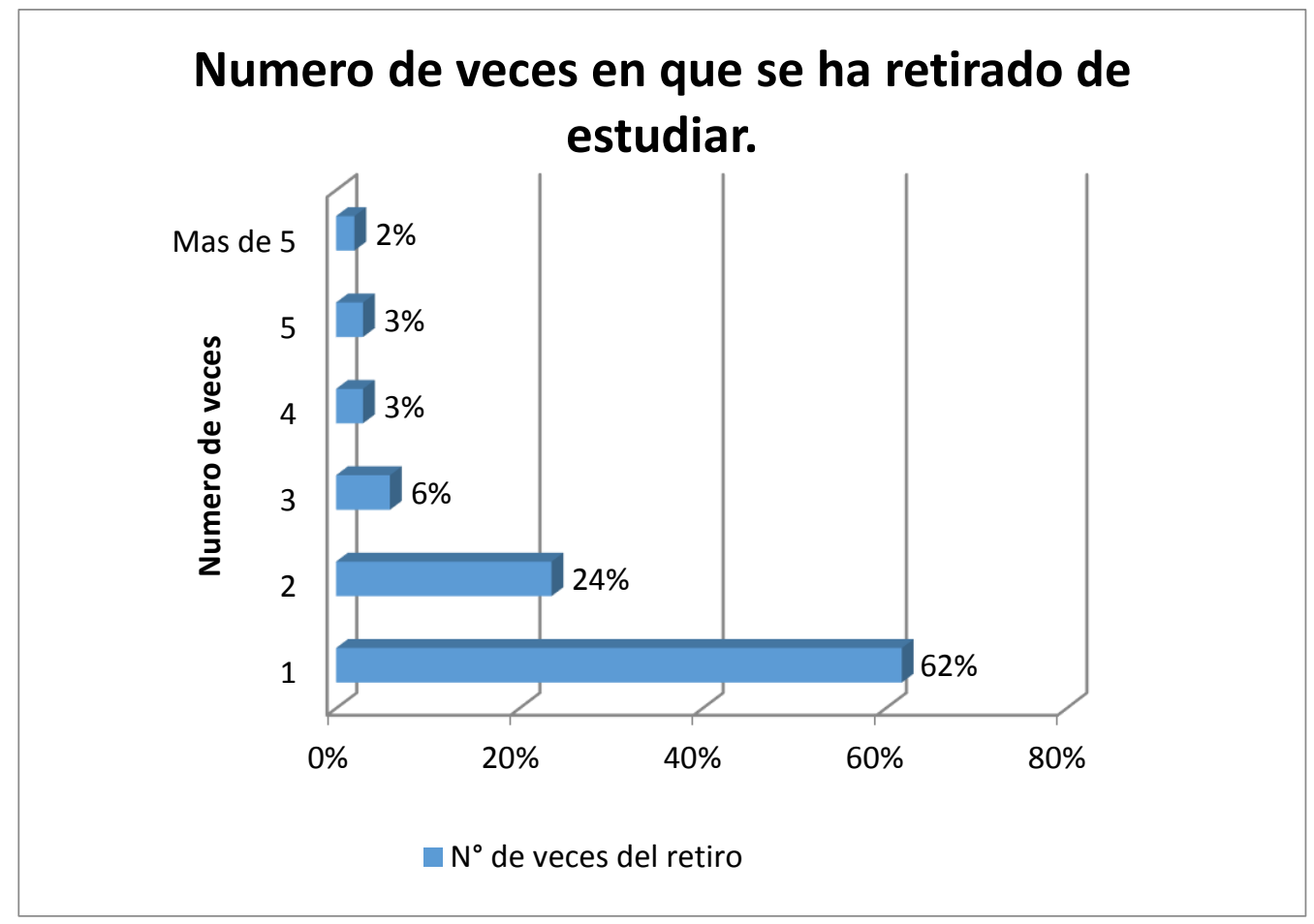

Fuente. Encuestas. Elaboración propia de la autora

Dentro de esta indagación también se pudo dar cuenta, que la edad predominante de los estudiantes, para retirarse, oscila entre los 14 y 17 años y que es en esta edad donde la mayoría cursan y pierden el año escolar para los grados sexto, séptimo, octavo y decimo

En relación con el tiempo que demoran los estudiantes para reintegrarse o retomar sus estudios matriculándose en el mismo colegio, se constató como lo muestra la gráfica \# 12, que el $68 \%$ tardan más de un año, el $9 \%$ un año y el $24 \%$ lo hacen al año siguiente. 
Gráfica \#12. Tiempo que tarda para retomar estudios.

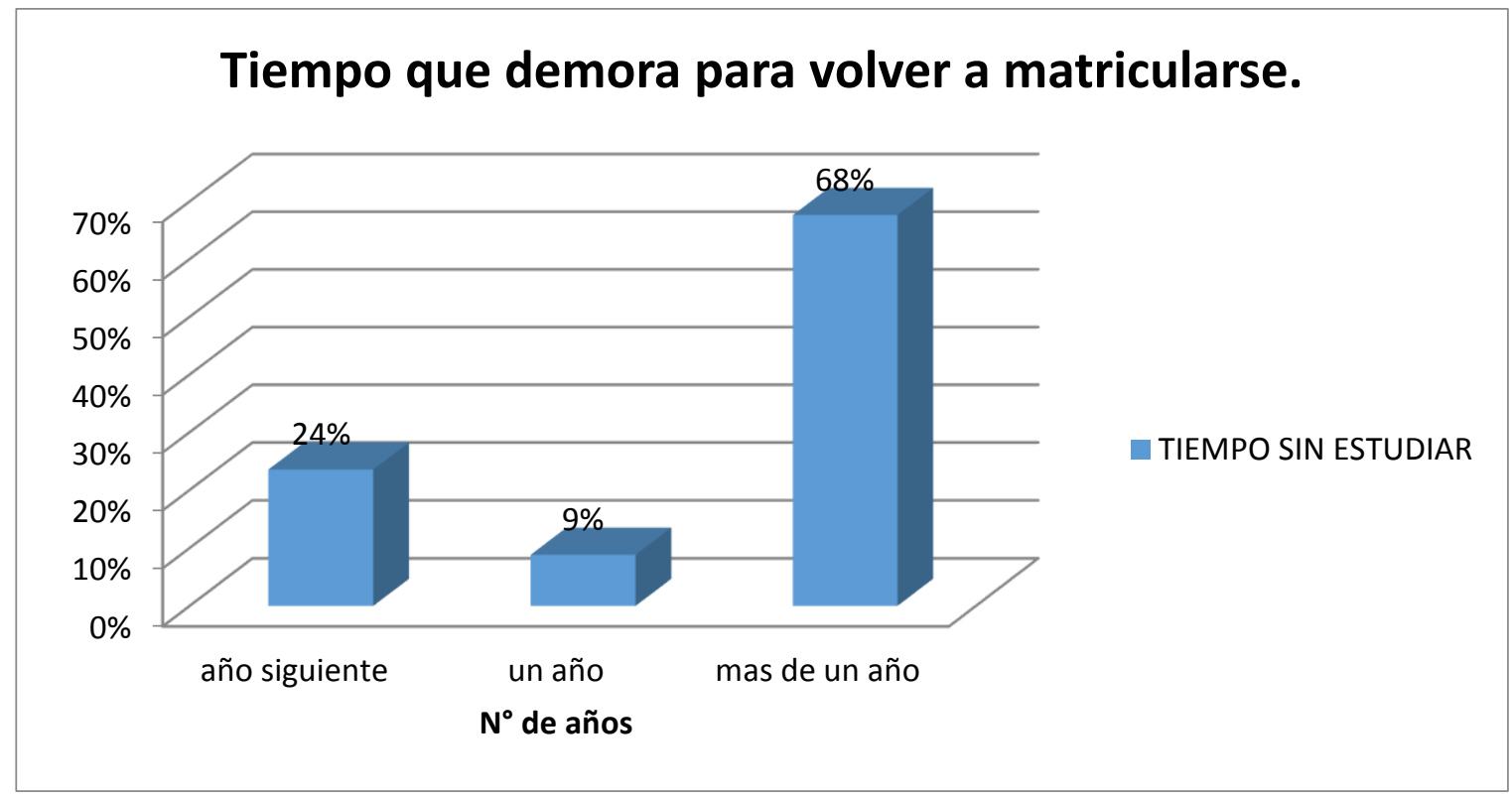

Fuente. Encuestas. Elaboración propia de la autora

Dada la información anterior es claro que la calidad de vida y la mejora de oportunidad de los estudiantes es limitada, más aún en un país que día a día exige unos estándares altos para entrar a competir en el mundo laboral, algo tan básico como el título de bachiller se convierte en un obstáculo para conseguir un trabajo que permita obtener unos ingresos mínimos. Como se puede constar según la información presentada anteriormente más de un $77 \%$ de los estudiantes de la jornada nocturna que también en su mayoría son jóvenes prolongan sus estudios y por ende dichas oportunidades.

\subsubsection{Incidencia de la Institución Educativa en la deserción temporal.}

Parte de los datos presentados anteriormente han mostrado que existen diversos factores por los cuales los estudiantes abandonan sus estudios, entre esos su desempeño escolar, la incidencia de la familia, de las personas con las cuales viven, o los problemas que más los afectan, haciendo evidente de manera general como esto influye en su decisión y evidenciando al mismo tiempo que ha 
tenido gran peso el tema socioeconómico y la necesidad de salir a buscar recursos interfiriendo los horarios laborales con los horarios escolares. Pero no se puede dejar de lado, entender y concientizar que ellos están inmersos y se mueven dentro de una Institución que hace parte de sus dinámicas, pero también de sus intereses por lo cual se hace indispensable indagar sobre la influencia o responsabilidad que tiene la Institución Educativa, con la decisión de los estudiantes de abandonar temporalmente sus estudios. Por consiguiente, estas razones se presentan en la gráfica \#13.

Gráfica \#13. Razones relacionadas con el colegio para retirarse.

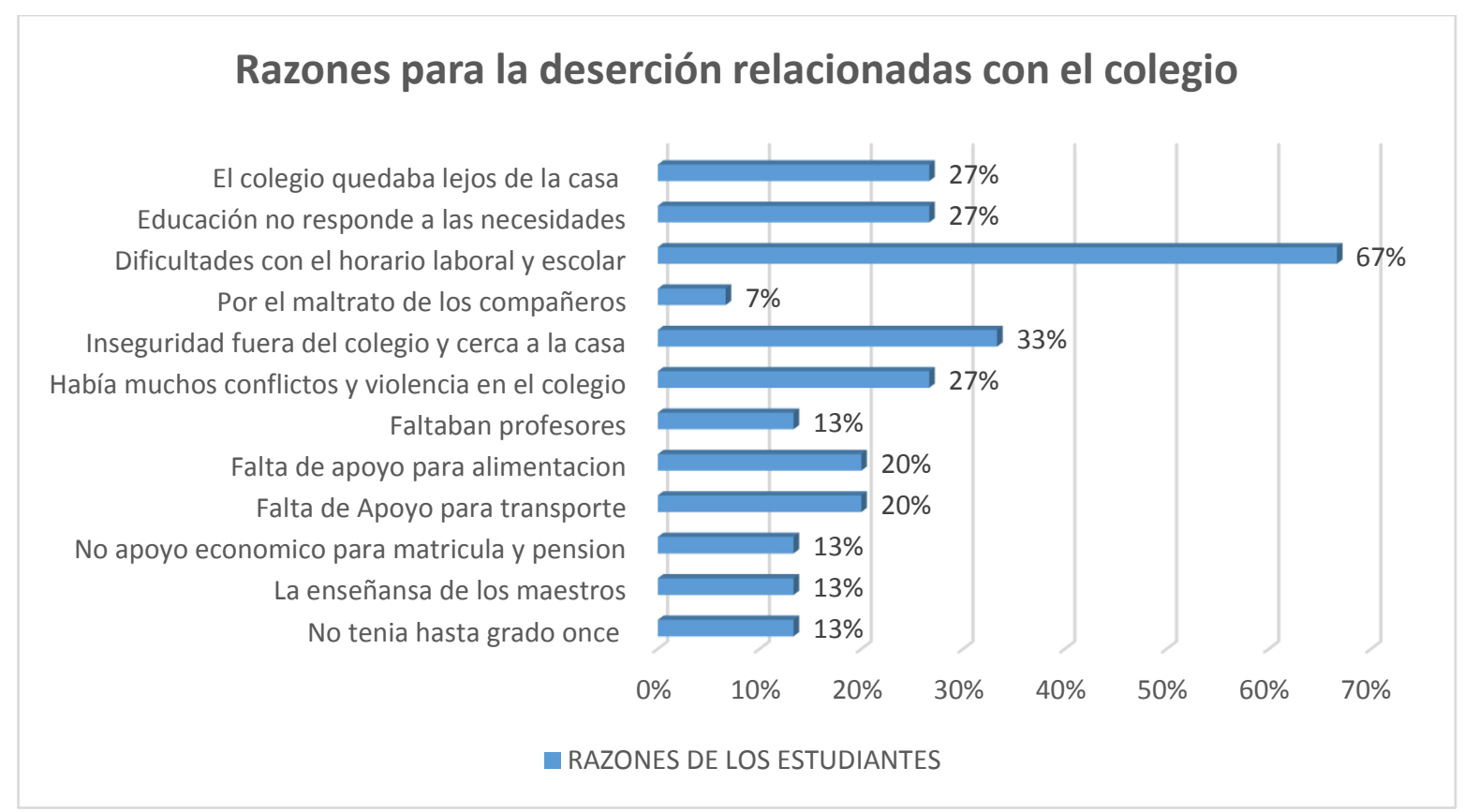

Fuente. Encuestas. Elaboración propia de la autora

Dentro de las razones presentadas la que resulta tener mayor relevancia para los estudiantes tiene que ver con la interferencia que tienen los horarios de trabajo con los horarios de estudio, lo cual permite analizar que los estudiantes consideran que el horario que ofrece el colegio para la jornada nocturna no es el más óptimo, pues no permite que se pueda hacer las dos cosas al mismo tiempo y las cuales resultan indispensables para el desarrollo social y 
económico del estudiante. Seguida de esta se evidencia un tema de inseguridad a la salida del colegio, lo que también permite extraer que los alumnos consideran que este problema obedece solo al colegio, pero haciendo un análisis más puntual y desde otra mirada, es un tema de concertación entre la institución y las autoridades que permita brindar seguridad a los estudiantes. Luego se presenta una, que a pesar de no tener un gran porcentaje termina influyendo de manera determinante por parte del colegio y tiene que ver con la mirada que tienen los estudiantes frente a la educación que ofrece el colegio pues consideran que esta no obedece ni responde a sus necesidades. Así mismo, otra, que también depende mucho de la institución, se relaciona con los conflictos y la violencia generados dentro del colegio.

\subsubsection{Incidencia de la dimensión Familiar en la deserción temporal.}

Entendiendo que la familia hace parte de la comunidad educativa y qué su relación con el estudiante son determinantes para un buen desarrollo de él o ella en su contexto escolar, pero que al mismo tiempo inciden en las decisiones que estos tomen frente a su retiro o permanencia en sus estudios, se indago aspectos familiares que representen una o varias razones para que se decida abandonar los estudios y que el estudiante frene su superación personal desde el ámbito educativo. De ahí los resultados expuestos en la gráfica \#14, extraídos de la pregunta ¿cuál de las siguientes razones relacionadas con la familia incidieron para la última vez que se retiró de sus estudios? Dentro de las razones más notables se encontró la carencia de dinero en los hogares, lo que lleva a que el estudiante tenga que retirarse para empezar a trabajar, convirtiéndose también el tema del trabajo en una de las razones expuesta. Así mismo se evidencia la poca importancia que la familia da a los estudios, esto, a pesar de no haber presentado un porcentaje alto en las respuestas influye de manera considerable en este aspecto, dado la importancia 
que tiene para la persona que busca cursar sus estudios contar con el apoyo familiar no solo desde lo económico sino también desde lo emocional. De la misma forma, pero con menor trascendencia esta la muerte de familiares y el tener que encargase de los oficios de la casa.

Gráfica \#14. Razones relacionadas con la familia para retirarse

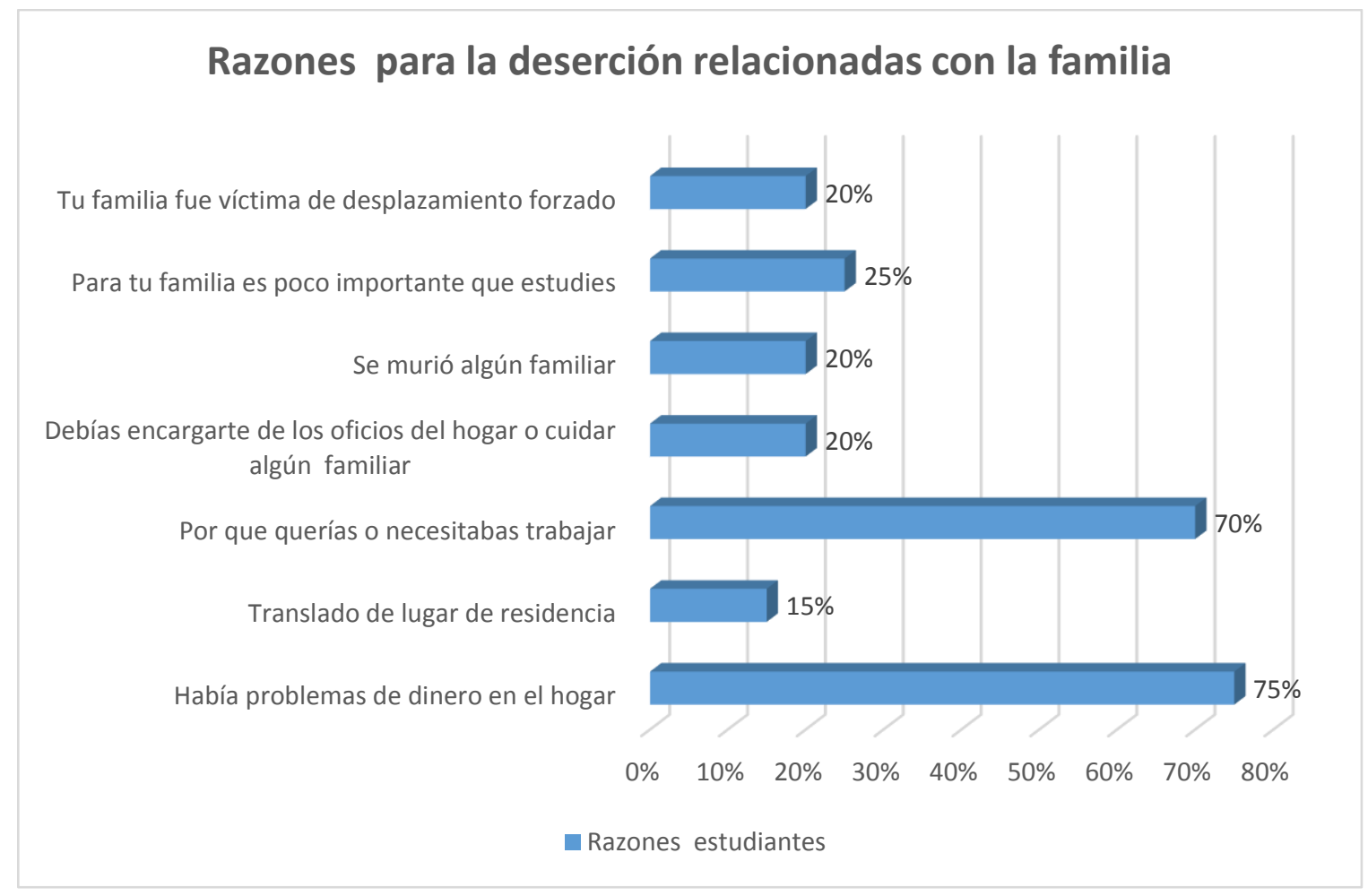

Fuente. Encuestas. Elaboración propia de la autora

\subsubsection{Incidencia de la Dimensión Personal en la deserción temporal.}

Es evidente, que los aspectos que ya se han mencionado como el desempeño escolar, la familia y la institución educativa están relacionados con parte de la decisión que pueda tener el estudiante para abandonar sus estudios y retirarse del colegio, pero no puede dejarse de lado la incidencia desde la dimensión personal, pues es el ser en ultimas, como tal inmerso en todos los contextos, el que se desarrolla y determina sus actuares, sus acciones y sus 
decisiones. Teniendo en cuenta lo expuesto, la gráfica \#15, permite identificar las razones más relevantes desde lo personal, que llevan a que el estudiante abandone los estudios, de forma temporal, por una sola vez o por varias. Existen aquí dos dimensiones importantes para destacar sin decir que las otras pierdan importancia o relevancia, se observa que nuevamente el tema económico aparece como una razón de peso, es totalmente comprensible que los estudiantes lo relacionen dentro de los aspectos personales, ya que esto se convierte en una desmotivación, pues para la persona es necesario contar con recursos económicos que le permitan suplir sus necesidades básicas, pero al mismo tiempo poder sostener sus estudios. El asumir la responsabilidad de la maternidad o la paternidad también entra en esta dimensión, pues muchos de los estudiantes como se mencionó en una parte de los análisis presentados anteriormente hacen parte de la población joven y bien se sabe que el país presenta un alto índice de paternidad y maternidad juvenil. Ahora en menor proporción, pero no por eso menos importantes se encuentra razones como las siguientes: por enfermedad, por consumo de sustancias psicoactivas, por desinterés en el estudio y por dificultades académicas.

Gráfica \#15. Razones personales para retirarse.

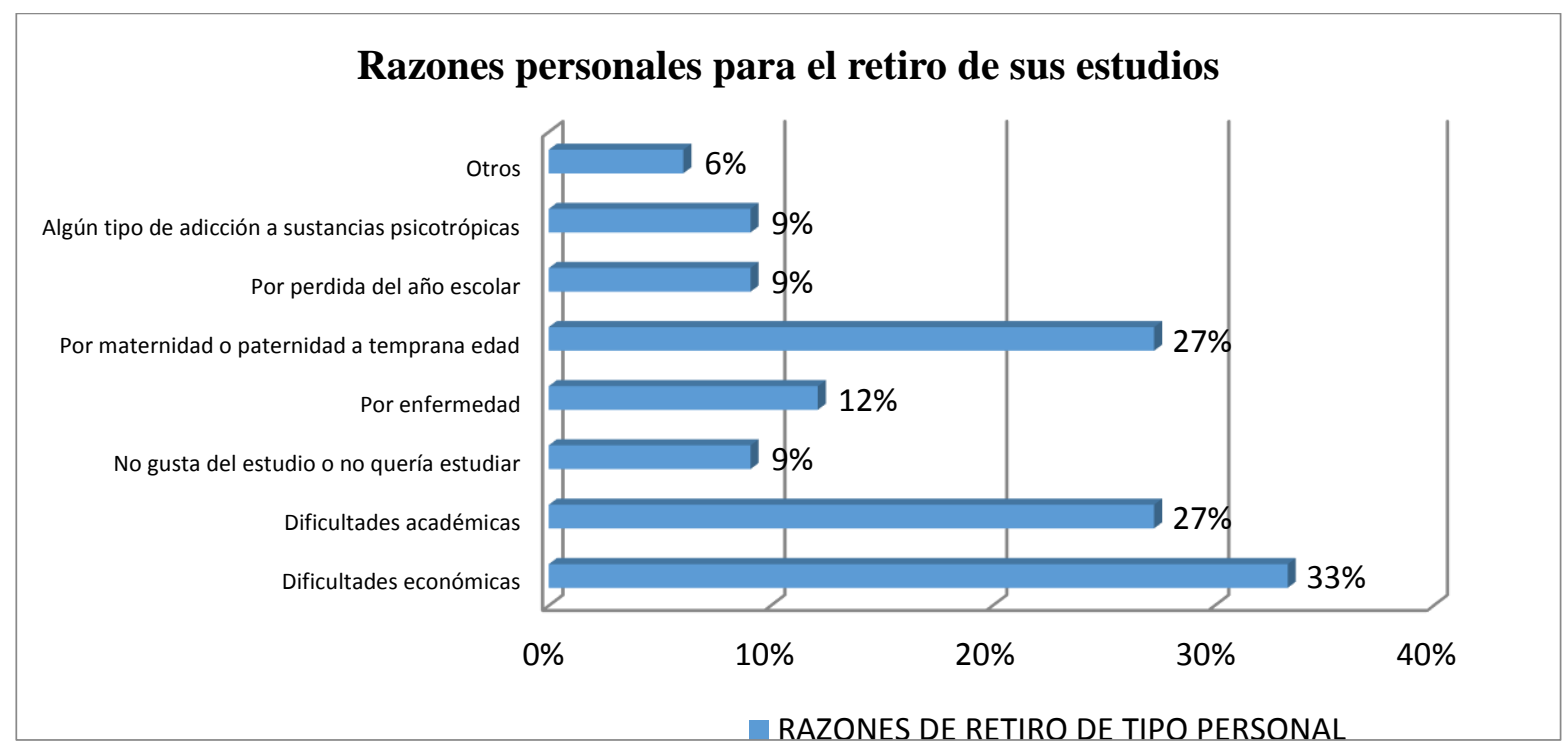

Fuente. Encuestas. Elaboración propia de la autora 
Reforzando la observación que se realizó frente a que el estudiante como tal es quien decide si abandona o no sus estudios, sin decir que no influya los aspectos antes mencionados y teniendo claro que la investigación habla sobre la deserción temporal, se buscó de igual manera conocer cuáles son los motivos que los impulsan a retomar nuevamente esta actividad. Para tal fin, se tomó la referencia de los resultados que arroja la gráfica \#16, donde se puede establecer que las motivaciones más grandes están dadas por el interés que tienen para superarse, lo cual está ligado al mismo tiempo en conseguir un mejor trabajo, que obviamente fortalece los análisis dados frente a la influencia que tiene el aspecto económico; aun así al analizar la gráfica se puede dar cuenta que la mayoría de las razones están dadas por la necesidad, pero al mismo tiempo por el interés que tiene la persona de salir adelante para mejorar su calidad de vida. Otras de las razones expuestas fueron: tener el título de bachiller para poder cursar estudios superiores, el aporte que quieren hacer a sus familias y el brindar un mejor futuro a sus hijos. Es así que los estudiantes que retoman sus estudios todavía ven en la educación una posibilidad viable para el mejoramiento de sus formas de vida 
Gráfica \#16. Razones para volver a estudiar.

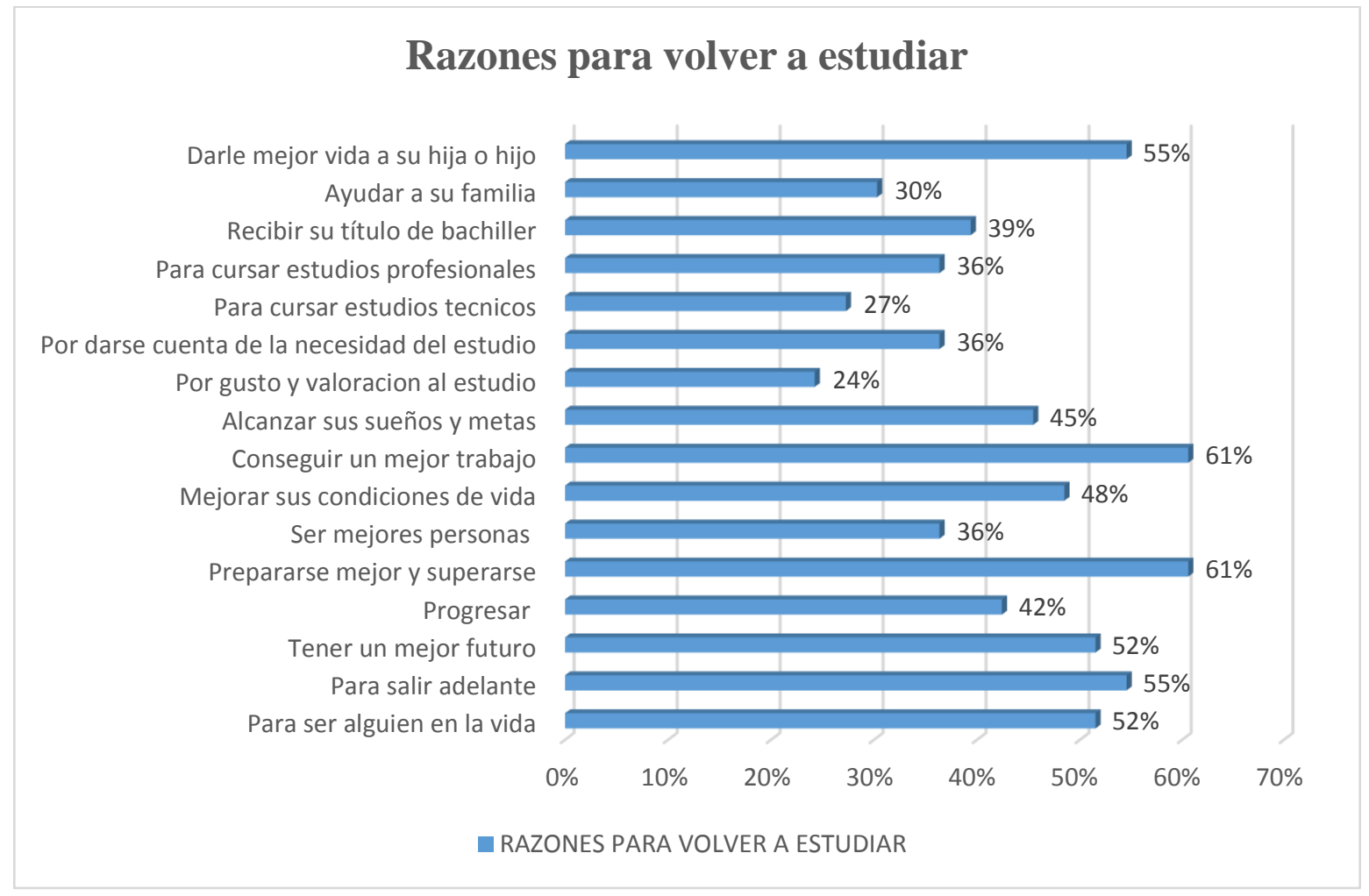

Fuente. Encuestas. Elaboración propia de la autora

Ya presentadas las razones que generan mayor incidencia en los estudiantes para retomar sus estudios, no se debe, ni se puede dejar de lado, hacer una reflexión sobre la poca importancia que tiene para los estudiantes el hecho de mostrar un interés por el estudio, pues a pesar de que regresan a las aulas y recibir sus clases, el interés por obtener su título de bachiller se da más por las oportunidades laborales que puedan tener, que por el interés de realmente obtener y cultivar conocimiento, lo cual se evidencia en el desinterés que muestran al regreso y en el trascurso del ciclo escolar y que determina al mismo tiempo lo itinerante que resulta ser sus estudios. 
Dado lo anterior y conociendo que son varias las necesidades básicas insatisfechas de los estudiantes, que los impulsan a tomar la decisión de abandonar sus estudios, se hace necesario y de vital importancia una política con unos lineamientos claros para la educación de jóvenes y adultos de la jornada nocturna que incluya un enfoque del desarrollo humano, permitiendo con esto, aportar a sacar de la pobreza de entendimiento a los estudiantes y de que de igual manera tenga en cuenta, que las necesidades de estas personas son múltiples e interdependientes, que existen realidades que determinan su vida y que no se pueden obviar, siendo posible con esto que la Institución Educativa provea algunos aspectos que satisfagan y logren mitigar las necesidades más fundamentales en los estudiantes y fortalezca su papel como aporte en la sociedad. Se sabe que el gobierno realiza algunos apoyos para los algunos estudiantes como el refrigerio o el subsidio de transporte, pero esto no se convierte en el todo, ya que se ha determinado que aun así la deserción o el abandono temporal se da independiente de esto, pues estas acciones responden a una coyuntura o inmediatez que no están ligadas a una política estable y general frente al tema.

\subsubsection{Apoyo institucional:}

Habiendo planteando y analizado las diferentes razones que llevan a que los estudiantes de la jornada escolar se retiren de sus estudios y los retomen nuevamente, se consideró conveniente y pertinente revisar cual es el apoyo que la institución educativa brinda y que puede ayudar a que estos desistan de alguna manera en tomar dicha decisión. La grafica \#17 permite identificar la información frente a estos apoyos recibidos. 
Gráfica \#17. Apoyo a nivel institucional

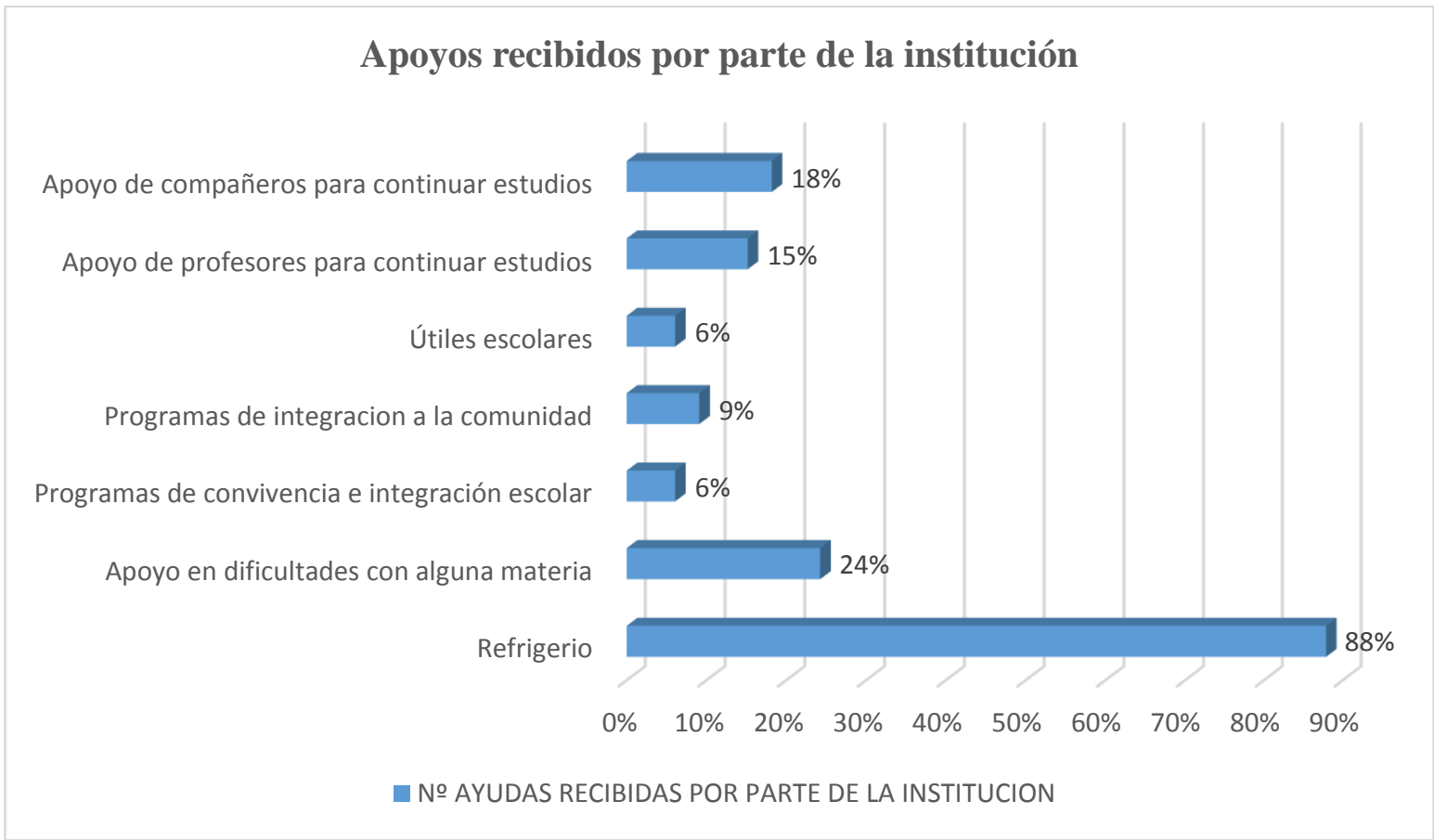

Fuente. Encuestas. Elaboración propia de la autora

Si se tiene en cuenta como ya se ha mencionado de manera reiterativa que los problemas económicos tienen una gran incidencia en el retiro de los estudiantes, es de destacar que el mayor apoyo que han recibido quienes fueron encuestados para este caso, tiene que ver con la entrega de refrigerio "Un estudiante que llega de trabajar, generalmente, en la construcción o en trabajos que exigen desgaste de energía física o que viven solos, reciben con agrado el refrigerio, ya que sólo pueden consumir algo hasta salir de la jornada". Actualmente el refrigerio entregado tiene un balance nutritivo que permite que los estudiantes puedan obtener energías y calorías para recibir bien sus clases, es de resaltar también en este punto que todos los estudiantes lo reciben y lo consumen, al mismo tiempo vale mencionar que el servicio de refrigerio que brinda la Secretaria de Educación - SED, se logró para la jornada nocturna, en el segundo semestre del año 2015, a petición de los docentes, quienes evidenciaron que los estudiantes acudían al colegio sin haber almorzado o 
no tenían dinero para comprar algo en el descanso. A pesar de este apoyo directamente relacionado con la gestión de los docentes se da un contraste con lo que plantean los estudiantes al manifestar que la ayuda por parte de docentes para resolver algún tipo de dificultad académica es muy baja y no sienten respaldo con esto y así mismo con los programas de convivencia e integración escolar.

Es evidente que el deporte y la cultura aportan al desarrollo de la persona y en muchos casos estimulan a los estudiantes a despertar un interés por su permanencia en el colegio y el buen desempeño en sus estudios e igualmente la capacidad que tenga esté para estar inmerso en la toma de decisiones y en la participación democrática y efectiva, razón por la cual se indago cual es la participación de los estudiantes en estos espacios y actividades, a partir de dos preguntas puntuales que fueron: ¿Ha participado en actividades culturales y deportivas del colegio? Y ¿Ha participado en la toma de decisiones escolares o en la solución de problemas que se presentan en el colegio?, los resultados a estas dos observaciones se reflejan en las gráficas \#18 y \#19 donde se evidencia que las actividades culturales y deportivas representan mayor interés para los estudiantes, que el hacer parte en la toma de decisiones, donde se encuentra una marcada diferencia entre los que si participan y los que no.

Gráfica \#18 Participación en actividades Grafica \# 19. Participación en la toma de decisiones. culturales y deportivas.
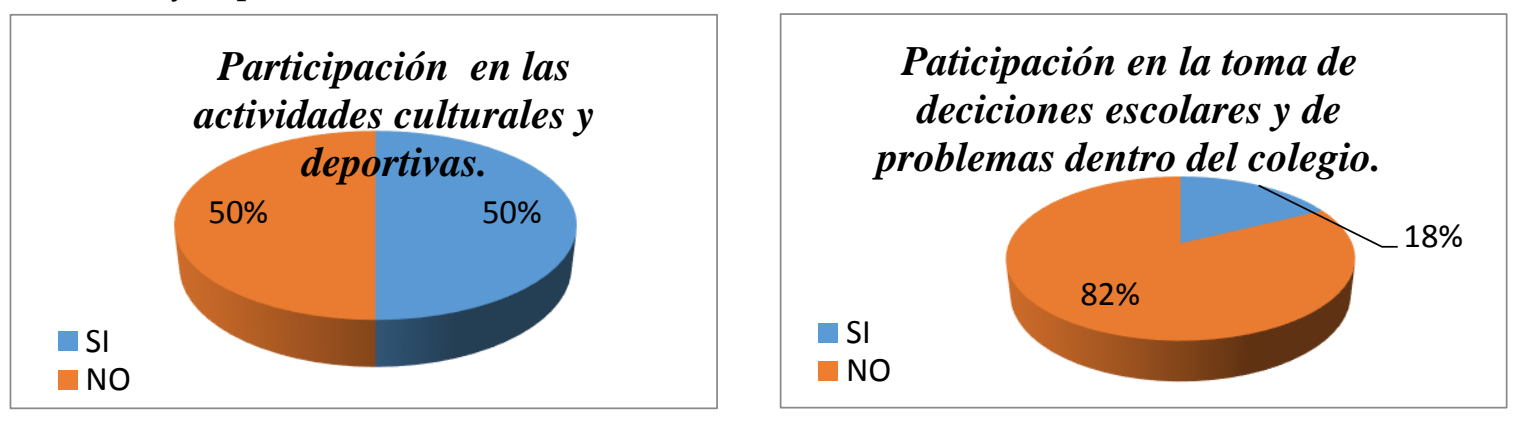

Fuente. Encuestas. Elaboración propia de la autora 
Otro factor de gran influencia para el estudiante es la relación que tenga con compañeros, docentes, administrativos y directivos del colegio, es decir como interactúa y se desarrolla en el contexto social dentro de la institución. El colegio no es ajeno a las problemáticas sociales que están inmersas en la ciudad y que se llevan al colegio de manera directa o indirecta, por ejemplo, el consumo de bebidas alcohólicas o sustancias alucinógenas y la falta de tolerancia para resolver problemas o diferencias. La forma en cómo la institución de salida efectiva a estas situaciones que no son las únicas, permite también que el estudiante se sienta estimulado para seguir, y esto de manera intrínseca que obviamente no está dentro de los grandes porcentajes de retiro de los estudiantes, se convierte en apoyo institucional para evitar la deserción temporal.

Los espacios físicos, los recursos tecnológicos, el trato que se recibe por parte de los docentes y de los compañeros se convierte también en aspectos importantes para los alumnos, pues esto determina en cierta medida el grado de satisfacción con el colegio y el permanecer activo con sus estudios. A partir de esto se indago con los estudiantes el grado de satisfacción con los aspectos mencionados, logrando establecer calificaciones que están de 1 a 5, siendo 1 la calificación más baja y 5 la más alta. La grafica \# 20 permite evidenciar cuales son estos niveles de satisfacción y la forma como fueron evaluados, de ahí que los mayores grados de insatisfacción se reflejan con el tema de las nuevas tecnologías obteniendo una calificación de 3 con un 52\% y seguido de estos las instalaciones físicas donde su evaluación esta sobre un 2 con un porcentaje del 30\%. Ahora, es de resaltar que los aspectos que generan mayor satisfacción en los estudiantes se encuentran en la forma como enseñan los profesores donde la calificación obtenida está en 5 con un porcentaje de $48 \%$ al igual que el trato de los directivos del colegio y su colaboración con los estudiantes donde la calificación que se obtiene es un cuatro (4). 
Gráfico \#20. Porcentaje de satisfacción de los estudiantes con el colegio

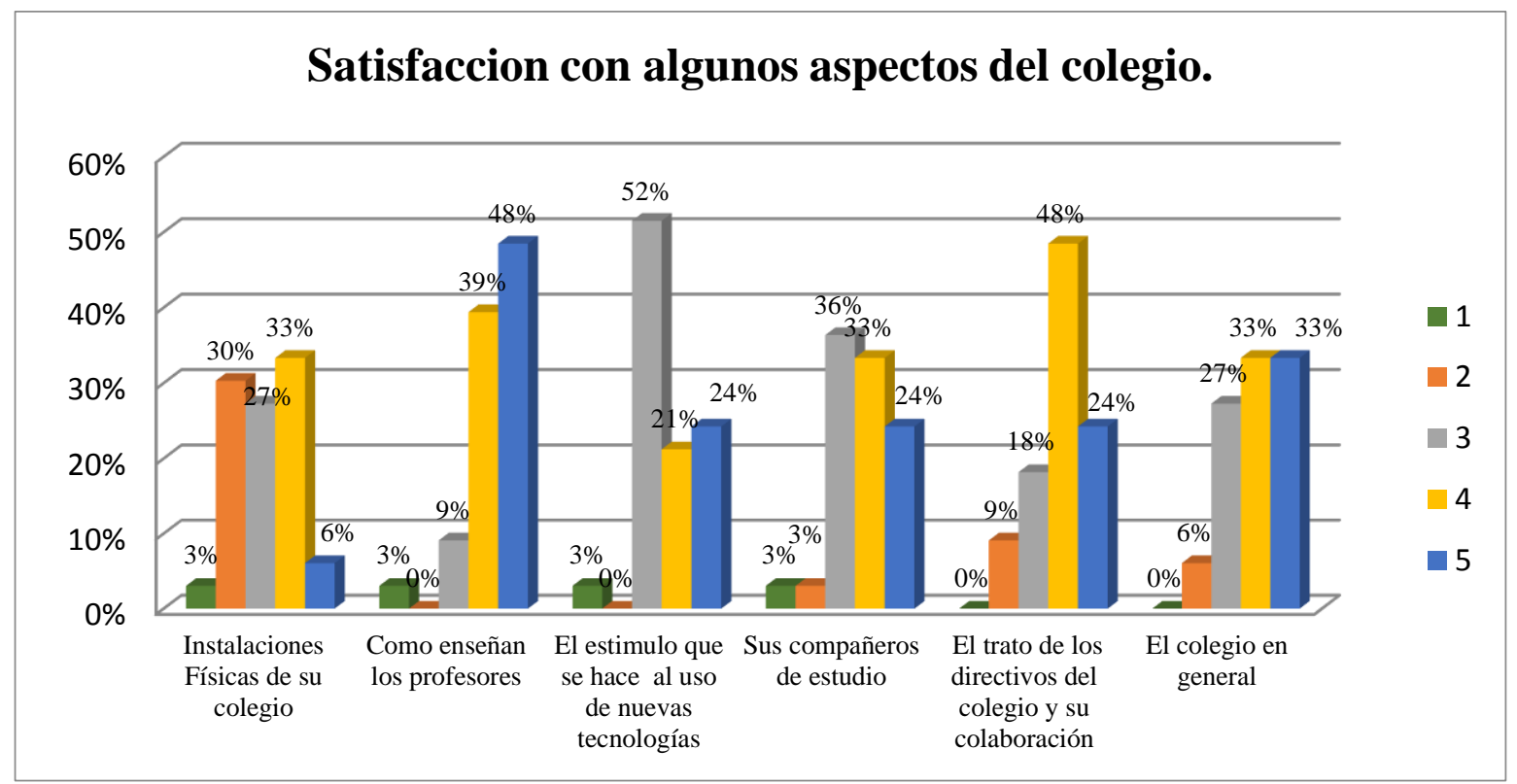

Fuente. Encuestas. Elaboración propia de la autora

\subsubsection{Apoyo familiar:}

Así como el apoyo institucional es importante para el estudiante, el apoyo familiar también en un aspecto de gran interés, este se convierte en un motor indispensable para el interés que pueda tener en permanecer en sus estudios o en retomarlos cuando por diferentes circunstancias ha tenido que retirarse. En la gráfica \#16 se pudo observar que en los datos arrojados sobre el análisis que se dio después de indagar con los estudiantes las razones por las cuales retoma sus estudios, se encuentra que el interés de dar una mejor vida a sus hijos o ser un apoyo para la familia es una razón de peso y estímulo para ellos; es por esto también que el apoyo que reciben de sus familiares debe ser revisado, pues en algunos casos si no se tiene este estimulo el desinterés puede ser mayor pues no deja de afectar que el estudiante determine como un estímulo sus familia pero que al mismo tiempo no reciba el apoyo de la misma. La gráfica \# 21 muestra cuales son esos apoyos que reciben a nivel familiar los estudiantes en cuanto al tiempo y a 
conocimiento, dejando ver de igual forma la frecuencia en que estos se dan. Los resultados que se obtienen denotan que se presenta un porcentaje muy alto estando en un 59\% la falta de apoyo para poder disponer de tiempo para realizar sus tareas escolares, respondiendo esto a lo evidenciado en las razones por las cuales se deben retirar de los estudios, pues muchos de ellos deben ayudar con las labores de la casa, así mismo con un porcentaje del $56 \%$ se encuentra la falta de ayuda para la realización de sus trabajos escolares, situación que se relaciona con el bajo nivel de educación con el que cuentan sus familiares y que de manera indirecta termina afectando al estudiante.

Gráfica \#21. Apoyo familiar

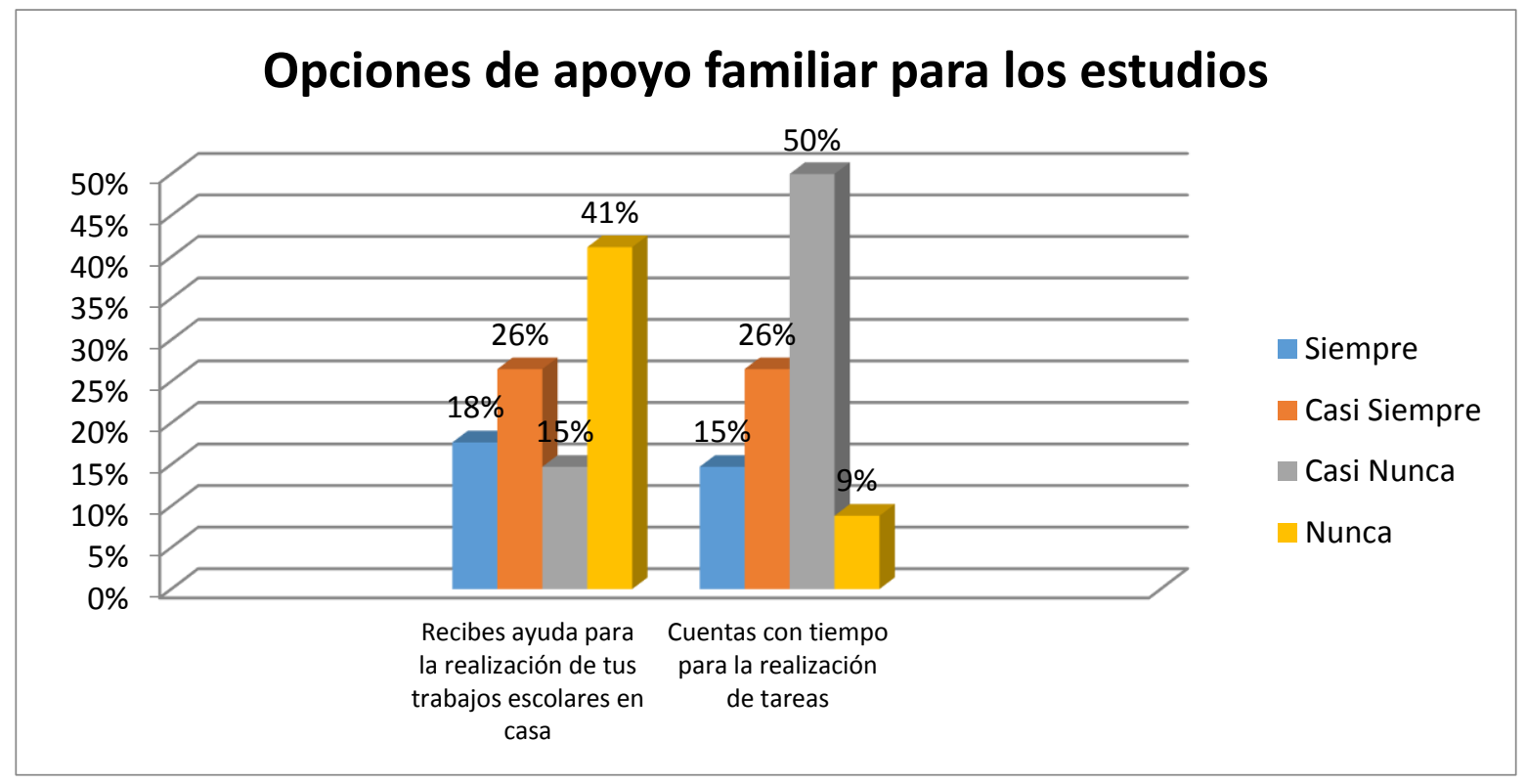

Fuente. Encuestas. Elaboración propia de la autora

La grafica \#22 permite conocer los resultados de la indagación que se llevó a cabo con los estudiantes para saber, con quien comparte su tiempo cuando no se encuentra estudiando, ya que esto permite analizar cuáles son las dinámicas de relación con su familia y la sociedad y determinar de alguna forma si logran incidir o no en la decisión de retirarse de sus estudios. La información que se obtuvo fue la siguiente: con un porcentaje de $34 \%$ los estudiantes permanecen 
solos, con menores de edad el porcentaje es de $26 \%$ y con su madre el porcentaje es de $18 \%$ convirtiéndose estos en los porcentajes más altos.

Gráfica 22. Datos. Personas con las que comparte el tiempo extraescolar. casa

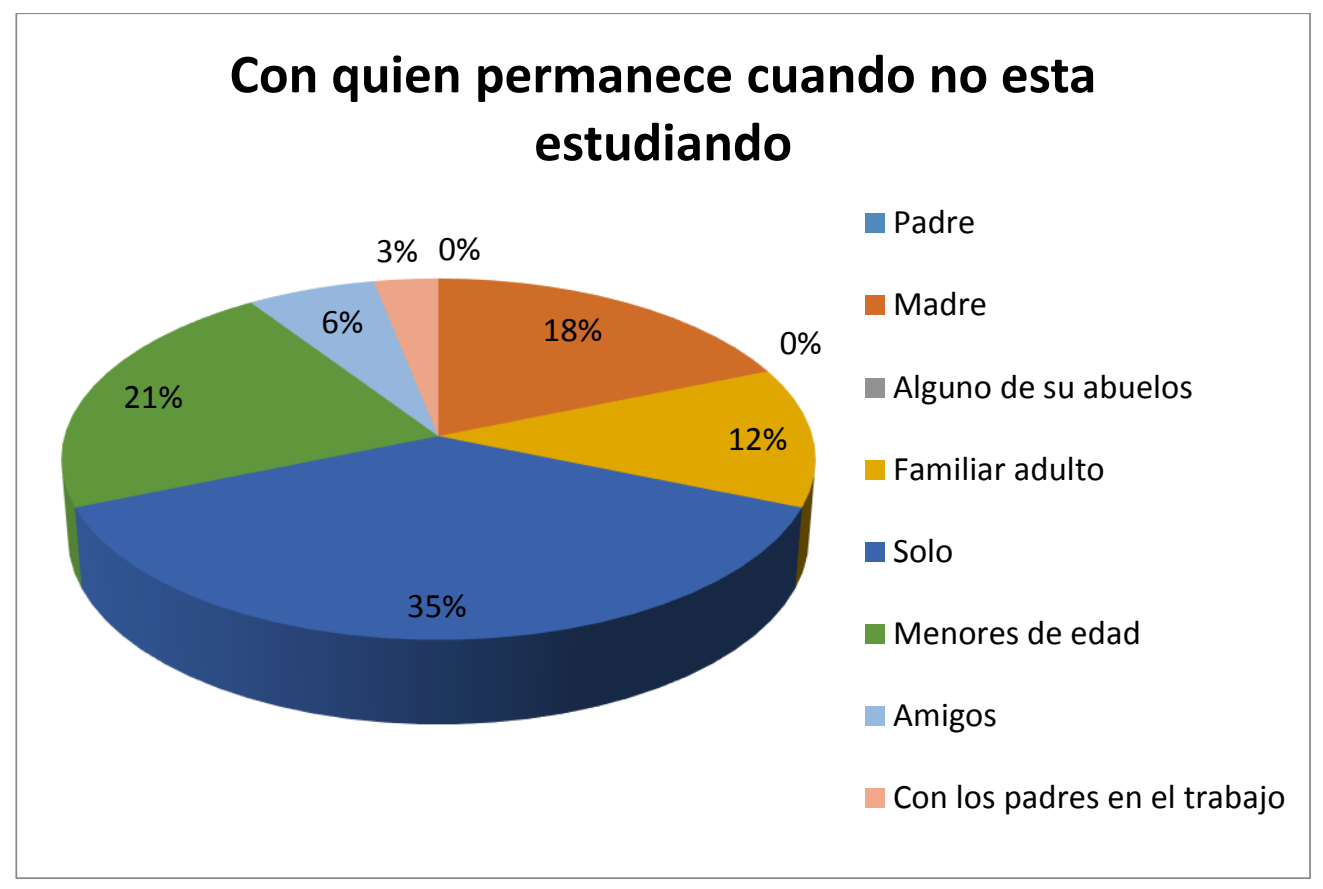

Fuente. Encuestas. Elaboración propia de la autora

\subsubsection{Expectativas personales con respecto a la educación:}

Teniendo en cuenta que los estudiantes encuestados han abandonado sus estudios y los han retomado nuevamente, se consideró importante preguntar si han pensado en la opción de volverse a retirar y dejar sus estudios de lado y cuál o cuáles serían las razones para esta decisión. La grafica \#23 evidencia estas razones, encontrando que el tema del trabajo vuelve a ser relevante con un porcentaje de $34 \%$, pero así mismo el tema de motivación en general obtiene un porcentaje que es considerable ya que se encuentra en $29 \%$ y con un $16 \%$ los problemas familiares que van ligados también a lo económico, llevando esto último a una reflexión sobre los aspectos de como la institución y la relación familiar influyen. Dentro de los porcentajes más bajos cada uno con un 3\% se puede encontrar situaciones de 
convivencia, problemas académicos, problemas psicológicos y el consumo de sustancias psicoactivas, a pesar de que estos presenten porcentajes bajos no dejan de ser un factor influyente y considerable.

Gráfica \#23. Razones que llevan al estudiante a pensar en retirarse nuevamente.

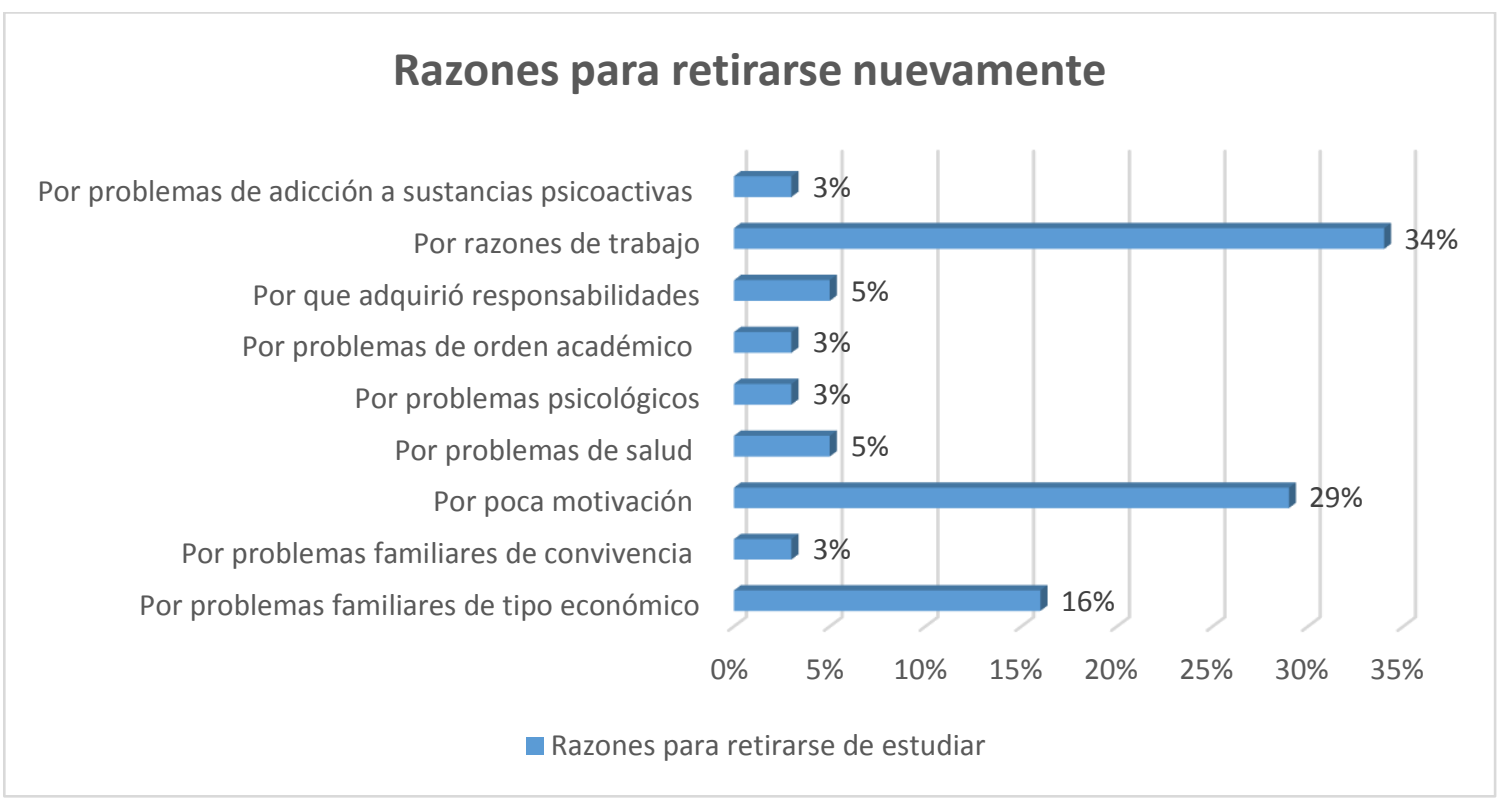

Fuente. Encuestas. Elaboración propia de la autora

Como se ha mencionado a lo largo de este trabajo una de las razones con mayor incidencia en la decisión que tienen los estudiantes de retirarse de sus estudios está ligada con lo económico y la necesidad de trabajar; por lo cual se formula la pregunta ¿por qué razón trabaja?, permitiendo con esto, tal como lo muestra la gráfica \#24, conocer que dentro de las razones más relevantes se encuentra con un $27 \%$ el sostenimiento de sus hijos, con un $24 \%$ el poder ayudar con los gastos del hogar y con un $23 \%$ el poder contar con su propio dinero. Ahora bien, dentro de los porcentajes más bajos los cuales están entre 5\% y $4 \%$ respectivamente se encuentra el hecho de que los estudiantes manifiestan que el trabajar los forma y los hace más responsables y también la aleja de las adicciones que influyen de forma negativa, razones que no pueden dejar de ser significativas 
ya que los estudiantes son conscientes que deben atacar estos problemas de alguna manera. Aun así, no se puede dejar de lado un porcentaje que se encuentra intermedio, el cual está en un $17 \%$ y obedece a la razón de que los estudiantes deben trabajar para poder sostener sus estudios, este aspecto se podría ver de manera positiva ya que demuestra el interés por mejorar su calidad de vida, ejerciendo las dos actividades al mismo tiempo, el estudiar y el trabajar, pero no deja de ser cuestionable que los estudiantes jóvenes tengan que asumir responsabilidades que no están acordes a su edad y a las actividades que deben desarrollar, no permitiendo hacer un aporte más efectivo a su contexto social y a su futuro, ya que no están preparados para asumirlas, lo que lleva a que retrasen su formación intelectual y sus oportunidades para el desarrollo de sus potencialidades y la aspiración a una mejor calidad de vida.

Gráfica \#24. Razones para trabajar

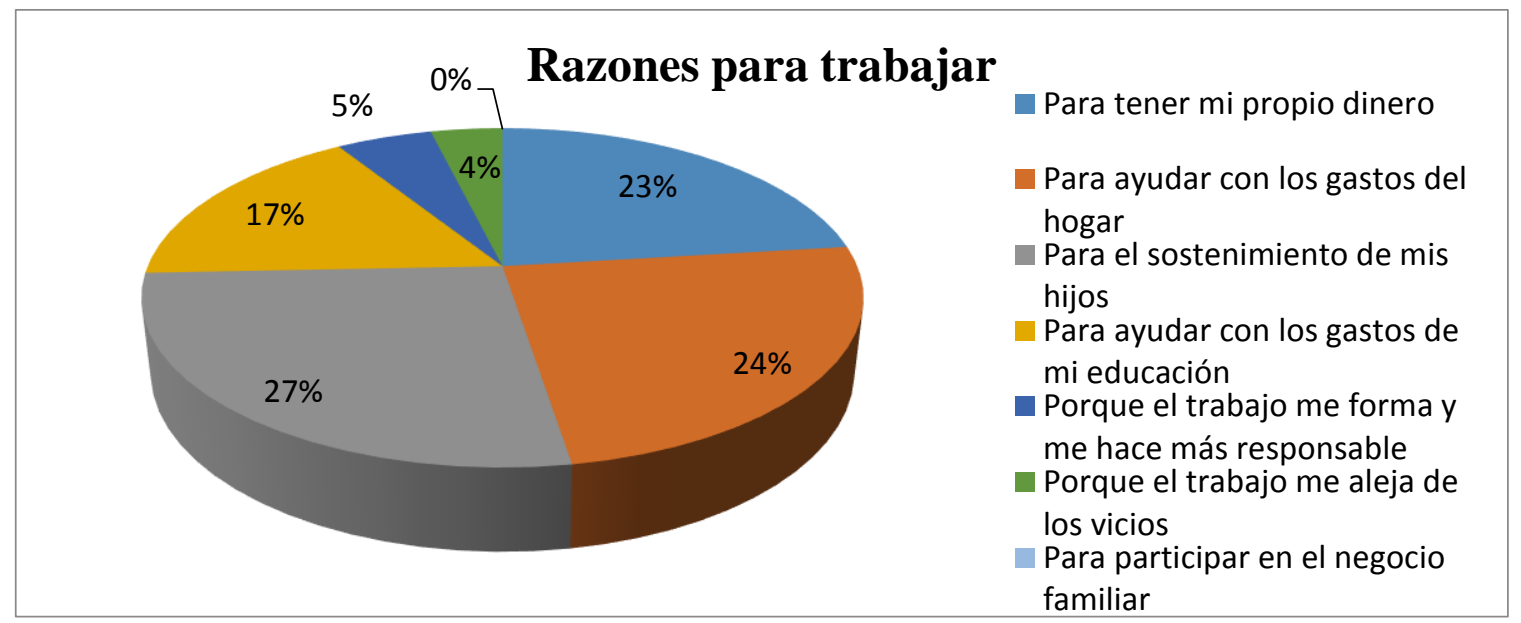

Fuente. Encuestas. Elaboración propia de la autora

Era importante poder establecer las razones que llevan a que los estudiantes trabajen, pero así mismo es importante conocer como esta actividad que es necesaria obviamente para el estudiante termina afectando su vida escolar. La grafica \#25 permita identificar cuáles son las afectaciones que se dan en este aspecto, donde se muestra que con un porcentaje del $50 \%$ la afectación más grande 
está dada en el tiempo que se limita para poder realizar sus tareas y cumplir con las responsabilidades académicas, así mismo y siguiendo la misma línea se encuentra con un $17 \%$ la afectación en el rendimiento escolar, esto no requiere obviamente tanta explicación ya que es comprensible que si dedica la mayor parte de su tiempo para trabajar cuando llega al colegio ya presenta un desgaste físico y mental. Por otro lado, se evidencia en su respectivo orden que con porcentajes del $15 \%, 12 \%$ y $6 \%$ las afectaciones están dadas por: 1 . el trabajo se convierte en un impedimento para poder ser constantes en la asistencia y cumplimiento de las clases, en ocasiones se cruzan los horarios, 2. Participación en actividades escolares que son propias de su edad (actividades deportivas, culturales, artísticas) esto para el caso de los más jóvenes Y 3. Participación en actividades culturales.

Gráfica 25. Afectación del trabajo en el estudio

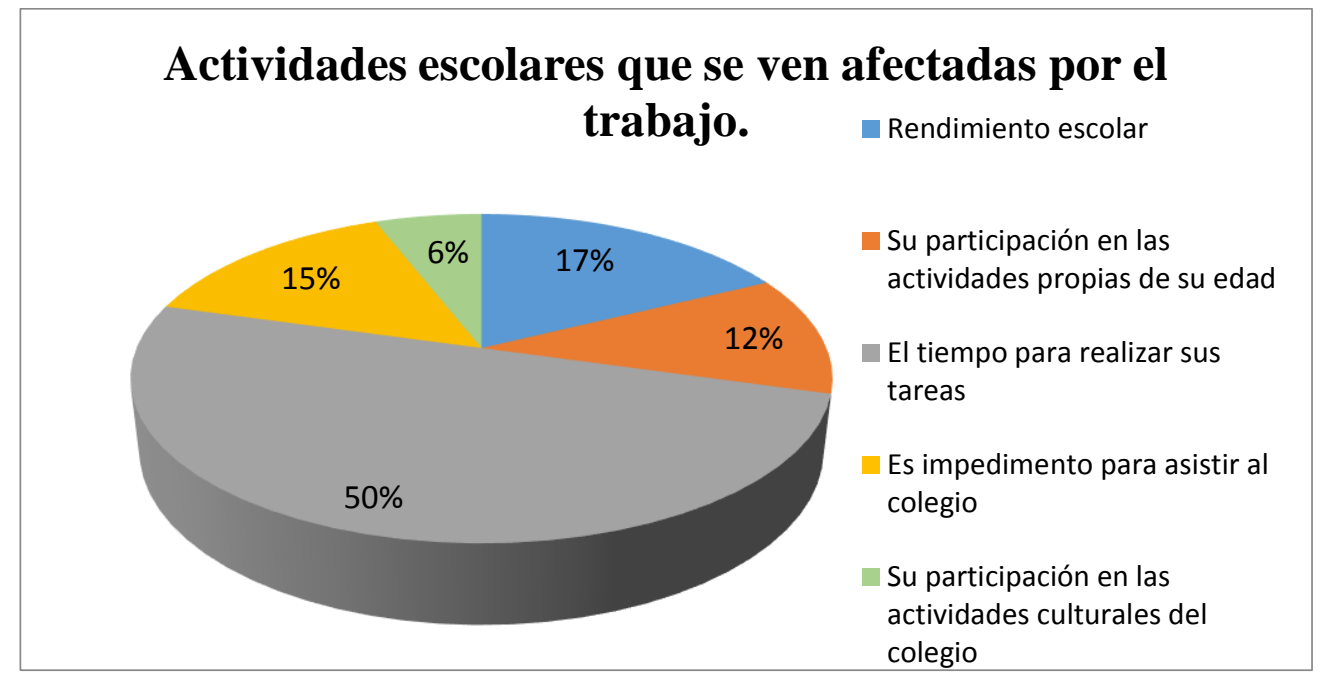

Fuente. Encuestas. Elaboración propia de la autora

\subsubsection{Encuesta 3:}

Para la investigación realizada, se desarrolló y aplico una tercera encuesta con docentes y directivos del colegio, (Ver anexo C. Encuesta No3) con el fin de averiguar cuál es la percepción que tienen, frente a las razones que llevan a 
los estudiantes a retirase y abandonar sus estudios, esta encuesta estuvo direccionada en los aspectos que inciden en los estudiantes, desde diferentes contextos como son: el desempeño escolar, la familia, la institución y lo personal. Las personas encuestadas fueron: el coordinador, la orientadora y un profesor del área de sociales. La grafica \#26 nos permite identificar cuáles fueron los resultados más relevantes para los docentes y directivos del colegio, obtenidos desde el contexto familiar, donde, con un porcentaje de $75 \%$ se evidencia que las razones más fuertes están determinadas desde lo económico ya que algunos de los estudiantes se deben retirar por la necesidad de trabajar para responder por sus hijos que ha tenido a temprana edad, por embarazo, sea del mismo estudiante o de su pareja o para ayudar a sus familias y hacer un aporte económico en sus hogares, y con un $25 \%$ los encuestados manifiestas que se debe al cambio de vivienda de los estudiantes y su grupo familiar debido al trabajo de alguno de los padres, aunque se debe aclarar que para los estudiantes esta última razón no incide de manera considerable.

Gráfica \#26. Razones de tipo familiar que causan el retiro de estudiantes

\section{Razones de orden familiar para el retiro de los estudiantes.}

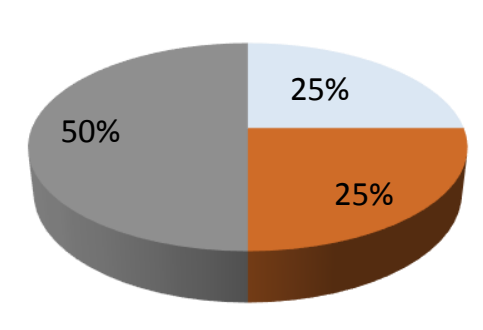

Había problemas de dinero en el hogar

- Por que la familia cambio de casa por el trabajo de alguno de los padres

- Porque necesitaban trabajar

Fuente. Encuestas. Elaboración propia de la autora 
En las razones de tipo personal que consideran los docentes y directivos para el retiro de los estudiantes, la gráfica \#27 relaciona diferentes razones. Con porcentajes muy similares que se consideran inciden en el abandono de los estudios, que resultan siendo de alguna manera un poco similar a la percepción que tienen los estudiantes, se encuentra el tema económico con uno de los porcentajes más altos. Pero si se hace una lectura diferente, resulta de interés, siendo desde la mirada de docentes y directivos que se evidencia el desinterés o la falta de gusto por el estudio donde el porcentaje es de un $18 \%$.

Gráfica \#27. Razones de tipo personal que causan el retiro de estudiantes.

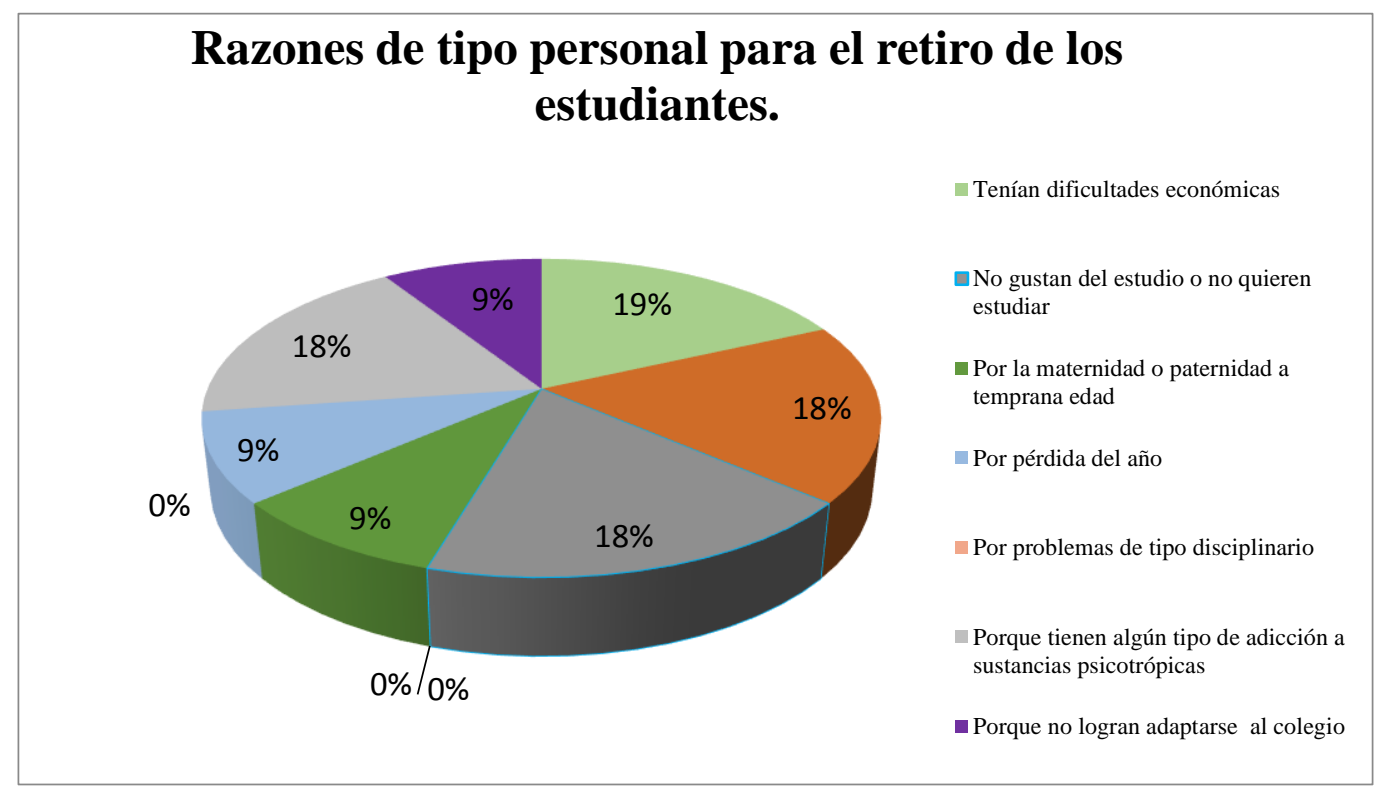

Fuente. Encuestas. Elaboración propia de la autora

Con respecto a las razones institucionales que pueden tener incidencia en el abandono de los estudios, los resultados arrojados tal como se refleja en la gráfica \#28, fueron los siguientes: con un porcentaje del $21 \%$ cada uno, se encuentra las dificultades con los horarios pues como ya se explicó anteriormente y tal como lo manifestaron también los estudiantes, en ocasiones se cruzan los horarios de clase con los laborales, la otra razón, tiene que ver con el 
tema de inseguridad que se presenta en la salida del colegio y mucho conflicto y violencia en el colegio. Ahora bien, con porcentajes de $8 \%$ cada uno, se encuentran razones frente a: la falta de educación de los padres que no los motivan, lo educación que se brinda en el colegio difiere de los intereses educativos de los estudiantes, y la forma como enseñan los maestros, razón que no fue evidente por parte de los estudiantes, otro porcentaje significativo es el maltrato de los compañeros, lo que indica que la violencia afecta tanto a docentes, directivos y estudiantes.

Gráfica \#28. Razones de tipo institucional que causan el retiro de estudiantes

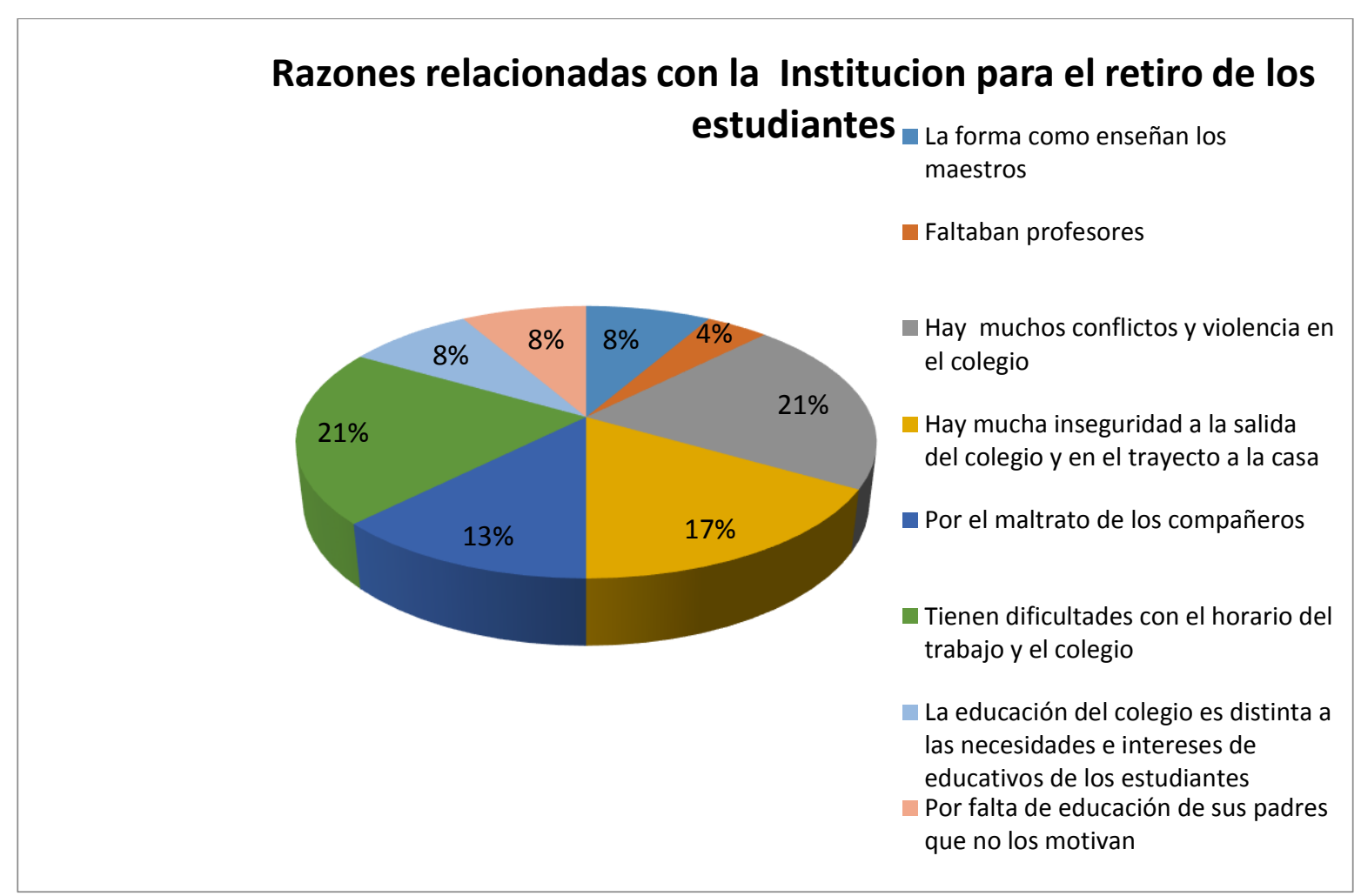

Fuente. Encuestas. Elaboración propia de la autora 


\subsection{Una mirada desde adentro}

La autora de este trabajo presenta la reflexión etnográfica a partir de su propia experiencia de 22 años como docente, dando un aporte subjetivo al análisis propuesto en los objetivos de la investigación.

A partir de la comparación de dos instituciones que ofrecen educación de adultos en las Localidades de Fontibón y Bosa; voy a presentar mi propia reflexión etnográfica sobre la problemática de la deserción, comparando mis experiencias de lo que sucede en uno y otro colegio, dando mi perspectiva subjetiva sobre lo que acontece, para tener más elementos de comprensión para el análisis

Si bien son localidades con habitantes que tienen problemas económicos y sociales similares, el trato con los estudiantes ha reflejado actitudes diferentes con respecto a determinadas situaciones y además el colegio de la Localidad de Bosa ofrecía bachillerato técnico mientras que el de la Localidad de Fontibón ofrece bachillerato académico.

"A modo de comparación y debido a mi experiencia personal de 7 años como docente en el colegio CEDI San Pablo de la localidad de Bosa, puedo decir que se presentaba una motivación por obtener conocimientos adicionales a los del bachillerato, es decir el aprendizaje de una labor adicional, que les permitía a los estudiantes, los cuales la mayoría provenían de familias con dificultades de convivencia, con problemas económicos y familias monoparentales, buscar un trabajo y mejorar su nivel económico, esto teniendo en cuenta que el colegio ofrecía bachillerato técnico para la jornada nocturna. De igual manera es importante mencionar que en este colegio si bien se daban retiros de estudiantes durante el año, esto no incidía para que se diera el cierre de cursos en la mitad de un periodo, por alta 
deserción. En los colegios de la localidad de Fontibón (Costa Rica e Integrado de Fontibón IBEP), la situación económica de los estudiantes no es tan precaria en comparación con los estudiantes del colegio CEDI San Pablo de la localidad de Bosa, en estos se encuentran estudiantes de edad avanzada (aunque es un porcentaje mínimo de estudiantes) que buscan obtener su título de bachiller los cuales cuentan con mejor estabilidad económica y que no necesariamente cursan sus estudios en la jornada nocturna para buscar un mejor nivel de vida, sino por satisfacción personal de poseer su título de bachiller.

En las conversaciones con los estudiantes se logró extraer que cansados de ver la situación económica de sus familias toman la decisión de salir a trabajar para ayudar y mediar esta situación familiar, e igualmente algunos lo hacen con deseos de independizarse por la búsqueda de otras posibilidades de vida y en otros casos por que asumieron responsabilidades de paternidad a temprana edad o conformación de hogares recientes. Así mismo se logró identificar en medio de estas conversaciones que tienen conflictos familiares, entre ellos dificultades con sus padrastros, que suelen abusar de ellas (en el caso de las mujeres) o los maltratan o tienen que vivir con otra familia que no es la propia y se ven humilladas o humillados lo que los impulsa a buscar trabajo para el sostenimiento propio. Estos estudiantes, después de tener trabajo, ven que económicamente no pueden sostenerse solas o solos, entonces deciden irse a vivir con su pareja o con amigos, lo cual les crea inestabilidad, pues viven cada seis meses o cada año con una persona diferente o deciden regresar a su casa, esta inestabilidad de hogar los obliga a desertar de sus estudios, e incide igualmente en que el colegio reciba estudiantes en cualquier época del año y los cuales en ocasiones proceden de otras instituciones.

Así mismo en el colegio de la localidad de Bosa se conoció el caso de estudiantes que conformaban una familia con una persona de edad mayor que ellas, esto solo por huir de sus problemas familiares y mejorar su situación económica, sin importar su estabilidad emocional; aunque estas personas las maltrataran o las mantuvieran sometidas soportaban la situación porque les pagaban el arriendo y la comida de sus hijos los cuales 
habían sido concebidos de relaciones con otras parejas, esta situación se logró percibir sobre todo en las mujeres y de igual manera se manifestaba que en ocasiones estas personas adultas las hacían retirar de sus estudios por celos.

En la localidad de Fontibón la consecución de empleo resulta ser más fácil que en la localidad de Bosa, pero aun así hay pocas oportunidades; a pesar de que existen zonas Francas debido a la cercanía con el Aeropuerto el Dorado la oferta es escasa para personas con poca preparación académica, de ahí que las actividades en las cuales se emplean no están muy ligadas a la industria de la zona y terminan vinculándose como: ayudantes en algún oficio, empleadas de servicio, cuidando niños, ancianos o en servicios generales y los que no encuentran empleo simplemente se dedican a los oficios del hogar. Adicionalmente cabe mencionar que las actividades laborales en las cuales se emplean, muchas veces les implica traslados largos dado a lo que menciono, frente a que la zona en la que viven no ofrece gran oferta laboral, por lo cual estos largos trayectos terminan incidiendo en la dificultad que presentan para llegar a tiempo al colegio y poder tomar sus clases de manera estable.

En el Colegio Integrado de Fontibón y Costa Rica, durante dos años (2009, 2010) se vincularon estudiantes que hacían parte de grupos reinsertados de la guerrilla y de paramilitares, como también soldados profesionales a quienes les exigían el título de bachiller. En esta época, se observó que el trabajo se hizo un poco más complejo, por el ingreso de este tipo de estudiantes específicamente para este caso de los reinsertados de grupos paramilitares, los cuales evidenciaban carencia de educación y de respeto por el otro, obviamente debido al contexto del cual hacian parte, cuando se les planteaba algo que no estaba dentro de su lógica, lo veían como un ataque y pretendían resolverlo todo con amenazas y violencia, situaciones que terminaron incidiendo en la convivencia escolar y afectaban de cierta manera el rendimiento académico de los mismos. Ahora en el caso de los soldados profesionales y reinsertados de la guerrilla, no se observó problemas de convivencia con los estudiantes que hacian parte de la localidad y por el contrario plantearon 
situaciones críticas y, sin hacerse evidentes, comentaban las situaciones de los pueblos más alejados del país, donde ellos actuaron. Inicialmente, esta experiencia obligó a vivir con una violencia interna de amenazas, que luego se fue transformando en una tolerancia de convivencia tranquila, pero de mucho cuidado. Por otra parte, los estudiantes con problemas de consumo de sustancias psicoactivas, pandillismo y delincuencia, se retiraron, porque se vieron amenazados por panfletos donde aparecieron sus nombres. Con los demás actores se pudo convivir.

A los dos años, los estudiantes reinsertados del paramilitarismo se retiraron, informando que el gobierno les ofreció el programa de convenio con Cafam para sábados y domingos, no se graduó ninguno en el colegio; mientras que los estudiantes reinsertados de la guerrilla y los soldados profesionales, lograron terminar sus estudios y muchos mejoraron su situación de vida.

Otros aspectos que se identificaron estaban relacionados con actividades de subsistencia económica de los estudiantes en los colegios de Fontibón donde el "rebusque" se hacía evidente con la venta de tintos, arepas, CD's, pero al mismo tiempo se presentaban robos menores, denominados por los mismos estudiantes como "desvare".

Como se mencionó anteriormente desde la experiencia como docente se ha evidenciado cuales son las actividades laborales a las cuales los estudiantes deben acceder por necesidad económica y que no representan trabajos formales o que les permitan obtener el pago de un sueldo mínimo, sino que al contrario los pagos se encuentran por debajo de este."

En la encuesta 2 se puede corroborar los datos de los trabajos que ejercen los estudiantes, lo cual se refleja en las siguientes graficas: La grafica \#29 presenta las actividades que desarrollan los estudiantes para obtener recursos económicos que les permitan su sostenimiento, siendo los más relevantes, el 
ayudante o auxiliar de algún oficio, empleada del servicio y mesera de restaurante o bar.

Gráfica \#29. Trabajos que los estudiantes desempeñan

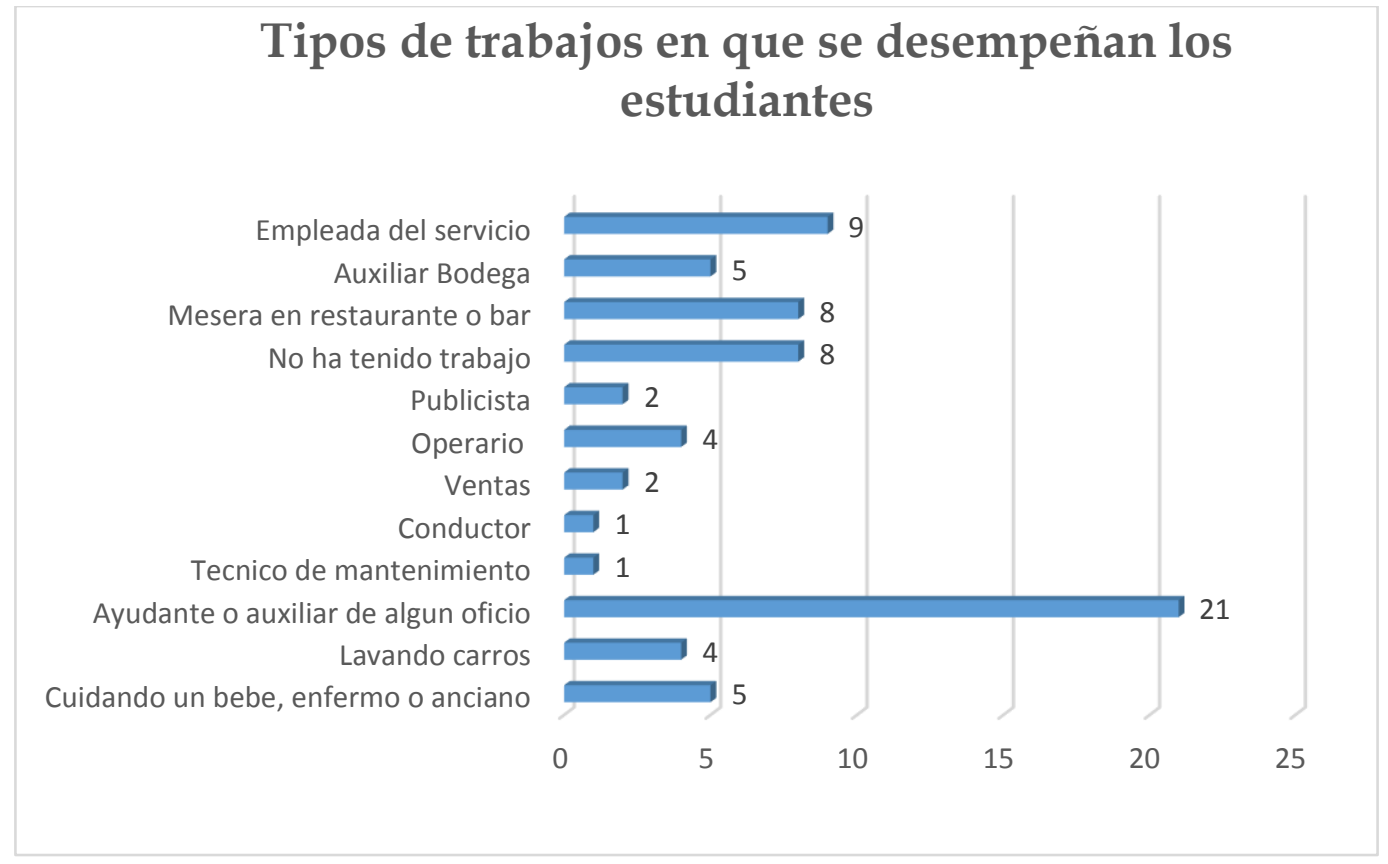

Fuente. Encuestas. Elaboración propia de la autora.

En la gráfica \#30 se observa que el $74 \%$ de estudiantes que trabajan no tienen seguridad social y algunos de ello son menores de edad, en sus empleos no existe un contrato legal y fácilmente abandonan su trabajo o son retirados de este.

Gráfica \#30Datos de estudiantes con seguridad social

ESTUDIANTES QUE TIENEN SEGURIDAD SOCIAL.

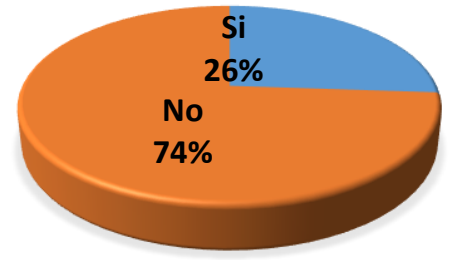

Fuente. Encuestas. Elaboración propia de la autora. 
"La labor como docente y el compromiso de la misma permite interactuar con los estudiantes no solo desde los aspectos académicos, sino que en ocasiones permite analizar y evidenciar contextos de tipo social y familiar que inciden en las formas de ser de los estudiantes o en sus actitudes y hasta en el mismo rendimiento académico. Actualmente, en el Colegio Integrado de Fontibón IBEP, se matriculan personas más jóvenes, de los cuales muchos de ellos poseen problemas de consumo de sustancias psicoactivas, en especial los estudiantes hombres, que van al colegio a distraerse, con desmotivación total por el estudio y por la vida misma. El problema de consumo en ocasiones termina llevándolos a actitudes muy eufóricas o muy pasivas las cuales se evidencian en las clases o en las horas de descanso, estos estudiantes en ocasiones no reaccionan con nada y perfectamente pueden estar 3 horas sin hacer absolutamente nada, sin participar en las actividades comunes de las clases, ni dar ningún tipo de rendimiento académico. Pero obviamente no es ajeno para el docente identificar que estas situaciones están dadas por la carencia que tienen estos estudiantes de afecto, de no contar con un grupo familiar estable y que les preste ayuda, generalmente viven con su mamá y hermanos, algunas veces con el padrastro con quien no tiene buenas relaciones y otros con familiares de tercer grado. Estos estudiantes cansados de sus problemas se resguardan en este tipo de sustancias que nos les permite avanzar y ni conseguir sus objetivos de mejorar la calidad de vida tanto de ellos como de sus familias. Igualmente se evidencia con estos estudiantes jóvenes que muchos cuentan con privaciones económicas lo cual los llevan a trabajar como se ha mencionado en trabajo poco estables formales con sueldos por debajo del mínimo pero que de una u otra manera permite en algo ayudar a sus familias a su propio sostenimiento. (Ver entrevistas realizadas subcapítulo 3.5).

Los estudiantes más jóvenes, con problemas de consumo de sustancias psicoactivas, no saben nada de sus familias, ni quieren saber de ellas, a pesar de convivir con ellos; tampoco tienen ningún control en sus casas y sus familias perdieron hace rato la autoridad sobre ellos; parece que existiese la regla "no me digas nada y yo no te creo problemas en la casa"; aunque en la calle tengan miles de problemas. Por consiguiente, los 
padres no tienen autoridad sobre sus hijos. Algunos padres, que todavía se preocupan por sus hijos, son ingenuamente engañados, pero sus hijos han perdido el rumbo hace rato. Los estudiantes solo piensan en resolver sus problemas de subsistencia, sus necesidades y generalmente sienten el rechazo por su comportamiento, y eso los hace más agresivos, convirtiéndose esto en un círculo vicioso. Las mujeres con problemas de consumo se vuelven violentas $y$, en lo general, se escudan en los errores de sus padres, por haberles obligado a convivir con su padrastro o madrastra o por haberlas abandonado. Cuando se les reprende, huyen de la autoridad cambiando de vivienda constantemente estando un tiempo con el papá, otro tiempo con la mamá, otro tiempo con los abuelos o algún familiar. Identificar todas estas circunstancias en los estudiantes lleva a argumentar, que estas tienen que ver mucho con la inestabilidad del estudiante con sus estudios y con la permanencia en el colegio, así mismo en el caso de las mujeres se ha evidenciado que después de retirarse, regresan al siguiente año en estado de embarazo o habiendo teniendo recientemente sus hijos. Es muy común ver a un buen número de estudiantes asistiendo al colegio con sus hijos menores de 4 años, no es raro encontrar en el aula de clase hasta 4 niños (bebés y niños de 2 y 3 años).

Ahora bien no todo resulta ser tan crítico, pese a todo lo presentado con los estudiantes jóvenes existen experiencias exitosas como la que se dan en los grupos de los ciclos escolares, donde estudian personas de edad mayor junto con jóvenes, allí se presenta una situación interesante, ya que las personas mayores terminan convirtiéndose en un apoyo para los jóvenes y en un referente de estímulo y respeto, estos adultos ayudan a corregir a los más jóvenes, cuando contestan o tienen comportamientos irrespetuosos, en ocasiones hacen las veces de papás o mamás y logran encausarlos con el estudio y les dan consejos, las mujeres en especial suelen recibirlos asertivamente y de manera humilde, esto ratifica porque los estudiantes consideran que dentro de los motivos más relevantes para el retiro del colegio no se encuentra los conflictos internos o entre compañeros, pues en general la convivencia es pacífica. Los estudiantes jóvenes, que no tiene problemas de consumo; pero que fueron expulsados de la jornada diurna, por problemas graves de 
comportamiento e indisciplina, en la jornada nocturna tienen un comportamiento diferente, pues, el convivir con gente adulta los hace tomar nuevas actitudes ante problemas de convivencia y de respeto. Este nuevo contexto los hace cambiar. En muchas ocasiones causaban sorpresa, los comentarios que hacían, cuando relataban lo que habían hecho en la jornada diurna y la razón por la cual los habían expulsado, pues, en nada se parecían con su comportamiento actual de buena convivencia donde es clara su reflexión y hasta arrepentimiento de esas situaciones y del tiempo desperdiciado. Por consiguiente, lo anterior permite evidenciar que la jornada nocturna es una oportunidad de cambio y de apertura de posibilidades para todos.

Otro aspecto que se hace evidente y que manifiestan los estudiantes en medio de las conversaciones de tipo informal que se llevan a cabo con ellos tiene que ver con los aspectos que influyen en los jóvenes que no han nacido en la ciudad, jóvenes que han tenido que trasladarse de espacios rurales por diferentes circunstancias de tipo social o económico, los cuales dan a conocer su inconformismo por esta situación pues dicho en sus palabras "en las veredas donde vivíamos nos sentíamos felices, nos iba bien en el estudio, así tuvieran problemas económicos; pero todo cambio cuando nos tuvimos que trasladarse a alguna ciudad" la mayoría de estos jóvenes antes de llegar a Bogotá vivieron en otras ciudades y sus cambios de hábitat eran frecuentes, no encontraban una estabilidad ni económica ni emocional, ni mucho menos académica, por consiguiente esta situación genera cambios de comportamiento y dificultades para adaptarse en diferentes espacios entre esos el colegio y lo cual se ve reflejado en comportamientos conflictivos y dificultades de convivencia. Sin embargo, para ellos el estar en la capital y en la ciudad que consideran de mayor oportunidad se convierte en un estímulo para pensar en una salvación a algunos de sus problemas pues la consideran como la opción más viable para culminar sus estudios y conseguir un trabajo que les permita mejorar sus condiciones de vida.

La experiencia como docente también me ha permitido identificar las diferencias a nivel de infraestructura de los colegios, de compromiso e interés de los 
directivos por ofrecer mejores condiciones a los estudiantes de la jornada nocturna que no siempre resultan iguales a los de la jornada diurna. En el colegio CEDI San Pablo de la localidad de Bosa se cuenta con una infraestructura excelente, con talleres que si bien no están en un 100\% dotados, se puede hacer uso de ellos por parte de los estudiantes de la jornada nocturna, se ofrece una educación técnica que como ya se dijo motiva a que el estudiante disminuya la intención de retiro; diferente es en colegio Integrado de Fontibón IBEP donde su infraestructura no es la más adecuada ni optima al igual que su dotación, en este existe un solo taller para física y química pero no está en servicio para los estudiantes de la jornada nocturna, la sala de computo cuenta con equipos obsoletos que no permiten que el estudiante se acerque a las nuevas tecnologías de manera oportuna. Aun así, resulta interesante mencionar que los estudiantes consideran que este no es un motivo de peso para que ellos decidan retirase de sus estudios". (Ver Encuesta 2).

\subsection{Voces de los protagonistas desde sus relatos de vida}

Con el fin de tener una mirada no solo cuantitativa, sino otra que recoja la vivencia misma de los estudiantes enriqueciendo así nuestra comprensión de la deserción se invitó a los estudiantes a realizar su autobiografía. De 60 autobiografías, se escogieron 10 relatos, que expresaron como una circunstancia de su vida el abandono escolar. Estas autobiografías se realizaron con los ciclos 4 (grado octavo y noveno).

En general, en los relatos de vida, se pudo determinar que el $75 \%$, de las personas eran hijos de padres campesinos y en sus años de infancia, si bien estudiaban, tenían que hacer trabajos de agricultura y ayudar en su casa, de igual manera se identificó que en su mayoría tenían una figura paterna casi inexistente. 
Por la inestabilidad del trabajo de sus padres, se cambian de casa y lugar de residencia, situación que los obliga a tener que trasladarse de colegio. En ocasiones las nuevas distancias del colegio a la casa hacia que desistieran de continuar con sus estudios, o simplemente, el cambio de colegio les afectaba su rendimiento escolar, lo cual llevaba a que perdieran el año o abandonar sus estudios.

\subsubsection{Relatos de estudiantes: factores que inciden para desertar en el estudio}

En los siguientes relatos se evidencia lo que los estudiantes cuentan de su vida y los factores que inciden para retirarse de estudiar:

Primer Relato: "Nací en una vereda llamada Santa Rita. En una casa de campo, donde una tía abuela. Ella ayudaba a mi mamá, que, siendo joven, ya contaba con un hijo que empezaba a dar sus primeros pasos. Edwin mi hermano mayor, solo me lleva quince meses, y por esa poca diferencia de edad, siempre no llevamos muy bien. Por ejemplo, estando en Bogotá, siempre cogíamos calle y nos montábamos en el Transmilenio. Podíamos pasar el día completo viajando en el Transmilenio, recorriendo toda la ciudad.

No puedo decir mucho de mi papá. Lo único que sé es que él estuvo presente cuando Mari Luz, mi mamá, me dio a luz. También estuvo allí mi tía, quien socorrió a mi mamá durante todo el embarazo y quien pasó a ser más adelante, casi mi mamá, porque mi mamá siempre estaba trabajando ya que mi papa nunca le colaboro con nuestra crianza. Mi tía tuvo una niña. Me cuenta ella, que mi prima era como una leona, negrita y mechuda. Fue la adoración para la familia quien recibía por primera vez, la bendición de una niña. Sobre todo, para el papá, él era el que más le daba afecto, pero cuando yo ya estaba un poquito más grande, al esposo de mi tía lo mataron por negocios que él tenía. 
Viviendo en la ciudad y después de la muerte del papá de mi prima, mi mamá y tía no nos podían cuidar porque tenían que salir a trabajar. Nos dejaba solos en la casa con un señor que era el marido que consiguió mi mamá. Él nos pegaba duro y casi siempre se aprovechaba de que éramos chiquitos y nos quitaba la plata que mi mamá nos daba. Luego, consiguió otro novio que si era buena gente y nos respetaba.

Otras veces nos dejaba al cuidado de mis tíos y como nosotros éramos muy gamines y nos queríamos salir todo el tiempo a la calle, mi tío Carlín, que era el más severo, se la pasaba pegándonos, y nos llevó a un internado en Madrid, Cundinamarca. Aunque el lugar no merecía el nombre de infierno, siempre mi hermano y yo nos preguntábamos por qué mi mamá lo había permitido. Eran tantas las ganas de salir de ahí, que mi hermano logró escaparse al año de entrar, pero yo, no pude. Me quede sola en el internado cinco años.

Al internado, mi mamá nos iba a visitar cada quince días. Nos llevaba pollo y pasábamos un rato muy bonito. Cuando me sacó en el 2010, nos llevó a donde ella vivía y entonces le pregunté porque nos había metido al internado, y ella me respondió que, porque nosotros éramos muy desjuiciados, que nos la pasábamos de arriba pa'bajo en la calle. Después todo cambió para bien. Recuerdo que mis tías nos llevaban a Maloka, a Divercity y a Cici Aquapark. En navidad, ellas nos llevaban al campo, a la casa del tío Virgilio y allá nos reuníamos con toda la familia. Nadábamos en un río que quedaba cerca y nos daban regalos a mí, y a mis primos pequeños. Apenas recibíamos un paquete, lo destapábamos ansiosamente y nos poníamos a jugar juntos.

Me puse a validar en el colegio México. Cursé el grado cuarto, quinto, pero sexto no lo pasé. Lo perdí por malas amistades. Entonces me cambié de colegio para empezar de nuevo sexto, pero lo perdí otra vez por los amigos que me conseguí. Empecé a meter vicio, metí hasta pegante y comencé, como dicen los ñeros, a farrear cada quince días. Salía mucho con mis supuestas amigas. 
Pero mis tías se enteraron de que estaba metiendo vicio y me trajeron a vivir con ellas a Fontibón. Como dicen ellas, me sacaron del fango y gracias a Dios, estoy estudiando en el ciclo 4 en el colegio Integrado de Fontibón en la noche y estoy trabajando para ayudarme con los transportes. Les agradezco a mis tías y a mi mamá que han sido una ayuda para mí.

Estoy contenta porque me salió cupo en el comedor gracias a mis tías que me ayudaron. Con eso y con el trabajo me siento mejor porque no les hago gastar plata a mis tías, ya que ahora salgo a pasear con ellas".

Segundo Relato: "Nací en una vereda llamada alambrado, a tres horas por camino de herradura del municipio de Pensilvania, Caldas. Mis padres fueron José Arturo y Martha. Juntos trabajaban como jornaleros.

Junto con mis 7 hermanos, asistíamos a la escuelita El Cauce, que quedaba a una hora de la casa. Teníamos que ir a pie limpio porque no teníamos recursos para unos zapaticos o botas de caucho. En invierno, llegábamos con barro hasta las rodillas porque por el mismo camino que cogíamos, pasaban vacas y caballos. Igual siempre, llegábamos sucios porque nos quedábamos jugando después de estudiar. Pero si se nos pasaba el tiempo jugando y llegábamos tarde a la casa, mi papá nos daba una fuetera.

En primero, yo tuve una profesora muy malgeniada, que nos pegaba con una regla. Entonces perdí ese año. Pero al siguiente año, llegó una profesora muy querida. Me acuerdo que estaba casada con un viejito y tenía ocho hijitos que también estudiaban ahí en la escuelita. Con ella aprendí muchas cosas y las aprendía rápido: en seis meses, yo aprendí a leer y a escribir. Como mis calificaciones eran solo cincos, ella me pasó a segundo. Pero en tercero, perdí todas las materias. Cuando lo repetí, volví a perder y mis papás me sacaron de estudiar. Dijeron que el estudio no era lo mío. Además, como que a la profesora le molestaba que no la fuera a acompañar a dormir todas las noches. 
Entonces me puse a trabajar con mis papás, hasta que hubo una sequía y nos fuimos a buscar trabajo en otras veredas e incluso pueblos. Terminamos trabajando por el Putumayo y el Valle de Cauca.

Cuando cumplí 20 años, me fui a Manizales, Caldas, a vivir con una amiga, pensando que allá encontraría mejores oportunidades de trabajo. Pero no fue así, allá había mucho desempleo y como no tenía estudio, era más difícil conseguir, y mucho menos podía ser policía, que era lo que yo quería.

Una hermana estaba viviendo en Bogotá, entonces me fui a vivir con ella, y me puse a estudiar en las noches. Pero me retiré sin haber terminado cuando me enteré de que había quedado embarazada. Como mi marido tenía familia en Fusa, me voy a vivir a Fusa con él. Después de un tiempo, me separé de él y me volví a casar. Del segundo matrimonio, tuve a mi segundo hijo y nos venimos a Bogotá para conseguir una mejor vida a los niños. Él se puso a trabajar en la construcción y yo, en un principio, lavando ropa ajena, para solventar nuestras necesidades". Cuando mis hijos estuvieron grandes, volví a estudiar, se me dificultaron algunas materias al principio, pero en general me va bien en el estudio, tengo problemas con mi esposo porque no está muy de acuerdo con que yo estudie y por eso falto algunas veces; él cree que yo voy a conseguir otro tipo, porque una hermana hizo eso con un compañero de aquí del colegio. La profesora me ayudo a convencerlo de que me dejara seguir estudiando, ahora ya voy a graduarme como bachiller".

\subsection{Palabras de entrevistados}

Se aplicó además una entrevista que nos permitió tener más elementos personales de lo que sucede al interior de los estudiantes que toman la decisión de retirarse del colegio. Para ello se aplicó una entrevista semiestructurada a 3 estudiantes que abandonaron la escuela y volvieron a 
terminar su bachillerato (Ver anexo D de preguntas orientadores de la entrevista). Para esta entrevista se escogió una estudiante de ciclo 6 y a dos estudiantes de ciclo 3.

Las entrevistas reflejan que, además de los problemas económicos, los estudiantes tienen dificultades familiares, porque provienen de hogares, donde son abandonados por el padre y; cuando la madre queda sola o busca otra pareja, surgen conflictos con los hijastros o con familiares de la madre, tales como tías, tíos, abuelos y; por consiguiente, varios adultos intervienen en su formación, generalmente, con violencia. La madre, tras varios errores, pierde autoridad sobre sus hijos, no hay buen ejemplo de los adultos y, por ende, los chicos no se dejan corregir y se escudan en los errores de los padres o adultos. Por eso los estudiantes toman la decisión de abandonar sus estudios, con la ilusión de mejorar sus condiciones económicas y ayudar a su familia o independizarse, en busca de mejores condiciones de vida.

Tras la inestabilidad generada en los anteriores conflictos familiares, los estudiantes asumen como madres o padres a temprana edad, agregándole una nueva problemática a su situación. Algunos, por su desespero y por su falta de afecto caen en el consumo de sustancias psicoactivas y terminan en la calle, aguantan hambre y si, desafortunadamente, sus nuevos amigos son personas que están en la delincuencia o en la venta y consumo de sustancias psicoactivas, su esporádica asistencia al colegio y su forma de vida, se transforman en un impedimento para continuar estudiando.

Con este cúmulo de problemas personales y en este ambiente social adverso, se desmotivan por el estudio, pierden años escolares, son retirados del colegio, van a buscar trabajo y no logran conseguir algo estable. Entonces, vuelven 
a estudiar, pero, como ya tienen responsabilidades con sus hijos, cuando consiguen algún trabajo temporal o informal, sus horarios interfieren con los horarios del estudio y, nuevamente, se retiran. A lo largo de este proceso, carecen de tratamiento para sus adicciones, las familias asumen el problema con resignación o, sencillamente, los abandonan a la calle, exponiéndose a la miseria y a la pobreza extrema.

En consecuencia, estos estudiantes, a quienes el contexto de situación les ha negado sus derechos fundamentales, primero, se transforman en un problema para la familia, quienes no saben qué hacer con ellos; segundo, se convierten en un problema de convivencia para el colegio, pues, estas personas llegan desmotivadas, drogadas, no participan ni cumplen con actividades escolares y tampoco cuentan con el apoyo familiar, que les permita a los educadores buscar diálogo y negociar procesos de cambio y mejoramiento del estudiante. El panorama se vuelve, entonces, desalentador para los docentes y directivos, quienes tampoco se animan a cambiar sus métodos de enseñanza o a implementar tecnologías que favorezcan la motivación y estimulen los intereses de estos estudiantes por el aprendizaje. 


\section{CAPÍTULO IV: SÍNTESIS INTERPRETATIVA}

Con base en el análisis de las informaciones obtenidas en las entrevistas, encuestas, relatos de vida y la observación participante de la investigadora en su práctica diaria como docente, se obtuvieron las siguientes categorías de análisis, que señalan cuáles han sido las necesidades fundamentales que han incidido en la insatisfacción de los estudiantes para tomar la decisión de retirarse del estudio. Las identificaciones de estas necesidades insatisfechas tienen, por consiguiente, origen en la familia, en el estudiante, en el colegio y en el contexto de poder que implementa y regula las políticas educativas.

Es importante aclarar que la necesidad no siempre se refiere a carencia o "falta de algo", ya que también pueden ser potencialidades latentes, es decir, necesidades de desarrollo que comprometan, motiven o movilicen a las personas. (Max-Neef, 1998).

Como ya quedó dicho, el trabajo de interpretación se apoya en planteamientos de Max Neef y los resultados se categorizan de acuerdo con su Matriz de Necesidades existenciales, que cubren y engloban el espectro de intereses y motivaciones educativas de los jóvenes adultos (Yuni, 2005); por este motivo se decidió usarlas como orientadoras de análisis e interpretación de los factores que inciden en la deserción escolar de los estudiantes de la jornada nocturna, en especial las necesidades axiológicas: subsistencia, protección, afecto, entendimiento, participación, ocio, creación, identidad y libertad, que tienen que ver con sus necesidades existenciales del ser, tener, hacer y estar.

Es importante aclarar que, si bien estas necesidades son orientadoras, no todas aparecen reflejadas en las encuestas, entrevistas y relatos de vida; por 
tanto, solo se tiene en cuenta aquellas relacionadas en las repuestas de los estudiantes, que coinciden con las necesidades enunciadas en la matriz de Max Neef y que determinan la decisión de abandonar sus estudios. Por consiguiente, se relacionaron las necesidades de subsistencia, protección y afecto con el contexto familiar; las necesidades de entendimiento, ocio y creación con el contexto escolar y; las necesidades de identidad, libertad y participación con el contexto social y personal.

\subsubsection{Contexto familiar: (Necesidades de subsistencia, protección y afecto)}

En el núcleo familiar, las necesidades existenciales y axiológicas, reflejadas en la vida de los jóvenes adultos, son:

Los estudiantes luchan por la subsistencia diaria, sin contar con su familia. Respecto a la Seguridad Social (salud física y mental), las encuestas demuestran que el 74\% no cuentan con seguridad social, el refrigerio que les están dando actualmente en el colegio lo reciben con agrado lo que corrobora su necesidad de alimentación. Igualmente, todas las encuestas coinciden en afirmar que las condiciones económicas precarias de la familia, los obliga a dejar el colegio y a buscar trabajo.

Tienen, además, problemas de adaptabilidad, pues, están recién llegados de sus sitios de origen (donde por las entrevistas realizadas manifiestan eran felices) y; aunque cuentan con más servicios, satisfactores de sus necesidades básicas (agua potable, saneamiento básico, educación), han puesto en riesgo su integridad y bienestar (vicios, uso de armas, problemas judiciales y tv comercial), que, si bien les satisface sus necesidades de ocio, les imposibilita las necesidades de

entendimiento, identidad, libertad y creatividad. Además, pierden su identidad, 107 
las tradiciones y conocimientos ancestrales familiares se pierden. Nuevamente las condiciones económicas de la familia no les permiten satisfacer necesidades de abrigo, ni ambientes seguros, pues, manifiestan en las entrevistas realizadas que viven con familiares con quien tienen conflicto, lo que afecta su contorno vital.

Cuando tienen conflicto con la familia salen de la casa a pagar arriendo o a vivir con amigos. Deben asumir responsabilidades de adultos y; por ello tienen necesidad de un trabajo que, generalmente, es inestable y mal remunerado como se evidencia en la gráfica $\mathrm{N}^{\circ} 30$, donde se informa los tipos de trabajos informales con que cuentan los estudiantes. Cuando manifiestan falta de tiempo para realizar sus tareas es porque, generalmente, salen de sus trabajos para el colegio, sin descanso alguno; por eso toman esta jornada escolar como distracción, descanso y el sitio para conseguir amigos. Para subsistir en su entorno social algunos deben acudir a la agresión y a la violencia, porque habitan en un medio hostil, donde se practica la ley del más fuerte.

La necesidad de protección está en riesgo permanente, pues, carecen del cuidado familiar, de autonomía y de vivienda. Deben trabajar para contribuir con los gastos del hogar o para la subsistencia propia o la de sus hijos que conciben a temprana edad. Precisamente, a estas personas que les quitaron sus derechos desde pequeños, porque debieron colaborar con los oficios del hogar o trabajando para contribuir con ingresos económicos, ahora también en su vida adulta se les niegan. A sus problemas económicos se le suman responsabilidades de adulto al tener que ejercer una maternidad o paternidad temprana al no ejercer su sexualidad con responsabilidad.

En las encuestas se refleja que un porcentaje alto de estudiantes jóvenes (66\%) deben permanecer solos durante el día o con otros menores, ya que 
su madre debe trabajar y la figura paterna no existe. Algunos deben asumir o colaborar con la crianza de sus hermanos. Falta el afecto familiar y el empoderamiento para mejorar su nivel de autoestima. No hay espacios de encuentro familiar. Sus amistades son muchas, pero pocas son de hermandad y solidaridad. La falta de afecto familiar hace que, fácilmente, sean vulnerables a cualquier tipo de relación de noviazgo; esto les afecta, emocionalmente, en algunos casos positivamente (motivándolos a salir adelante) y en otros casos negativamente.

En algunos casos de estudiantes el entorno social los induce a darle importancia a ser hincha o fan de un equipo de futbol y tener una falsa satisfacción de participación; el robo para darle una falsa satisfacción a la subsistencia; la prostitución para tener una falsa satisfacción de afecto, y tener la ropa de moda, a sentir una falsa sensación de satisfacción de identidad. El medio lo induce a defenderse en la calle del que no comparte sus ideas o no es fan de su mismo equipo de futbol, es decir, la censura que, con el pretexto de satisfacer la necesidad de protección, imposibilita la satisfacción de necesidades como subsistencia, afecto, participación, identidad y libertad.

El estudiante que tiene una familia paternalista, que, si bien satisfacen las necesidades de protección, dificultan seriamente la posibilidad de satisfacer otras como entendimiento, creación, identidad, afecto y libertad (Max-Neef, 1998).

\subsubsection{Contexto escolar: (Necesidades de entendimiento, ocio y creación)}

El que un gran porcentaje (81\%) de estudiantes haya perdido entre uno y cinco grados escolares, contra un 19\% de estudiantes que no han perdido ningún año escolar, indica que su desempeño no es el mejor y que estos 109 
estudiantes tienen dificultades o vienen con deficiencia de aprendizaje, o los métodos de enseñanza utilizados por los docentes no han sido los mejores, hasta tal punto que los estudiantes terminan desmotivándose y abandonan sus estudios. Se retiran porque no llenan sus expectativas de mejorar su calidad de vida, ya que encuentran una escuela que los homogeniza, que no les ofrece la posibilidad de tener su propio juicio crítico ni fortalece su autonomía, ni productivos, que no generan ideas, ni son capaces de transformar su realidad, que no aprenden a vivir en la diferencia, "es un estudiante que se dedica a escuchar un maestro, cuando lo que debía hacer en el aula es realizar actividades con el acompañamiento del maestro y el interés del docente debería ser: saber si su alumno aprendió y no en dedicarse a enseñar" (Cajiao, 2013).

Por lo anterior, tienen temor de participar, porque, generalmente, en vez de interpretar, se dedican a copiar y a repetir los textos; no logran razonar ni interpretar aspectos que les permitan intervenir, sustentar y argumentar frente a los demás.

De los estudiantes que se retiran un $68 \%$ prolongan sus estudios por más de un año y, por ende, la posibilidad cercana de mejorar su calidad de vida. Al ser desplazados, pierden identidad, pues, por necesidad, tratan de adecuarse a una nueva realidad que, a veces coincide con sus intereses y a veces, los afectan.

Ahora bien, los modelos de desarrollo basados en el crecimiento económico, donde los seres humanos están en función de la economía y con un ritmo de consumo desorbitado, supuestamente, para satisfacer sus necesidades, son un desmotivador de su rendimiento académico, pues, el estudiante está pendiente de lo que publicitan los Medios de Comunicación, donde se venden 
objetos y formas de ser, para ser felices; todo esto en función de adquirir cosas, que nada tienen que ver con la preocupación por el mejoramiento de su intelecto ni tampoco con las necesidades humanas fundamentales y sus satisfactores de los que habla Max Neef para el crecimiento cualitativo de las personas.

Finalmente, es importante mencionar que en las encuestas se muestra la falta de apoyo de la familia a sus hijos en el proceso escolar y; desafortunadamente, quienes acuden a la educación nocturna carecen de éste, pues la mayoría según la encuesta 2 permanecen solos en sus casas o con otros menores. Carecen, entonces, de orientación y control para la realización de sus trabajos.

\subsubsection{Contexto social y personal: (Necesidades de identidad, libertad y participación)}

Según el punto de vista de los estudiantes, en la comunidad educativa los satisfactores falsos, que no logran un desarrollo sostenible en la vida de los adultos y de los jóvenes están relacionados con:

El nivel de participación en la toma de decisiones escolares y la solución de problemas de la Institución: Cuando se les preguntó, el 87\% dijo no haber participado. Lo que los hace indiferentes a los problemas de su institución, no se sienten útiles.

Respecto a sus satisfactores de descanso son pseudo satisfactores, ya que su tiempo libre lo dedican a ver televisión, o a compartir con amigos consumiendo sustancias psicoactivas, que estimulan una falsa satisfacción de una 
necesidad, limitando su entendimiento, creación y participación. Además, su cultura familiar ha perdido la práctica de valores humanos y sus nuevos valores/antivalores los ponen en conflicto o con sus familias o con el nuevo contexto.

Las razones de abandono de sus estudios de tipo personal, que los estudiantes manifiestan en su mayoría obedecen a dificultades económicas y por maternidad o paternidad temprana. Esta última razón genera aún más problemas de tipo económico y desmotivación por el estudio.

El que el $62 \%$ de estudiantes se hayan retirado del estudio 1 vez y el $30 \%$ lo hayan hecho 2 y 3 veces y un $3 \%$ lo hayan hecho 4 y 5 veces, es decir, se van y vuelvan, evidencia un problema que hay que atender enfocándolo no solo a brindar educación, sino que esta sea significativa para su vida.

\subsubsection{Contexto institucional - políticas públicas}

En cuanto a la política pública esta se ha centrado en los satisfactores y no en las Necesidades fundamentales, en especial se debe proponer una política que tenga en cuenta que "la persona es un ser de necesidades múltiples e interdependientes y por ello las necesidades humanas deben entenderse como un sistema en que las mismas se interrelacionan e interactúan" ( (Max Neef, 1998, pág. 41)

Desde la organización de la Institución Educativa: el punto de vista de los estudiantes señala que, en la comunidad educativa, los satisfactores falsos 
que no logran un desarrollo sostenible en la vida de los adultos y de los jóvenes son:

Las razones de tipo institucional que tienen que ver con la deserción son: las dificultades que se tienen con el horario de trabajo y el colegio y por la inseguridad que tienen entre el trayecto de la escuela a la casa.

Ahora bien, los estudiantes reconocen el apoyo que reciben de la institución para no retirarse del colegio como son el refrigerio y el apoyo de los docentes cuando manifestaron que se iban a retirar.

Si bien los estudiantes consideran que la infraestructura física del colegio no influyo en su decisión de retiro si encuentran que esta no es la adecuada, en especial porque encuentran el atraso que existe en las tecnologías de la información y la comunicación (no existe taller de computadores), ni laboratorios.

Desde el punto de vista de los estudiantes se señala que, a nivel de las políticas educativas aplicadas en esta Institución Educativa, los satisfactores falsos que no logran un desarrollo sostenible en la vida de los jóvenes y adultos son:

Según relatos de vida y entrevistas los estudiantes son un problema para la familia, porque no saben qué hacer con ellos, y; son un problema para el colegio, pues, llegan desmotivados, drogados y sin deseo de aportar intelectualmente; no participan ni cumplen con actividades escolares y tampoco cuentan con el apoyo familiar para lograr cambios en los estudiantes. El panorama se vuelve a veces desalentador para los docentes y directivos, quienes tampoco se animan a cambiar sus métodos de enseñanza o a implementar e invertir en 
tecnologías, que favorezcan el aprendizaje y logren la motivación de los estudiantes.

Es importante para el estudiante volverlo a motivar con el estudio, enseñándolo a innovar, a liderar, a ser ciudadano, a manejar la economía de su hogar, a que sea capaz de determinar sus necesidades básicas y humanas que tiene que satisfacer y que le dan mejor calidad de vida.

En general es importante identificar los satisfactores, ya que no todos conducen a la satisfacción de una necesidad, sino por el contrario son destructores o dan una falsa sensación de satisfacción de una necesidad.

Las necesidades humanas al ser finitas y pocas, pueden satisfacerse pero dependen de la cultura y de la elección de los satisfactores; por ejemplo en nuestro país el armamentismo, la violencia y el desplazamiento son satisfactores destructores, que en lugar de pretender satisfacer la necesidad de protección imposibilitan la subsistencia, el afecto, el entendimiento, la participación, y libertad, y los pseudo-satisfactores, que para nuestro caso sucede con la sobreexplotación de recursos naturales que aparentemente satisfacen la subsistencia, pero que en realidad han arrasado con el ambiente y dejado miles de familias pobres, peor que antes de que explotaran sus recursos, el nacionalismo que se despierta con la selecciones de futbol, y el vivir a la moda, satisface una necesidad de identidad momentánea, motivada por los medios de comunicación, pero que en realidad los envilece, la democracia aparenta una satisfacción de participación, que es falsa pues a los estudiantes o no se les da una verdadera opción de participación en el colegio y externamente no ejercen bien los mecanismos de participación por ignorancia o apatía, no se les enseña a ser 
ciudadanos, por ocuparse de enseñar contenidos, en las cátedra de Ciencias Sociales.

En general los pseudo-satisfactores; que son aquellos que aparentar satisfacer una necesidad pero que en realidad aumentan otras necesidades y son lo que más se presentan en la vida estudiantil del colegio de acuerdo a lo relacionado en las entrevistas y relatos de vida, a saber: los estereotipos que aparentan satisfacer la necesidad de entendimiento, prostitución la necesidad de afecto, los símbolos la necesidad de identidad, el adoctrinamiento la necesidad de entendimiento, el productivismo eficientista la necesidad de subsistencia.

Igualmente sucede con los inhibidores, que son aquellos que generalmente sobre satisfacen una necesidad, dificultando seriamente la satisfacción de otras necesidades, por ejemplo, el paternalismo inhibe la necesidad de entendimiento, participación, identidad y libertad o la televisión comercial que satisface la necesidad de ocio, pero en realidad inhibe la necesidad de entendimiento, creación e identidad. 


\section{CONCLUSIONES Y RECOMENDACIONES}

Se refleja en el estudio de caso, que los factores sociales, económicos y familiares son determinantes en la decisión que asume el estudiante frente a su retiro temporal. Estos no son ajenos, ni se excluyen dentro de su proyección de mejora en su calidad de vida que permita el desarrollo humano como un todo.

El factor que se muestra más relevante y el cual arrojo los mayores porcentajes, es el económico, la exigencia para el estudiante independiente de si es joven o adulto para suplir sus necesidades económicas y familiares lleva a que los niveles de deserción se presenten en forma alta y reiterativa.

En consecuencia, los problemas económicos de los estudiantes no son solo un fenómeno meramente material, sino algo más complejo, que además los excluye de las políticas sociales de equidad, y de los derechos económicos, democráticos, sociales y culturales.

Es evidente que la educación en la jornada nocturna resulta más cómoda para estudiantes con unas características específicas ya que a ella llegan jóvenes que han presentado dificultades de convivencia y comportamiento en la jornada diurna, así mismo aquellos que ya cuentan con una edad extraescolar, pero con un gran porcentaje se encuentran los que deben trabajar y aquellos que quieren culminar sus estudios en corto tiempo.

La educación nocturna no brinda las mejores garantías en la cuanto a calidad para esta población, más aun teniendo en cuenta que cada vez se suma población muy joven que en su mayoría se ve obligada a dejar sus estudios por 
condiciones económicas y familiares, que requieren que esta educación brinde mejores oportunidades para su calidad de vida.

La deficiente economía del país, pero al mismo tiempo los bajos niveles de educación llevan a que cada vez más los jóvenes asuman responsabilidades a muy temprana edad obligándolos a ingresen al mundo laboral en condiciones poco optimas y dignificantes, con horarios extensos que no permiten el cumplimiento en sus responsabilidades académicas lo que conlleva a la deserción.

Las políticas actuales y los lineamientos establecidos por el Ministerio de Educación Nacional están muy alejados de las realidades y de las necesidades de la población que opta por escoger la educación nocturna como la alternativa más viable para la culminación de sus estudios.

Se requiere con urgencia una política pública en la jornada nocturna para la educación de jóvenes y adultos, que regule su funcionamiento, atendiendo a las necesidades de la población y que tenga en cuenta los lineamientos de una educación pensada con criterios de un desarrollo alternativo.

El contexto local (condiciones de la localidad de Fontibón) aunque no es de mayor relevancia, pero no por eso menos importante, afecta e incide de manera considerable las motivaciones de los estudiantes para la toma de decisión frente al desarrollo de sus estudios y la deserción temporal de los mismos.

Dado esto, las políticas educativas deben estar relacionadas de igual manera con la administración local de forma integral que permita al estudiante encontrar espacios más óptimos y seguros para sus desplazamientos. 
La inversión local debe priorizar la mejora de la infraestructura del colegio y la dotación del mismo, respondiendo a las necesidades no solo de estudiantes de la jornada diurna sino al mismo tiempo de la jornada nocturna, permitiendo un nivel de igualdad y entendiendo que estos últimos también aportan al desarrollo económico, social y cultural del entorno local y distrital.

Es necesario que los estudiantes se apropien de las problemáticas que los aquejan, ayuden a plantear, pero así mismo a exigir mejoras para la atención de estas, que están relacionadas con lo establecido en la matriz de satisfactores mencionados por Max Neef.

La dinámica de participación en toma de decisiones y en actividades escolares es mínima en la jornada nocturna lo cual influye en cierta medida en la adaptación y mejora de los lineamientos establecidos tanto por el colegio como por el MEN (entendiendo que esto no es un factor de obligatoriedad, pero sí de compromiso y de deber ciudadano que está relacionado con el desarrollo humano).

La deserción implica, un sentido invisible, que se esconde tras un fracaso escolar, con sentimientos personales de pérdida de autoestima y vivencias de frustración, que provocan autoexclusión sociocultural, tal como se conoció en las informaciones obtenidas de la voz de los sujetos investigados.

La educación nocturna debe responder a una alternativa de educación que permita el desarrollo del ser humano desde todos sus componentes no a un espacio que no genera ningún deber ni disciplina.

Aunque un porcentaje de estudiantes no se encuentran inconformes por la forma como les enseñan los docentes, pero si muestran un alto nivel 118 
desmotivación por el estudio es evidente que hay que cambiar tanto los contenidos como las formas de enseñanza, pues, se está fallando en lo que es práctico, cotidiano e interesante para el estudiante.

Las políticas y lineamientos educativos no deben ser ajenos al contexto económico de esta población y sería muy conveniente hacer articulaciones desde el MEN y el Ministerio de Trabajo que permitan relacionar unas condiciones adecuadas a esta población, sin llevar a que los cruces de horarios de lo laboral y lo académico sea un factor de deserción, permitiendo que esto aporte al desarrollo integral del estudiante, dignificando su actividad laboral y educativa.

Es necesario romper los paradigmas de enseñar contenidos $\mathrm{y}$ cambiarlos por proyectos o problemas que estén presentes en su realidad o entorno, ir más allá del ciclo lectivo especial integrado CLEI, que propone el Decreto Reglamentario 3011, y buscar la integralidad y la trasdisciplinaridad.

Esta trasdisciplinaridad se debe enfocar a cuatro campos del ser y del accionar de esta población; siendo estos: Ser, que involucra el cuidado de la persona interna y externamente (ética, religión, esparcimiento, deporte y anatomía de su cuerpo). Ser Social, que involucra a la persona en sus relaciones con otros, con su pasado, su presente y su entorno (ciencias sociales, ciencias biológicas y ambiente). Ser Analítico, que involucra a la persona resolviendo problemas abstractos de sí y su entorno (matemáticas, las ciencias y la tecnología). Ser Político y Ciudadano, que involucra todo el contexto de participación, dialogo, (humanidades y comunicación). 


\section{REFERENCIAS BIBLIOGRÁFICAS}

Banerjee, A. V., \& Duflo, E. (2013). Repensar la porbreza. Bogotá: Taurus.

Brusilovsky, S. (2006). Educación escolar de adultos. Una identidad en construcción. Buenos Aires: Novedades Educativas.

Bustamante, B. E. (2006). Tesis de grado:"Me fui y volvï:un estudio sobre la deserción y el regreso al sistema educativo colombiano". Medellin: Universidad de Antioquia.

Cajiao, F. (2013).

CODHES. (2014). El Desplazamiento forzado y la imperiosa necesidad de la paz. Boletin No82. Informe desplazamiento 2013, 3.

Colombia conserva el deshonroso título del segundo país con más desplazados. (2015). Semana, 3-5.

DANE. (1978). Obtenido de Elementos para la historia de la Educación en Colombia en el siglo XX. .

De Zubiria, M. (2007). Psicologia de la felicidad. Bogotá: www.pedagogiaconceptual.com.

Decreto Presidencial No. 3011. (19 de Diciembre de 1997). Obtenido de http://www.mineducacion.gov.co/1621/articles-86207_archivo_pdf.pdf

Diario Oficial Número 28038. (27 de Octubre de 1952). Decreto Número 2320 de 1952. Bogotá.

Diario Oficial 33995. (2 de agosto de 1966). Decreto Número 1830. Bogotá.

DIARIO OFICIAL No. 28038. Decreto 2320. (27 de Octubre de 1952). Obtenido de http://www.mineducacion.gov.co/1621/articles-103393_archivo_pdf.pdf: http://www.mineducacion.gov.co/1621/articles-103393_archivo_pdf.pdf 
Dirección de Evaluación - Secretaría de Educación del Distrito - SED -. (s.f.). (s.f.). Obtenido de Dirección de Evaluación - Secretaría de Educación del Distrito SED -. (s.f.).

Dirección de Evaluación - Secretaría de Educación del Distrito - SED -. (s.f.). (6 de Diciembre de 2012). Secretaría de Educación del Distrito. Obtenido de www.educacionbogota.edu.co: http://www.sedbogota.edu.co/evaluacion.

Easterly, W. (2001). En busca del crecimiento. Barcelona: Antoni Bosch.

Escobar, V. A. (2007). La Invencion del Tercer Mundo. Construccion y deconstruccion del desarrollo. Caracas: Fundación Editorial el perro y la rana.

Flores, M. (2004). Andragogía, motivación intrínseca del aprendizaje. Caracas: Universidad Nacional Abierta.

Freire, P. (1976). Pedagogía del oprimido. América Latina.

Freire, P. (1997). Educación como practica de la libertad. Barcelona: Siglo veintiuno editores.

Gidley, J. (2.006). Más allá de la homogeneización de educación global. Academia.edu, 2.

Ley General de Educación 115. (8 de febrero de 1994). Obtenido de http://www.educacionbogota.edu.co/index.php?option=com_content\&vie $\mathrm{w}=$ article\&id=2688: politica-publica-de-educacion-para-adultos-busca-seruna-realidad-para-bogota\&catid $=49 \& I$ temid $=354$

Martínez de Morentin de Goñi, J. (2.006). ¿Qué es eduacion de adultos? Revista del Centro de Formacion UNESCO, 2.

Max-Neef, M. A. (1998). Desarrollo a escala humana. Barcelona: Icaria Editorial, S.A.

MEN. (1994). Ley General de Educacion 115 de 1994. Bogotá: Magisterio. 
MEN. (2015). http://www.mineducacion.gov.co/1621/article-82806.html. Obtenido de http:// www.mineducacion.gov.co/1621/article-82806.html: http:/ / www.mineducacion.gov.co/1621/article-82806.html

MEN. (28 de Mayo de 2016). Obtenido de www.mineducacion.gov.co: http:/www.mineducacion.gov.co/1621/article-82745.html

MEN. Deserción Estudiantil en la Educación Superior. . (2009). Metodología de seguimiento, diagnóstico y elementos para su prevención. Bogotá: Ministerio de Educación Nacional-Revolución Educativa y SPADIES. Bogotá. Obtenido de Proyecto MEN-CEDE Universidad de los Andes, Bogotá, 2009. .

Montero , E., Villalobos , J., \& Valverde, A. (2.007). Factores Institucionales, pedagógicos, psicosociales y sociodemográficos asociados al rendimiento académico en la Universidad de Costa Rica:un análisis multinivel. Revista Electrónica de Investigación y Evaluación Educativa, 1.

Prohaska, L. (1.973). El proceso de maduración en el hombre. Barcelona: Herder.

Rodríguez, G., Gil, J., \& García, E. (1996). Metodologia de la investigación cualitativa. Granada, España: Aljibe.

Sachs, J. (2007). El fin de la pobreza. Bogotá: Random House Mondadori.

Sanchez, O. (2014). Politica pública de educacion para adultos: busca ser una realidad. Encuentro programas de educacion para adultos, (pág. 1). Bogotá.

Sen, A. (2010). Desarrollo y libertad. Bogotá: Planeta.

Sen, A., \& Kliksberg, B. (2011). Primero la gente. Una mirada desde la ética del desarrollo a los principales problemas del mundo globalizado . Argentina: TEMAS Grupo Editorial SRL.

UNESCO. (1997). La educación de las personas adultas, la declaracion de Hamburgo, la agenda para el futuro. Hamburgo: UNESCO. 
UNESCO. (2010). Informe mundial sobre aprendizaje y educacion de adultos.

Hamburgo: Unesco.

Valencia, F. (2004). Conflicto y violencia escolar en Colombia. Revista cientifica Guillermo de Ockham Vol 7,1.

Velásquez, E. Z. (1990). Colombia: violencia, democracia y derechos humanos. Medellin, Colombia: Ariel Colombia.

Yuni, J. A. (2005). Educacion de adultos mayores. Teoria, investigacion e intervenciones. Córdoba : Brujas. 
ANEXOS 


\section{ANEXO A: ENCUESTA Nº 1 \\ ENCUESTA FACTORES QUE INCIDEN EN LA DESERCIÓN ESCOLAR J. N.}

1) ¿Cuál es tu edad, ciclo que cursas y sexo?

Edad Ciclo

Género: Femenino Masculino

Completa o marca con una $X$ la respuesta que se ajusta más a tu caso personal

2) ¿Por qué razón o razones te encuentras estudiando en la jornada nocturna?

(Por favor marca máximo tres -3- opciones)

a) Por mi edad

b) Por ser adulto mayor

c) Porque quede embarazada

d) Porque me toco retirarme de estudiar en el día para poder trabajar

e) Porque quiero terminar el bachillerato más rápido

f) Porque tuve problemas de indisciplina y me retiraron del colegio en el día

g) Por problemas de tipo familiar

h) Porque recibo ayuda del gobierno por pertenecer a un grupo de desplazamiento forzado o reinsertado o desmovilizado o acción social

i) Porque no tuvieron como continuar pagándome mis estudios

j) Porque tenía problemas de aprendizaje, mal rendimiento académico

k) Porque tengo problemas de consumo de sustancias psicoactivas

1) Por pereza y desmotivación con el estudio

m) Porque me toca ayudar con los oficios de la casa, cuidar a mis hermanos

n) ¿Por otra razón ___ Cuál?

3) Te has retirado de estudiar de este colegio o de cualquier otro colegio de la jornada nocturna y has vuelto a continuar tus estudios en los últimos tres años? (2011- 2014) Si ___ No _ Cuántas veces

4) ¿Por qué razones te has retirado de estudiar de la jornada nocturna?

a)

b) 
c)

d)

ANEXO B: ENCUESTA N ${ }^{\circ} 2$

ENCUESTA FACTORES QUE INCIDEN EN LA DESERCION ESCOLAR J. $\mathbf{N}$.

Lee cuidadosamente y conteste con sinceridad cada una de las preguntas marcando con una $\underline{X}$ la opción verdadera o completando la información solicitada

A) Información general

1) Edad Género

2) Lugar de nacimiento

3) Con quién vive actualmente

4) Nivel educativo alcanzado por su madre

Primaria Bachillerato Universidad Técnico

5) Nivel Eeucativo alcanzado por su padre Primaria__ Bachillerato ___ Universidad Técnico

6) Nivel educativo alcanzado por padrastro o madrastra Primaria Bachillerato Universidad Técnico_

7) ¿La familia siempre ha vivido aquí? SI No

8) ¿Cuántas veces han cambiado de lugar de vivienda?

9) ¿Cuál de los siguientes problemas se han presentado en los 2 últimos años en tu hogar?

- Problemas económicos

- Enfermedad

- Separación de los padres

- Muerte de alguno de los miembros del hogar

- Abandono del hogar de alguno de los padres

- Abandono del hogar por parte del estudiante 
- Vive con alguien en condición de discapacidad o enfermedad grave

\section{B) Desempeño escolar}

10) ¿Antes de iniciar la primaria estuviste en algún jardín o preescolar? Sí No

11) ¿A qué edad iniciaste el primero de primaria?

12) ¿Has perdido algún curso? cuantos cursos que cursos perdieron

13) El último curso que perdiste por cuál de las siguientes razones fue:

- No les gustaba el estudio

- Porque las materias eran muy difíciles

- Por fallas

- Por falta de tiempo

- Porque la forma como enseñan y califican los docentes es inadecuada

- Por enfermedad

- Por problemas con los horarios del trabajo

- Por problemas de falta de dinero en la familia

- Por cuidar de hermanos o familiares

14) ¿Alguna vez te has retirado de estudiar? Cuantas veces

15) La última vez que te retiraste: ¿cuántos años tenías? ¿En qué mes te retiraste?

16) ¿La última vez que te retiraste de estudiar te matriculaste al año siguiente o dejaste un año o más sin estudiar?

17) ¿El colegio donde se retiro era público o privado?

18) ¿En cuántos colegios has estudiado? DIMENSIÓN INSTITUCIONAL

19) ¿La última vez que te retiraste de tus estudios fue por cuál de las siguientes razones relacionadas con el colegio? 
a) El colegio no tenía hasta grado once

b) La forma aburrida como enseñan los maestros

c) Faltó ayuda del colegio para el pago de pensión o matricula

d) Faltó ayuda del colegio en transporte

e) Faltó ayuda del colegio para los útiles escolares

f) Faltó ayuda del colegio en alimentación

g) Las instalaciones del colegio eran desagradables

h) Faltaban profesores

i) Había muchos conflictos y violencia en el colegio

j) Había mucha inseguridad a la salida del colegio y en el trayecto a la casa_

k) Por el maltrato de los profesores

1) Por el maltrato de los compañeros

m) Tenía dificultades con el horario del trabajo y el colegio

n) La educación del colegio era distinta a tus necesidades e intereses de educativos

o) Porque el colegio quedaba lejos de tu casa

DIMENSIÓN FAMILIAR

20) ¿La última vez que te retiraste de tus estudios fue por cuál de las siguientes razones relacionadas con la familia?
a) Había problemas de dinero en el hogar
b) Tu familia cambio de casa por el trabajo de alguno de los padres
c) Por que querías o necesitabas trabajar
d) Debías encargarte de los oficios del hogar o cuidar algún familiar
e) Se murió algún familiar
f) Para tu familia es poco importante que estudies
g) Tu familia fue víctima de desplazamiento forzado
h) Tu familia fue víctima del conflicto armado 


\section{DIMENSIÓN PERSONAL}

21) ¿La última vez que te retiraste de tus estudios fue por cuál de las siguientes razones personales?
a) Tenías dificultades económicas
b) Tenías dificultades académicas
c) No gustaba del estudio o no quería estudiar
d) Por enfermedad
e) Considerabas que los estudios que tenías eran suficientes
f) Por tu maternidad o paternidad a temprana edad

g) Porque perdiste el año

h) Porque te sacaron del colegio por problemas de tipo disciplinario

i) Porque tienes algún tipo de adicción a sustancias psicotrópicas

j) Porque no me logre adaptar al nuevo colegio

22) ¿Por qué razones volviste a estudiar?
a) Porque quieres ser alguien en la vida
b) Porque quieres salir adelante
c) Tener un mejor futuro
d) Progresar
e) Prepararse mejor y superarse
f) Ser mejores personas
g) Mejorar sus condiciones de vida
h) Conseguir un mejor trabajo
i) Alcanzar sus sueños y metas
j) Porque les gusta el estudio o lo valoran

k) Porque durante el retiro me di cuenta de la necesidad del estudio

1) Porque recibieron apoyo o influencia de los padres o familiares cercanos para hacerlo

11) Por cambios en las condiciones familiares y sociales 
m) Por apoyos institucionales o mejoras en la oferta educativa

n) Para poder seguir estudiando educación técnica

ñ) Para seguir con alguna carrera profesional

o) Para recibir su título de bachiller

p) Para ayudar a su familia

q) Darle mejor vida a su hija o hijo

23. Estas trabajando?....Si___ No___

24. La última vez que trabajaste en que te desempeñaste

25. En tu trabajo te pagaron seguridad social ...Si No

\section{C) Apoyo institucional}

23) En el último año recibiste alguna ayuda o servicio gratuito como:
a) Refrigerio o alguna comida
b) Ayuda cuando tenía dificultades en alguna materia
c) Programas para mejorar la convivencia escolar o integración de los estudiantes

d) Programas de integración a la comunidad

e) Recibió útiles escolares

f) Apoyo psicológico o terapias de lenguaje

g) Transporte escolar

h) Ayuda con uniformes

i) Sus profesores le han ayudado para continuar sus estudios

j) Sus compañeros le han ayudado a continuar sus estudios

k) Ayuda terapéutica por el consumo de algún tipo de droga adictiva

24) ¿Ha participado en las actividades culturales y deportivas del colegio? $\mathrm{Si} \_$No

25) ¿Ha participado en la toma de decisiones escolares o en la solución de problemas que se presentan en el colegio? Si No 
26) ¿Qué situaciones se presentaron en el colegio en estos 2 últimos años?
a) Tus compañeros te han buscado para jugar
b) Tus compañeros te han buscado para trabajar en grupo
c) Tus compañeros te han buscado para consumir algún tipo de droga adictiva
d) Tus compañeros te han buscado para amenazarte o insultarte
e) Se han presentado conflictos entre estudiantes
f) Se han presentado conflicto entre estudiantes y profesores
g) Se ha presentado vandalismo o pandillismo
h) Se ha presentado alcoholismo
i) Se ha presentado consumo o venta de drogas
j) Se ha presentado discriminación

27) Califica de 1 a 5 que tan satisfecho te sientes con los siguientes aspectos del colegio, siendo 5 la mejor calificación:

Aspectos de la Institución
a) Instalaciones Físicas de su colegio
b) Como enseñan los profesores
c)El estímulo que se hace al uso de nuevas tecnologías
d)Sus compañeros de estudio
e) El trato de los directivos del colegio y su colaboración
f) El colegio en general

\begin{tabular}{|l|l|l|l|l|}
\hline 1 & 2 & 3 & 4 & 5 \\
\hline & & & & \\
\hline & & & & \\
\hline & & & & \\
\hline & & & & \\
\hline & & & & \\
\hline & & & & \\
\hline
\end{tabular}

\section{D) Apoyo familiar}

28) Sobre el apoyo de tu familia marca la opción que más se presenta en tu caso

a) Recibes apoyo económico de tu

\begin{tabular}{|l|l|l|l|}
\hline Siempre & $\begin{array}{l}\text { Casi } \\
\text { Siempre }\end{array}$ & $\begin{array}{l}\text { Casi } \\
\text { Nunca }\end{array}$ & Nunca \\
\hline & & & \\
\hline
\end{tabular}


familia

b) Recibes ayuda para la realización de tus trabajos escolares en casa

c)Cuentas con tiempo para la realización de tareas

d)Recibes motivación para asistir al colegio

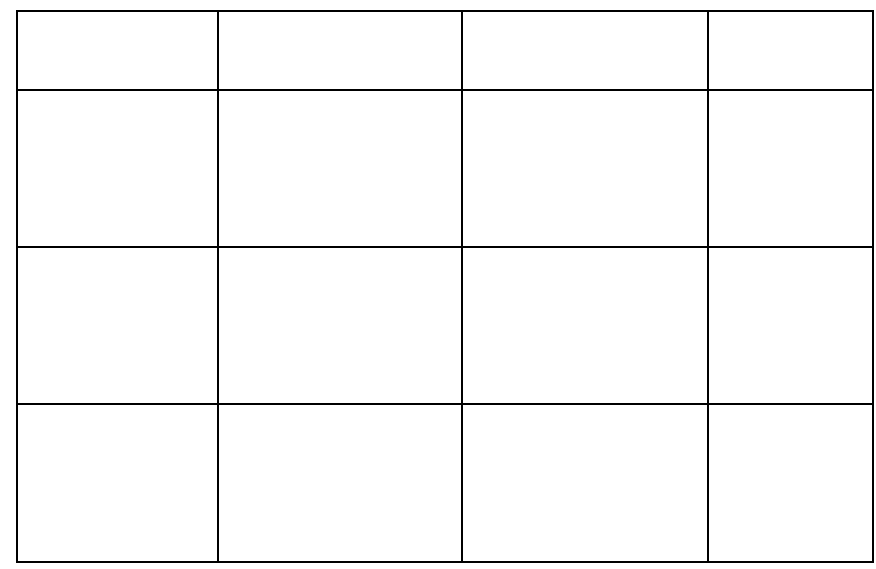

29) Con quienes permaneces la mayor parte del tiempo cuando no estás estudiando

Con su padre

Con su madre

Con alguno de sus abuelos

Con un familiar adulto

Solos en casa

Con otros menores en casa

Con amigos en la calle

Con los padres en el trabajo

\section{E) Expectativas de la educación}

30) ¿Hasta qué nivel educativo deseas continuar estudiando?

a) Hasta Básica secundaria (Noveno grado)

b) Hasta Educación media (Onceavo grado)

c) Hasta el nivel Técnico profesional

d) Hasta el nivel Tecnológico

e) Hasta el de profesional universitario

f) Hasta el de Postgrado

g) Desearía que te formaran en algún saber que ya tienes o desearías tener de tipo no formal 


\section{F) Intención de deserción}

31) ¿Alguna vez has pensado en retirarte de estudiar? Sí No

32) ¿Por qué has pensado en retirarte de estudiar?
a) Por problemas familiares de tipo económico de convivencia otro

b) Por poca motivación

c) Por problemas de salud

d) Por problemas psicológicos

e) Por problemas asociados a la institución educativa

f) Por problemas de orden académico

g) Por que adquirió responsabilidades

h) Por razones de trabajo

i) Porque no le gusta el estudio

j) Por problemas de adicción a sustancias psicoactivas

k) Por problemas de convivencia

33) Señala que tan de acuerdo estas con cada uno de las siguientes afirmaciones:

a) Lo que aprendo en el colegio me servirá para el futuro

b) Lo que aprendo en el colegio me servirá para mejorar la situación familiar de mi familia

c) Lo que aprendo en el colegio me servirá para mejorar la situación de mi comunidad

d) Lo que aprendo en el colegio me servirá para conseguir un mejor trabajo

\begin{tabular}{|l|l|}
\hline $\begin{array}{l}\text { De } \\
\text { acuerdo }\end{array}$ & $\begin{array}{l}\text { En } \\
\text { desacuerdo }\end{array}$ \\
\hline & \\
\hline & \\
\hline & \\
\hline & \\
\hline
\end{tabular}


e) Lo que aprendo en el colegio me servirá para mejorar mi desempeño en el trabajo

f) Lo que aprendo en el colegio me servirá para mejorar mis ingresos económicos

g) Las clases de los profesores son divertidas o entretenidas

h) Me gusta ir al colegio

i) Tengo la intención de retirarme del colegio por falta de dinero

j) Tengo la intención de retirarme del colegio por falta de ayuda de la familia

k) Tengo la intención de retirarme del colegio por irresponsabilidad

1) Tengo la intención de retirarme del colegio por situaciones de violencia

m) Tengo la intención de retirarme del colegio por problemas con los compañeros

n) Tengo la intención de retirarme del colegio porque los profesores enseñan inadecuadamente

o) Tengo la intención de retirarme del colegio

p) Tengo la intención de retirarme del colegio por razones de desplazamiento

q) Tengo la intención de retirarme del colegio porque se me presento un trabajo estable

r) Tengo la intención de retirarme del colegio porque se me presento un trabajo temporal

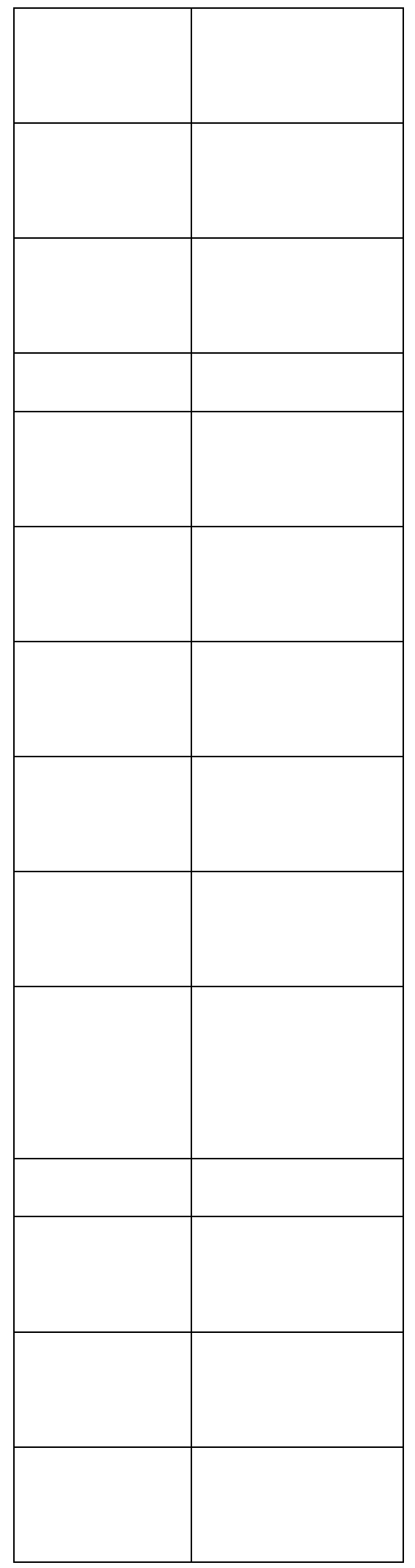


s) Tengo la intención de retirarme del colegio por las exigencias académicas de algunas asignaturas (muchas tareas y trabajos)

34) ¿Por qué razón trabajas?

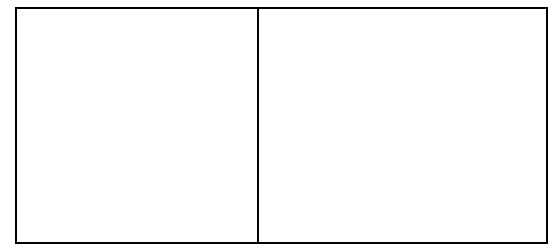
a) Para tener mi propio dinero
b) Para ayudar con los gastos del hogar
c) Para el sostenimiento de mis hijos
d) Para ayudar con los gastos de mi educación
e) Porque el trabajo me forma y me hace más responsable
f) Porque el trabajo me aleja de los vicios
g) Para participar en el negocio familiar

35) En qué medida el trabajo le ha afectado.......
a) Rendimiento escolar
b) Su participación en las actividades propias de su edad
c) El tiempo para realizar sus tareas
d) Es impedimento para asistir al colegio
e) Su participación en las actividades culturales del colegio

\author{
¡MUCHAS GRACIAS POR SU COLABORACIÓN Y POR RESPONDER \\ CON SINCERIDAD A CADA UNA DE LAS PREGUNTA
}


ANEXO C: ENCUESTA N ${ }^{\circ} 3$ A DOCENTES Y DIRECTIVOS

ENCUESTA FACTORES QUE INCIDEN EN LA DESERCION ESCOLAR J. N.

Lee cuidadosamente y conteste con sinceridad cada una de las preguntas marcando con una $\underline{X}$ la opción verdadera o completando la información solicitada

DIMENSIÓN FAMILIAR

Consideras que el retiro de los estudiantes se da por

a) Había problemas de dinero en el hogar

b) Por que la familia cambio de casa por el trabajo de alguno de los padres

c) Porque necesitaban trabajar

d) Debían encargarse de los oficios del hogar o cuidar algún familiar

e) Se murió algún familiar

f) Porque para la familia es poco importante el estudio

g) Porque la familia fue víctima de desplazamiento forzado

h) Porque la familia fue víctima del conflicto armado_

\section{DIMENSIÓN PERSONAL}

a) Tenían dificultades económicas

b) Tenían dificultades académicas

c) No gustan del estudio o no quieren estudiar

d) Por enfermedad

e) Consideran que los estudios que tienen son suficientes

f) Por la maternidad o paternidad a temprana edad

g) Por pérdida del año

h) Por problemas de tipo disciplinario 
i) Porque tienen algún tipo de adicción a sustancias psicotrópicas

j) Porque no logran adaptarse al colegio

DIMENSION INSTITUCIONAL

Consideras que el retiro de los estudiantes se da por

b) La forma como enseñan los maestros?

e) Falta ayuda del colegio para los útiles escolares

f) Falto ayuda del colegio en alimentación

f) Las instalaciones del colegio son desagradables

g) Faltaban profesores

h) Hay muchos conflictos y violencia en el colegio

i) Hay mucha inseguridad a la salida del colegio y en el trayecto a la casa__

j) Por el maltrato de los profesores

k) Por el maltrato de los compañeros

1) Tienen dificultades con el horario del trabajo y el colegio

11) La educación del colegio es distinta a las necesidades e intereses de educativos de los estudiantes

m) Por falta de educación de sus padres que no los motivan

¡MUCHAS GRACIAS POR SU COLABORACIÓN Y POR RESPONDER CON SINCERIDAD A CADA UNA DE LAS PREGUNTAS! 


\section{ANEXO D: ENTREVISTA SEMIESTRUCTURADA}
a. ¿Con quién viviste en tu infancia?
b. ¿Fuiste feliz en tu infancia?,
c. ¿Qué hacías entre la edad de 5 a 9 años?
d. ¿Cómo eran las relaciones familiares
e. ¿Cómo te iba en el colegio?
f. ¿Cómo eran las relaciones con tus compañeros?
g. ¿Cuándo tuviste los primeros problemas con tu familia y por qué?
h. ¿En cuántos colegios has estudiado?
i. ¿Cómo resolviste tus problemas?
j. ¿Por qué razones abandonaste el estudio?
k. ¿Por qué volviste a estudiar?
1. ¿Cómo son tus relaciones familiares ahora?
m.¿Estás trabajando?
n. ¿Qué inconvenientes tienes con el estudio y el trabajo? 